Portland State University

PDXScholar

\title{
The Effects of Commuter Rail on Population Deconcentration and Commuting: A Salt Lake City Case Study
}

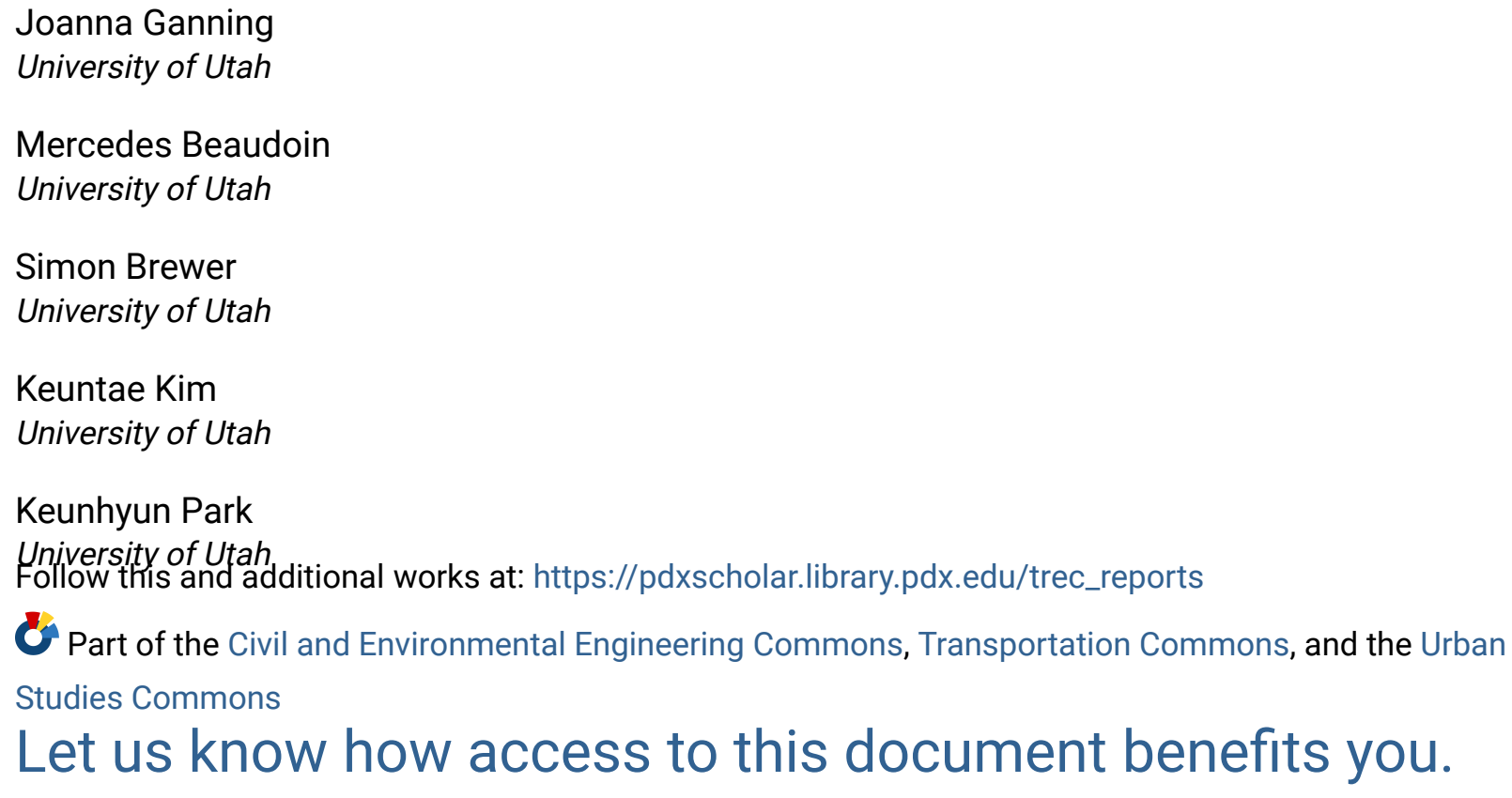

This Report is brought to you for free and open access. It has been accepted for inclusion in TREC Final Reports by an authorized administrator of PDXScholar. Please contact us if we can make this document more accessible: pdxscholar@pdx.edu. 


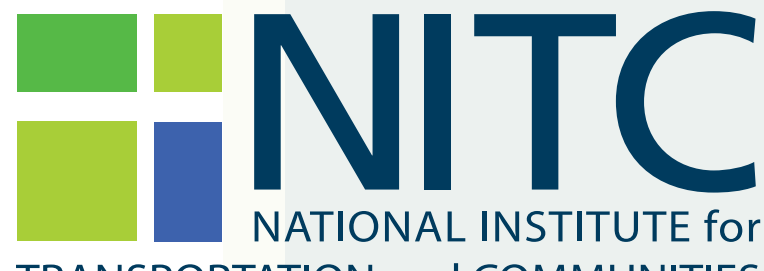

TRANSPORTATION and COMMUNITIES

FINAL REPORT

\section{The Effects of Commuter Rail on Population Deconcentration and Commuting: A Salt Lake City Case Study}

NITC-RR-778 January 2016

NITC is the U.S. Department of Transportation's national university transportation center for livable communities.

\#": TREC 


\title{
THE EFFECTS OF COMMUTER RAIL ON POPULATION DECONCENTRATION AND COMMUTING: A SALT LAKE CITY CASE STUDY
}

\section{Final Report}

NITC-RR-778

\author{
by \\ Joanna Ganning (PI) \\ Mercedes Beaudoin \\ Simon Brewer \\ Keuntae Kim \\ Keunhyun Park
}

Metropolitan Research Center

University of Utah

for

National Institute for Transportation and Communities (NITC)

P.O. Box 751

Portland, OR 97207
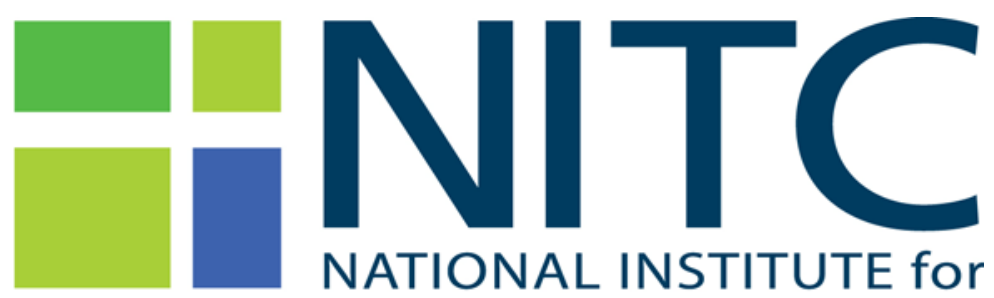

TRANSPORTATION and COMMUNITIES

December 2015 



\section{Technical Report Documentation Page}

\begin{tabular}{|c|c|c|}
\hline 1. Report No. 778 & 2. Government Accession No. & 3. Recipient’s Catalog No. \\
\hline \multirow{2}{*}{\multicolumn{2}{|c|}{$\begin{array}{l}\text { 4. Title and Subtitle } \\
\text { The Effects of Commuter Rail on Population Deconcentrating and Commuting: A Salt Lake City } \\
\text { Case Study }\end{array}$}} & $\begin{array}{l}\text { 5. Report Date } \\
\text { December 30, } 2015\end{array}$ \\
\hline & & 6. Performing Organization Code \\
\hline \multicolumn{2}{|l|}{ 7. Author(s) } & 8. Performing Organization Report No. \\
\hline \multicolumn{3}{|c|}{ Joanna Ganning (PI), Mercedes Beaudoin, Simon Brewer, Keuntae Kim, and Keunhyun Park } \\
\hline \multicolumn{2}{|l|}{ 9. Performing Organization Name and Address } & 10. Work Unit No. (TRAIS) \\
\hline \multicolumn{2}{|l|}{$\begin{array}{l}\text { Metropolitan Research Center } \\
\text { University of Utah } \\
375 \text { South } 1530 \text { East Room 235, } \\
\text { Salt Lake City, Utah } 84112\end{array}$} & $\begin{array}{l}\text { 11. Contract or Grant No. } \\
\text { NITC-RR-778 }\end{array}$ \\
\hline \multirow{2}{*}{\multicolumn{2}{|c|}{$\begin{array}{l}\text { 12. Sponsoring Agency Name and Address } \\
\text { National Institute for Transportation and Communities (NITC) } \\
\text { P.O. Box } 751 \\
\text { Portland, Oregon } 97207 \\
\end{array}$}} & $\begin{array}{l}\text { 13. Type of Report and Period Covered } \\
\text { Final Report }\end{array}$ \\
\hline & & 14. Sponsoring Agency Code \\
\hline
\end{tabular}

15. Supplementary Notes

\section{Abstract}

All transportation systems have the ability to transform human settlement patterns, which can affect a range of social, economic and environmental issues. Considering investments in rail infrastructure have increased in recent decades (Bureau of Transportation Statistics, 2007; Israel \& Cohen-Blankshtain, 2010), it is important for planners and researchers to understand how these rail systems influence land use, metropolitan development patterns, and population migration. The following paragraphs summarize the studies and their findings.

The Effects of Commuter Rail Establishment on the Relationships between the Built Environment, Travel Behavior, and Residential SelfSelection (RSS): To help regional and transportation planners better understand the role that commuter rail plays in directing intra-regional development, this chapter provides a longitudinal investigation of the influence of commuter rail on surrounding neighborhoods' RSS, travel behavior and the built environment. We first analyze the role of commuter rail establishment in influencing change in neighborhood-level demographics, housing and economics (signs of RSS), and travel behavior. Second, we compare surveyed commuter rail riders to residents of the commuter rail stations' host and neighboring areas. The results indicate that the development of commuter rail does not alter the host tracts in any of the characteristics observed, but rather suppresses population growth in neighboring tracts. Paired with direct evidence from a commuter rail user survey, we conclude that the use of commuter rail is more likely influenced by the built environment than by RSS.

The Effects of Commuter Rail Establishment on Population Deconcentration: Research to date has not established the efficacy of commuter rail systems in attracting migrants most likely to use such an amenity. Through the application of a modified population deconcentration model, this chapter finds that the provision of a commuter rail station significantly increases neighborhood-level out-commuting and gross migration, which signals success in attracting migrants requiring commuting infrastructure. These findings also signal that commuter rail encourages regional population deconcentration, but the evidence is insufficient to form a conclusion and the evidence from Chapters 2 and 4 signal otherwise.

Developing an Agent-Based Model (ABM) For Estimation of Land Use Changes around Commuter Rail Stations over Time: This chapter improves the understanding of commuter rails' effect on future land use changes through spatial interaction modeling. In particular, we develop an innovative agent-based model (ABM) that allows us to estimate and visualize the probability of land use changes per parcel based on proximity to commuter rail stations, freeway exits, and the region's central business district. Briefly, this chapter concludes that the development of a commuter rail station is statistically significantly associated with decreases in single-family residential land use near the station, which is met by increases in multifamily and mixed-use development. The spatial effects of stations on individual land uses vary by land use type, and no generalizable area of influence could be established.

This report points to potential future research, as well as implications for planning practitioners.

\section{Key Words}

Commuter Rail, Residential Self-Selection, Built Environment, Character

Change, Transportation Planning, Household-Location Decisions, Population Deconcentration, Suburbanization,

\section{Distribution Statement}

No restrictions. Copies available from NITC: www.nitc.us

\begin{tabular}{l|c}
\hline $\begin{array}{l}\text { 19. Security Classification (of this report) } \\
\text { Unclassified }\end{array}$ & $\begin{array}{c}\text { 20. Security Classification (of this page) } \\
\text { Unclassified }\end{array}$
\end{tabular}

Unclassified

\section{No. of Pages}

101 


\section{ACKNOWLEDGEMENTS}

This research was funded by the National Institute for Transportation and Communities (NITC), in addition to The Wasatch Front Regional Council and The Ivory Boyer Real Estate Center at the University of Utah. Additional support and contributions came from Simon Brewer in the University of Utah's Geography Department and from Danny Wall in the University of Utah's Finance Department. Furthermore, we acknowledge and thank the anonymous peer reviewers who provided immensely helpful insights and corrections to this report.

\section{DISCLAIMER}

The contents of this report reflect the views of the authors, who are solely responsible for the facts and the accuracy of the material and information presented herein. This document is disseminated under the sponsorship of the U.S. Department of Transportation University Transportation Centers Program and the partners mentioned above in the acknowledgements in the interest of information exchange. The U.S. Government and mentioned partners assumes no liability for the contents or use thereof. The contents do not necessarily reflect the official views of the U.S. Government or the other partners. This report does not constitute a standard, specification, or regulation. 


\section{TABLE OF CONTENTS}

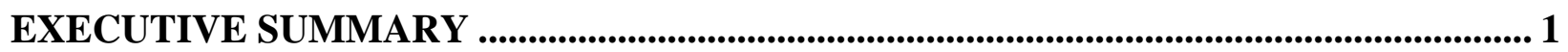

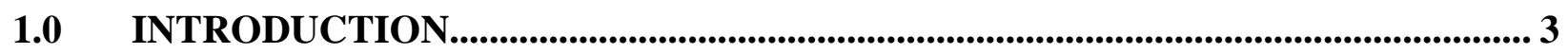

1.1 THEORETICAL OVERVIEW.................................................................................. 4

1.2 BRIEF ORIENTATION TO COMMUTER RAIL SYSTEMS ……………………......... 5

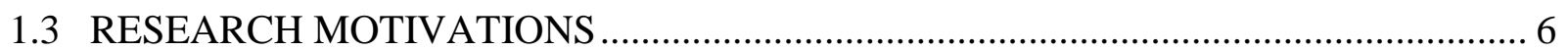

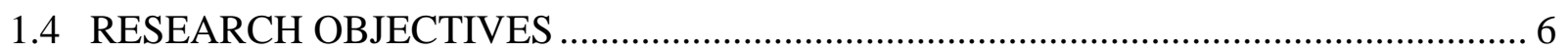

1.5 THE STUDY REGION: THE SALT LAKE-PROVO-OREM COMBINED

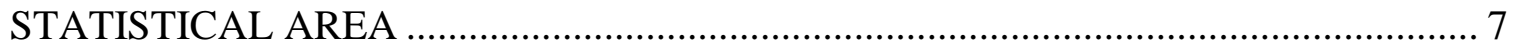

1.6 THE TRANSIT SYSTEM: FRONTRUNNER COMMUTER RAIL …………………...... 9

\subsection{THE EFFECTS OF COMMUTER RAIL ESTABLISHMENT ON THE} RELATIONSHIPS BETWEEN THE BUILT ENVIRONMENT, TRAVEL BEHAVIOR, AND RESIDENTIAL SELF-SELECTION.............................................................................. 11

2.1 RSS, TRAVEL BEHAVIOR, AND THE BUILT ENVIRONMENT …………............. 12

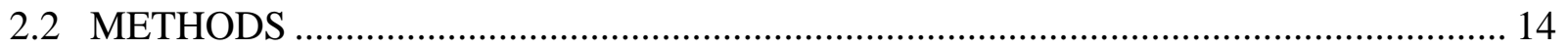

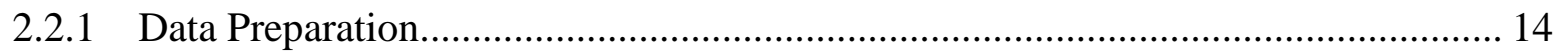

2.2.2 The Utah Transit Authority Survey …………..................................................... 17

2.2.3 Calculating Change in Character .......................................................................... 17

2.2.4 Testing the Effect of Commuter Rail on Change in Character ................................ 18

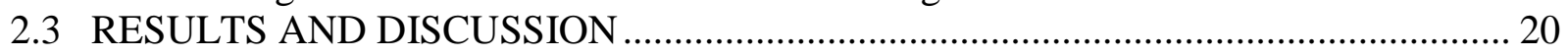

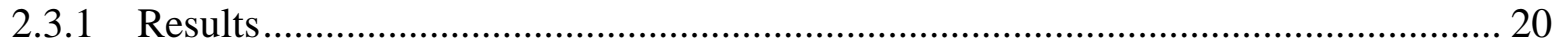

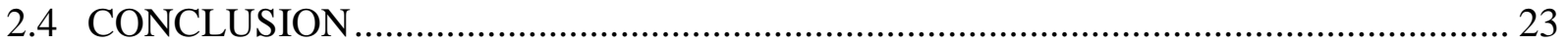

3.0 THE EFFECTS OF COMMUTER RAIL ESTABLISHMENT ON MIGRATION AND COMMUTING ......................................................................................................................... 25

3.1 THEORETICAL OVERVIEW OF DECONCENTRATION ........................................ 26

3.2 A BRIEF HISTORY OF DECONCENTRATION AND ITS RELATIONSHIP TO TRANSPORTATION IN THE U.S......................................................................... 27

3.3 AN OVERVIEW OF MIGRATION LOCATION DECISION MAKING AND

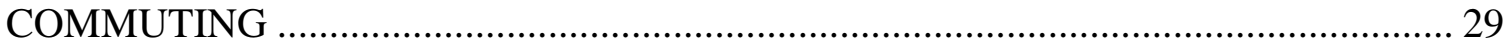

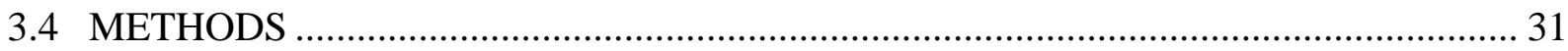

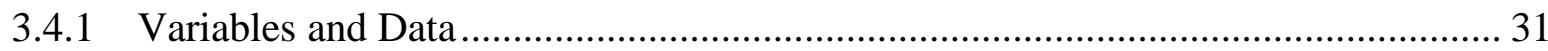

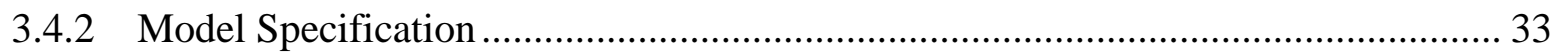

3.4.3 Methodological Departures from Literature and Limitations ...................................... 34

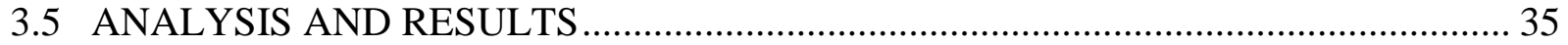

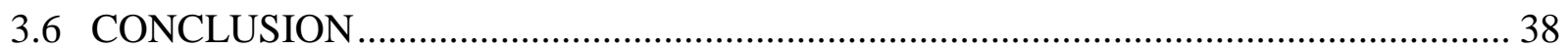

4.0 DEVELOPING AN AGENT-BASED MODEL (ABM) FOR ESTIMATION OF LAND USE CHANGES AROUND COMMUTER RAIL STATIONS OVER TIME ......... 40

4.1 METHODS: OVERVIEW OF AGENT-BASED MODELING (ABM)........................... 40

4.2 THE ODD PROTOCOL: DESCRIBING AND FORMULATING THE ABM ............... 41

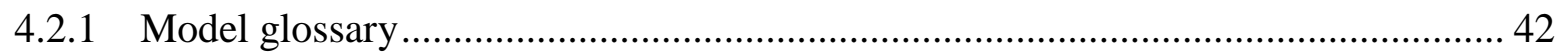

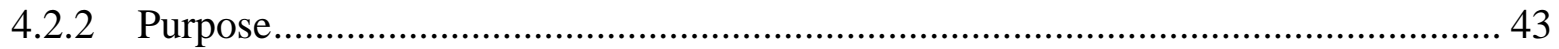

4.2.3 Defining Entities, State Variables, and Scales........................................................... 43

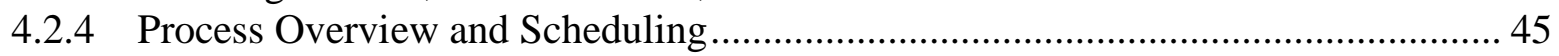




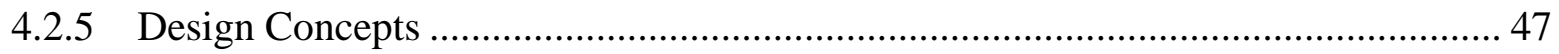

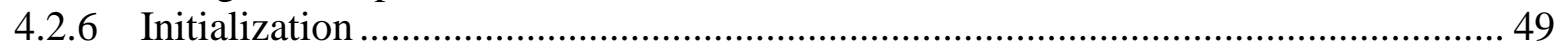

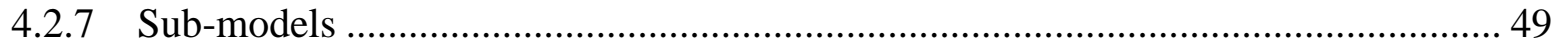

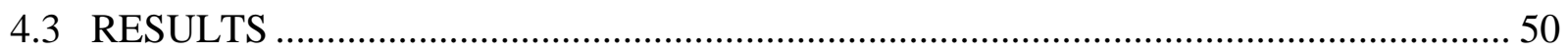

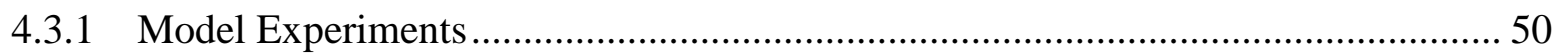

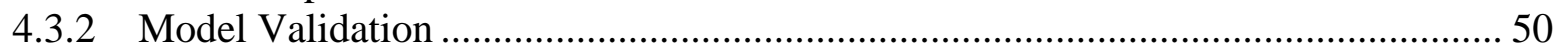

4.3.3 Analysis of Transition Matrix for Changes in Land Use Types .............................. 52

4.3.4 Interpreting Three Scenario Outcomes ................................................................... 54

4.3.5 Future Simulations of Land Use Change .................................................................... 58

4.3.6 Estimating the Area of Influence of FrontRunner Stations Based on Land Use

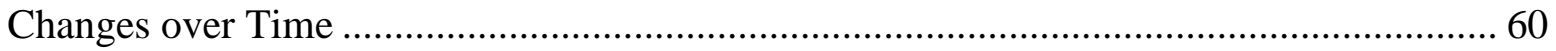

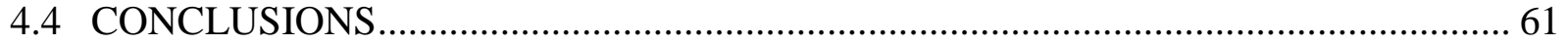

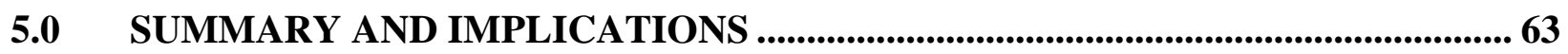

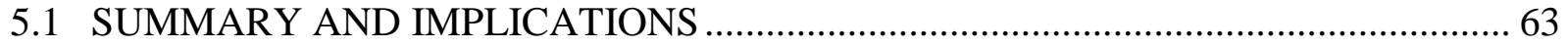

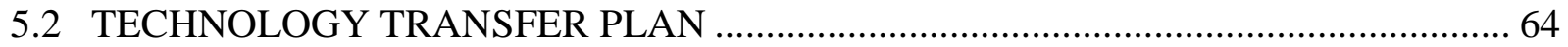

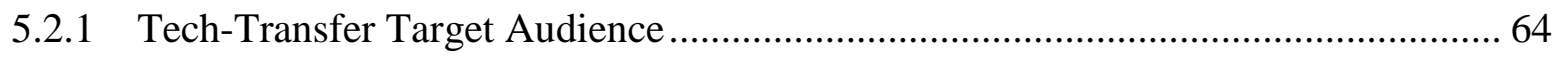

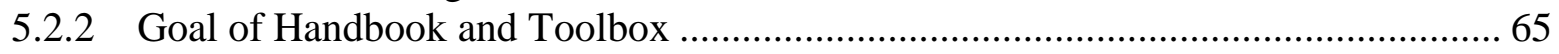

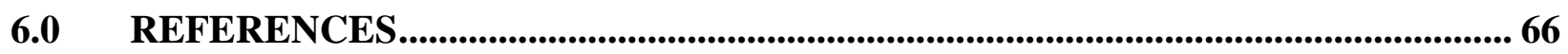

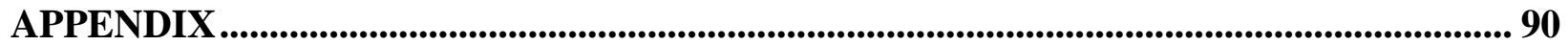

Appendix Table A1: Sub-Variables Comprising Dependent and Independent Variables

\section{LIST OF TABLES}

Table 2.1 List of variables, data sources, approach to calculation, and characteristic areas ........ 15

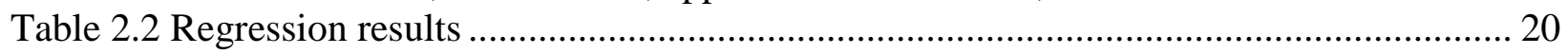

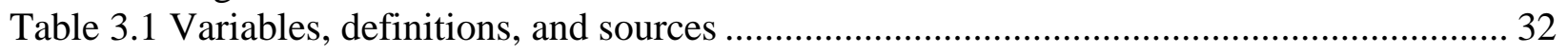

Table 3.2 Regional population deconcentration model results........................................................ 36

Table 3.3 Out-commuting rate and number, 2002 and 2011 .......................................................... 37

Table 4.1 Parcel agent variables in the ABM of this study ...................................................... 44

Table 4.2 A comparative analysis of land use between the observed and the simulated land use maps (2010) ……........................................................................................................ 51

Table 4.3 Transition probability matrix of land use change between 2007 and 2010 in Salt Lake County ....................................................................................................................... 53

Table 4.4 Simulation results of the number of parcels for single-family and multifamily

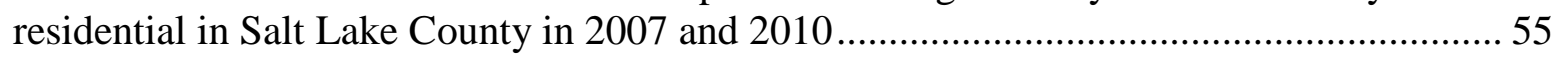

Table 4.5 Three scenario results of land use changes by distance from the FrontRunner stations in Salt Lake County in 2010 ........................................................................................... 57

Table 4.6 Simulation results of the number of parcels for single-family and multifamily

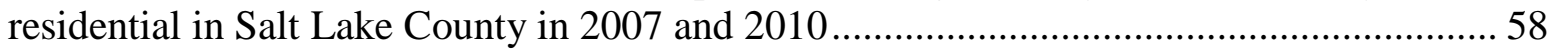

Table 4.7 Land use changes between 2010 and 2025 in Salt Lake, Davis, and Weber County ... 59 


\section{LIST OF FIGURES}

Figure 0.1 Salt Lake Central FrontRunner station ........................................................ 1

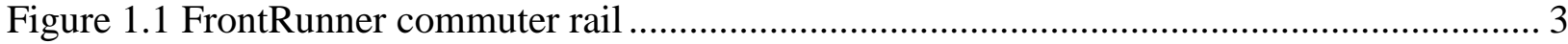

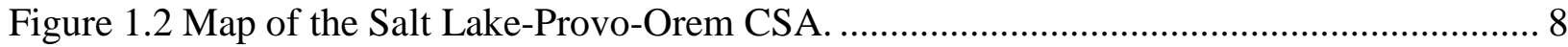

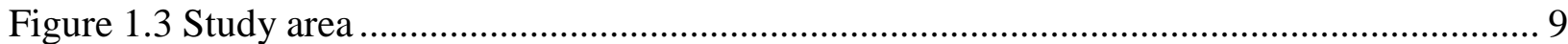

Figure 1.4 Park-and-ride facility next to a FrontRunner station.............................................. 10

Figure 2.1 FrontRunner's Temple Square station .......................................................... 12

Figure 3.1 FrontRunner's Woods Cross station ..................................................................... 25

Figure 3.2 MSA population and jobs 1950-1990, U.S. reported by Mieszkowski \& Mills, 199327

Figure 3.3 FrontRunner station wayfinding signage........................................................... 28

Figure 3.4 Bike lockers are located at each of the FrontRunner stations. ................................ 39

Figure 4.1. Transitional probability as a function of distance to station.................................. 45

Figure 4.2 Transition probability vector for retail land use class ........................................ 46

Figure 4.3 Process overview of the agent-based model........................................................... 48

Figure 4.4 Observed land use and simulated maps of land use type in Salt Lake County in 2010

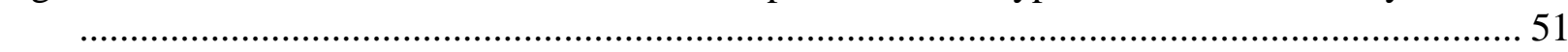

Figure 4.5 Observed changes in land use types between 2007 and 2010 ............................... 52

Figure 4.6 The actual and simulated land use map of Salt Lake, Davis, and Weber County...... 60

Figure 5.1 FrontRunner corridor under highway infrastructure .............................................. 65 



\section{EXECUTIVE SUMMARY}

All transportation systems have the ability to transform human settlement patterns, which can affect a range of social, economic and environmental issues. However, only highway infrastructure has been emphasized in research regarding commuting and developing human settlement patterns. Considering investments in rail infrastructure have increased in recent decades (Bureau of Transportation Statistics, 2007; Israel \& Cohen-Blankshtain, 2010), it is important for planners and researchers to understand how these rail systems influence land use, metropolitan development patterns, and population migration in the 21st century.

This report provides insight into the ways in which the investment of a commuter rail system can affect facets of human settlements. Our research evaluates the effects of a case study commuter rail system, FrontRunner, located along the Wasatch Front in Utah, which makes this report the first of its kind to focus on a metropolitan area with a population below three million. The Wasatch Front is a rapidly growing metropolitan area dealing with unique air quality issues — one of the nation's regions with the worst winter inversions. To mitigate such air quality issues, while also managing population growth and preserving natural resources, the Utah Transit Authority (UTA) has constructed a multimodal transit system which includes the FrontRunner commuter rail. While this report focuses on the Wasatch Front, we have sought to produce either generalizable

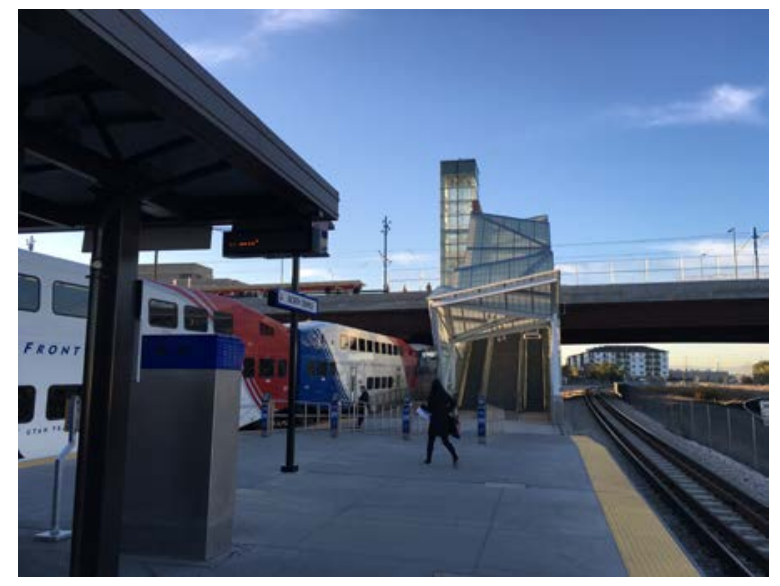

Figure 0.1 Salt Lake Central FrontRunner station results or replicable methods, allowing re-testing in non-comparable settings.

For this report, the Metropolitan Research Center has pursued multiple studies using the U.S. Census Bureau's Longitudinal Employment-Household Dynamics (LEHD) data on worker origin and destination from 2002 through 2012, U.S. Census Bureau Decennial Census and American Community Survey Data, as well as FrontRunner On-Board Survey data provided by UTA. The analyses for these studies combine descriptive and econometric methods from related literature and previous work done by the principal investigator (PI Joanna Ganning).

The overarching objective of our research is to provide systematic evidence if and how regional commuter rail either (A) replaces long commutes by car to create a sustainable, integrated urbanized region or (B) facilitates further suburbanization or deconcentration. Additionally, we provide an agent-based model to estimate the probability of land use transformation for each parcel of land surrounding a commuter rail station. Below we provide abstracts for the two empirical studies and our model. 


\section{The Effects of Commuter Rail Establishment on the Relationships between the Built Environment, Travel Behavior and Residential Self-Selection}

While dozens of studies investigate the relationship between the built environment and travel behavior, none quantify the relationship between these two elements and residential selfselection (RSS) after the intervention of a commuter rail. To help regional and transportation planners better understand the role that commuter rail plays in directing intra-regional development, this chapter provides a longitudinal investigation of the influence of commuter rail on surrounding neighborhoods' RSS, travel behavior and the built environment.

Methodologically, we do this first by analyzing the role of commuter rail establishment in influencing change in neighborhood-level demographics, housing and economics (signs of RSS), and travel behavior. Second, we compare surveyed commuter rail riders to residents of the commuter rail stations' host and neighboring areas. The results of these analyses indicate that the development of commuter rail does not alter the host tracts in any of the characteristics observed, but rather suppresses population growth in neighboring tracts. Paired with direct evidence from a commuter rail user survey, we conclude that the use of commuter rail is more likely influenced by the built environment than by RSS. Thus, as planners influence the built environment directly, these findings can be used to take steps toward increasing ridership and system efficacy.

\section{The Effects of Commuter Rail Establishment on Population Deconcentration}

American suburbanization and highway infrastructure have developed simultaneously, with research showing that highway construction induces demand (American Public Transportation Association (APTA), 1997; Brock \& Souleyrette, 2013). An alternative to highway development, commuter rail systems are primarily used to support journeys to work. Yet research to date has not established the efficacy of these systems in attracting migrants most likely to use such an amenity. Through the application of a modified population deconcentration model, this chapter finds that the provision of a commuter rail station significantly increases neighborhood-level outcommuting and gross migration, which signals success in attracting migrants requiring commuting infrastructure. These findings might also signal that commuter rail encourages regional population deconcentration, but the evidence is insufficient to form a conclusion and the evidence from Chapters 2 and 4 signal otherwise.

\section{Developing an Agent-Based Model (ABM) For Estimation of Land Use Changes around Commuter Rail Stations over Time}

This chapter aims to improve the understanding of commuter rails' effect on land use changes over time through spatial interaction modeling. In particular, we develop an innovative agentbased model (ABM) that allows us to estimate and visualize the probability of land use changes per parcel based on proximity to commuter rail stations, freeway exits, and the region's central business district. This model can help better inform planners and decision-makers of how integrating a commuter rail system into regional plans will affect surrounding land uses. Briefly, this chapter concludes that the development of a commuter rail station is statistically significantly associated with decreases in single-family residential land use near the station, which is met by increases in multifamily and mixed-use development. The spatial effects of stations on individual land uses vary by land use type, and no generalizable area of influence could be established. 


\subsection{INTRODUCTION}

Recent research reveals American metropolitan regions continued to sprawl from 2000 to 2010 (Hamidi \& Ewing, 2014). American metropolitan development, specifically suburbanization, has hinged on the provision of highway infrastructure, and research shows that increasing highway miles induces demand (APTA, 1997; Brock \& Souleyrette, 2013). Extensive use of automobiles via suburbanization affects the environmental, social and economic well-being of metropolitan residents. The U.S. federal government's transportation demand management (TDM) policy initiatives have responded to these issues by synergizing air quality and energy conservation concerns into transportation planning processes, thus encouraging public transit. Transportation planning organizations have responded variably, with some favoring public transit more than others.

One organization supporting public transit is the Wasatch Front Regional Council (WFRC), which used the U.S. Department of Housing and Urban Development's (HUD) Sustainable Communities Regional Planning grant program to develop the Wasatch Choice for 2040 regional plan. This plan calls for node-based development that is projected to reduce vehicle miles traveled (VMT), per capita water use and energy use, and to protect open space, among other goals. The FrontRunner commuter rail (Figure 1.1) plays an important role in achieving these goals by connecting workers to jobs without the use of (or with reduced use of) private vehicles.

This report provides an overview of the case study region, commuter rail and theoretical foundation for commuter rail research in relation to metropolitan development. This report includes three studies we have conducted to test (1) the relationship between commuter rail, residential self-selection and the built environment; (2) the effects of commuter rail on population deconcentration; and (3) how land use development patterns change around commuter rail stations over time.

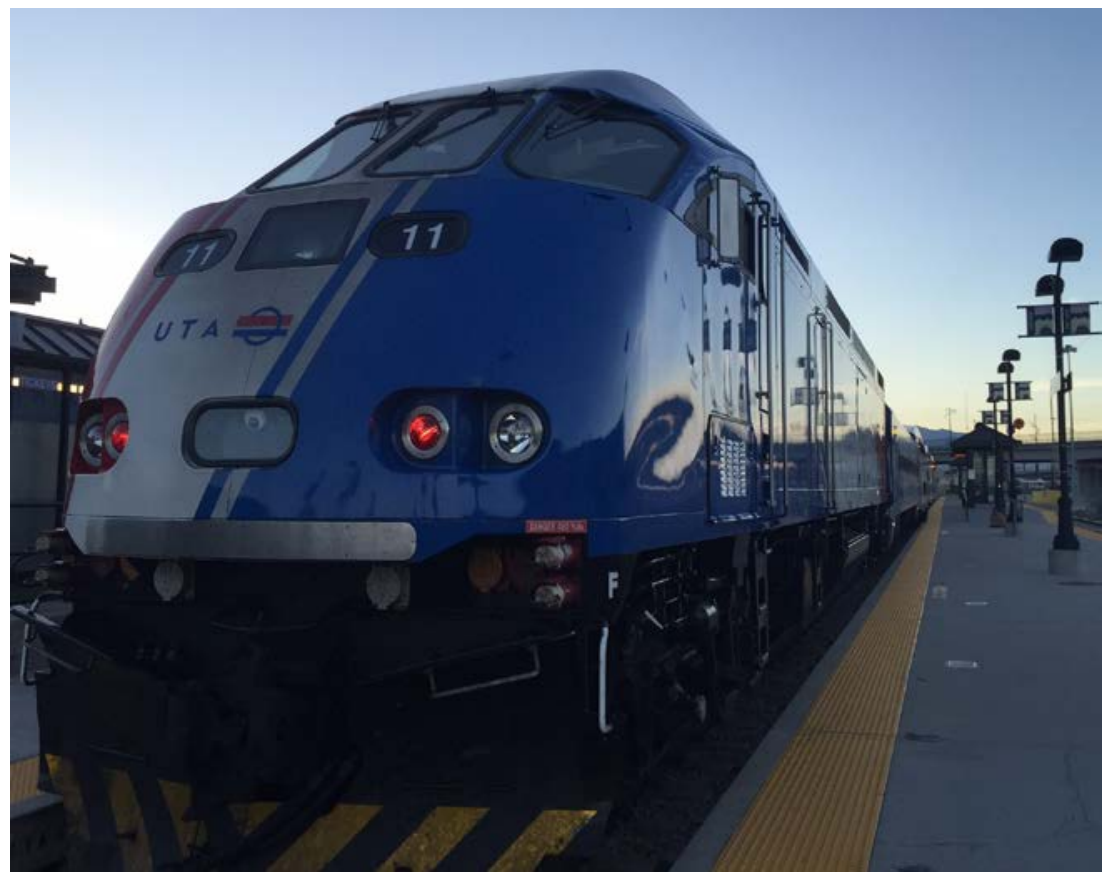

Figure 1.1 FrontRunner commuter rail 


\subsection{THEORETICAL OVERVIEW}

Since the APTA first quantified the benefits of commuter rail in 1997, literature on the effects of commuter rail have been conducted nationwide (Levinson \& Allen, 2014; Cervero, 1996; Lane et al., 2006) and on individual commuter rail systems (Ayvalik \& Khisty, 2002; Engel-Yan, 2014). Pushkarev et al. (1982) studied the relationships among commuter rail ridership, demography, transportation, and physical aspects for nationwide commuter rail systems. However, now that analysis is out of date, it does not include the effects of commuter rail on deconcentration over time, nor does it include the built environment changes caused by commuter rail associated with distance from both stations and central business districts (CBD).

In Chapter 2, we were inspired by Cao et al. (2009) as well as Ewing and Cervero (2010) to provide a longitudinal investigation of the influence of commuter rail on surrounding neighborhoods' residential self-selection, travel behavior and the built environment. This chapter's research differentiates itself from a majority of relevant studies for many reasons: (1) we focus on a particular mode of transit (commuter rail) rather than combining multiple modes; (2) our methodological design analyzes the role of commuter rail establishment in influencing change in neighborhood-level demographics, housing and economics (signs of RSS), and travel behavior; and (3) we compare surveyed commuter rail riders to residents of the commuter rail stations' host and neighboring areas.

The results of this chapter, particularly the spatial lag from the development of commuter stations, might encourage planners to consider transect-based transit planning. While the use of transect planning as a tool for improving community sustainability is trending (Bohl \& PlaterZyberk, 2006; Duany \&Talen, 2002; Talen, 2002), transect-based transit planning is less wellknown. Yet, as Payton and Hawkes (2012) describe, using transects—or "station area typologies" — can help municipalities and transportation agencies to identify context-specific urban design issues and create plans which are consistent with the needs, character and density of stations or communities.

In Chapter 3, we study the effect of commuter rail implementation on migration and commuting. Population migration has been evaluated through various theoretical perspectives which anticipate different redistribution tendencies (Berry, 1976; Bunting \& Filion, 1999; Carlino, 2000; Coffey \& Shearmur, 2002; Dean et al., 1984; Frey, 1987; Israel \& Cohen-Blankshtain, 2010; Kahsai \& Schaeffer, 2010; Pfister et al., 2000; Renkow \& Hoover, 2000; Stanback, 1991). We follow in the theoretical footsteps of Renkow and Hoover (2000), Ganning and McCall (2012), and Rupasingha, Liu and Partridge (2015), among others, by applying a modified population deconcentration model to observe if the provision of commuter rail significantly increases out-commuting, which signals success in attracting migrants requiring commuting infrastructure. The results of this chapter suggest further analyses, and clearly relate to the findings in Chapter 2.

For Chapter, 4 we consider the growing interest in the relationship between commuter rail and spatial land use changes over time through individual-level spatial interaction modeling. Spatial interaction models, for example Lowry's gravity model, have demonstrated that the accessibility and connectivity from transportation investments can foster density and mixed-use development near transportation nodes or routes (Acheampong \& Silva, 2015; Batty, 2012; Silva \& Wu, 2012). 
Specific to public transportation, these models have focused on the density and diversity of land uses as a function of distance to stations or routes. While much of this research has focused on transit generally or rail specifically, studies to date have not focused on the effects of commuter rail on proximate land use changes.

\subsection{BRIEF ORIENTATION TO COMMUTER RAIL SYSTEMS}

Since the APTA first quantified the benefits of commuter rail in 1997, studies of the general effects of such transit systems have proliferated nationwide (Allen \& Levinson, 2014; Belzer et al., 2011; Nelson et al., 2015; Seskin, Cervero \& Zupan 1996). Some studies demonstrate how commuter rail can improve economic development, expand housing options, reduce dependence on automobiles, and decrease greenhouse gas emissions (APTA, 1997; Ayvalik \& Khisty, 2002; Deka \& Marchwinski, 2014; Kennedy, 2002; Nelson et al., 2015; Seskin, Cervero \& Zupan, 1996). Since this report intends to add to commuter rail literature, this section provides a brief overview of what commuter rail is and describes commuter rail and its ridership in the U.S.

Commuter rail refers to a rail corridor that connects downtowns and other major activity centers to suburban developments within a greater metropolitan area. The average trip distance for commuter rail passengers reflects this metropolitan development pattern. In 2013, the average trip was 24.7 miles, which is nearly five times the distance of light rail riders (APTA, 2015). To cover these long distances efficiently, commuter rail service is characterized by high speeds and infrequent stops. These aspects of service, along with the train's average seating capacity and size, differentiate them from other rail investments (e.g., light rail). The trains themselves are composed of either self-propelled cars, which run primarily on electricity, or cars hauled by locomotives, which run on diesel.

As of 2013, there were 26 commuter rail systems in operation across 29 major U.S. metropolitan areas. The nation's commuter rails operate on 8,691 miles of track, which either follow freight railroads or the right-of-way of former freight railroads (Allen \& Levinson, 2014).

Since commuter rail trips were first recorded in 1974, they have more than doubled, and the number of trips is still growing. U.S. Census data reveals that annual unlinked commuter rail passenger trips, meaning the number of times passengers board commuter rail vehicles, grew to 480 million in 2013 - a 17\% increase since 2003 (APTA, 2015). This number seems large, yet commuter rail trips represented only $4.5 \%$ of all public transit trips in 2013.

Many factors influence the use of commuter rail. The availability of parking spaces at park-andride lots, for example, impacts ridership. Nearly 30\% of rail passengers drive to stations and an additional $10 \%$ arrive as passengers of others' private vehicles (APTA, 2015). Ridership also responds to changes within the CBD. A 10\% increase in employment density in the CBD has shown to increase ridership by 7.1\% (Transit Cooperative Research Program,1996). Other ridership influences range from shifts in the real estate market and gasoline prices to the number of households within the radii of the system's corridor and household income (Merriman, 1998). 


\subsection{RESEARCH MOTIVATIONS}

This research was also motivated by a stark lack of existing research specifically covering the demographic or land use implications of commuter rail systems. Since the APTA first quantified the benefits of commuter rail in 1997, an abundance of literature regarding the effects of commuter rail have been pursued (Ayvalik \& Khisty, 2002; Cervero, 1996; Engel-Yan, 2014; Lane et al., 2006; Levinson \& Allen, 2014). Pushkarev et al. (1982) studied the relationships among commuter rail ridership, demography, transportation and physical aspects for nationwide commuter rail systems, but the analysis was published prior to the development of many of the datasets and analytical methods now available.

As the chapters reflect in their literature reviews, while some research exists on each of our topics, these papers are limited both in number and scope. Given the rising number of commuter rail systems and increase in commuter rail investment throughout the U.S., we are motivated to provide knowledge to practitioners regarding best practices, and conclude in this study that planners should focus on amenities of the built environment that facilitate ridership and on zoning near commuter rail stations to encourage mixed-use development. We are also motivated to provide solid methodological advances for researchers, which we do through (1) extending the existing population deconcentration model; (2) providing innovative methods for testing the relative influences of self-selection and the built environment on travel behavior; and (3) applying simulation methods to models of land use change. We also hope this work advances the scholarly discussion on what commuter rail should and does provide for metropolitan regions.

\subsection{RESEARCH OBJECTIVES}

For this section of the report, we describe our objectives and motivations for pursuing commuter rail-specific research. The initial objection of this report was to address the question: Does regional commuter rail replace long commutes by car, thus creating a sustainable, integrated urbanized region, or does it facilitate further suburbanization and increased vehicle miles traveled along the route? To address this question, we identified four research objectives: (1) estimate the catchment area for commuters surrounding a commuter rail station; (2) estimate the effect of commuter rail on the mode choices of existing residents of surrounding neighborhoods and the residential location selection bias of new residents; (3) estimate the extent to which commuter rail influences commuting and migration; and (4) analyze land use changes driven by the development of commuter rail stations. Taken together, the research addressing these objectives provides valuable information on the role commuter rail plays in influencing regional population deconcentration.

Through the research reported in this document, these objectives evolved to reflect data availability as well as both research constraints and opportunities. Most notably, we were forced to abandon the first objective upon learning that the data covering the FrontRunner system would not permit this analysis, and that the mode choice data available through the U.S. Census Bureau has high margins of error at the Census-tract level.

In contrast, our research assessing the residential location selection bias of new residents far exceeds the initial research objective. We expanded the scope of our research to not only 
evaluate residential location selection bias, but to conduct path-breaking research on the relationships between self-selection, the built environment, and travel behavior near commuter rail stations. In this work, we compare the spatial effects of commuter rail on changes in economics, demographics, transportation behavior and housing, and compare these to the effects of light rail. The results of this work can be found in Chapter 2 of this report. Briefly, this research finds that the built environment influences travel behavior more so than does selfselection, vis-à-vis the development of commuter rail.

The research estimating the effect of commuter rail on the relationship between commuting and migration proceeded as designed, and can be found in Chapter 3 of this report. The research reflecting the fourth objective can, similarly, be found in Chapter 4.

Taken together, this research reveals that commuter rail likely does not hasten regional population deconcentration. While the research in Chapter 3 finds that commuter rail significantly increases both gross migration and out-commuting from a Census tract, the research in Chapter 2 suggests that these population shifts are also influenced more by the built environment than self-selection, suggesting that in-migrants were likely suburban residents rather than residents of more urban areas. Chapter 4 finds, and Chapter 2 corroborates, that commuter rail discourages single-family residential development and encourages mixed-use development near the station area, allowing the possibility to plan for dense nodes of planned development.

This research was motivated by two of NITC's themes: making the best use of data and analytical tools, and taking long-term actions to reduce emissions. This project has made novel methodological contributions, pulling from regional science and simulation modeling, to inform urban planning research and practice.

\subsection{THE STUDY REGION: THE SALT LAKE-PROVO-OREM COMBINED STATISTICAL AREA}

FrontRunner runs through four counties: Weber, Davis, Salt Lake and Utah. Together, along with six other counties, this area comprises the Salt Lake-Provo-Orem Combined Statistical Area (CSA). This CSA (highlighted in Figure 1.2) is home to more than 1.5 million people and is the geographic concentration of roughly $80 \%$ of Utah’s population. 
The Wasatch Front, the long and narrow metropolitan region within the CSA, is constrained by natural features: the Great Salt Lake to the west and the Wasatch Range to the east. These geographical constraints direct the location of population growth. Additionally, both the area's population and major employers have expanded outside the CBD, which has increased suburban development. In fact, suburban development has almost continuously connected the entire urban region. Such expansion has propelled the integration of forward-thinking transportation options

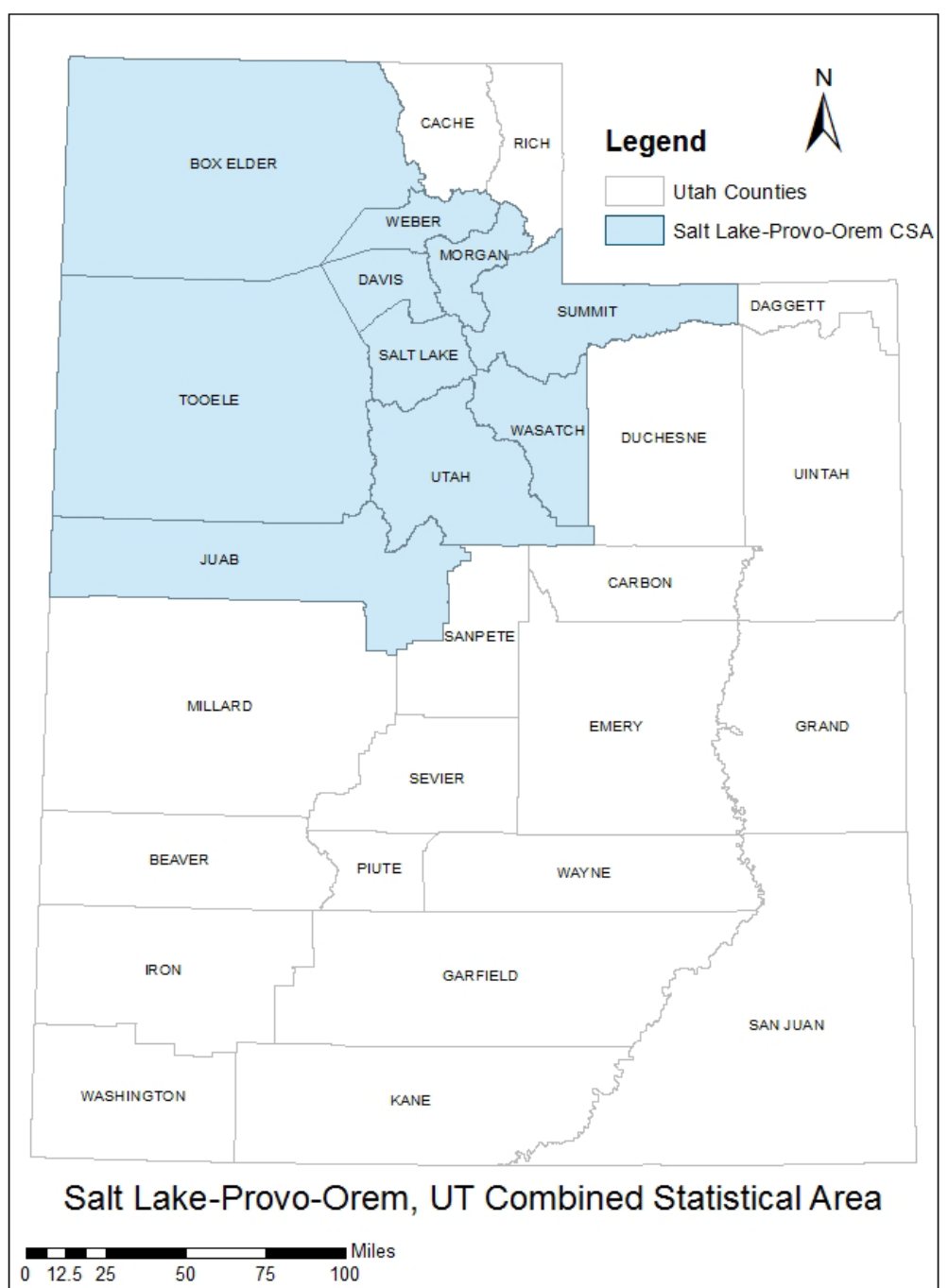

Figure 1.2 Map of the Salt Lake-Provo-Orem CSA. (i.e., the FrontRunner commuter rail) to run through the largest cities in the region: (A) Salt Lake City, the largest and most central city; (B) Ogden City in Weber County, with the most northern station stop; and (C) the City of Provo located in Utah County, with the most southern station stop.

In addition to FrontRunner, the region hosts a range of transportation options. For public transit, UTA runs a number of daily bus routes, as well as MAX - a bus rapid transit system - and TRAX, a light rail system. For drivers, Interstate-15 stretches through the middle of the region and connects Utah with Idaho and Arizona, while Interstate-80 runs east-west, connecting Utah to Wyoming and Nevada. With these transportation options, the travel behavior in the region is unique. According to the U.S. Census Bureau's American Community Survey (ACS), the CSA has a slightly lower percentage of workers driving alone to work than the national average (75.7\% versus $76.5 \%)$, but also a lower percentage taking public transport (2.8\% versus 5.2\%; ACS, 2014). Additionally, commute times throughout the CSA are slightly shorter than the national average, at 22 minutes versus 26 minutes (ACS, 2014).

Currently, Utah has the fastest growing population in the U.S., which is one of the reasons it is an interesting area to study. More to scale for this study, the Salt Lake-Provo-Orem CSA boasts a median age of 29.5, which is much younger than the national median of 36.7 (ACS, 2009-2013). Further, the CSA's population is more educated than the national average. While $28.8 \%$ of the U.S. population has at least a bachelor's degree, $31.4 \%$ of the CSA population has received a 
bachelor's degree. The labor force participation rate in the CSA (69.4\%) is high compared to the U.S. (63.3\%; ACS, 2014). And the CSA has a significantly lower unemployment rate than the nation (3.6\% versus 5.1\% in September 2015; Bureau of Labor Statistics).

The growth and development in the CSA, along with the region's geographic features, make the area prone to air quality problems. To alleviate the significant air quality issues while accommodating the quickly growing population, the Wasatch Front Regional Council (in consortium with other regional planning and community organizations) under the U.S. Department of Housing and Urban Development's (HUD) Sustainable Communities Regional Planning grant program developed the Wasatch Choice for 2040 regional plan. This plan calls for node-based development that is projected to reduce vehicle miles traveled (VMT), per capita water use and energy use, and to protect open space, among other goals. The FrontRunner system plays an important role in this plan by connecting workers to jobs without the use of (or with reduced use of) private vehicles to reduce VMT and improve air quality. The physical and social factors of the Salt Lake-Provo-Orem CSA, combined with the recent addition of the FrontRunner commuter rail system, make the region an opportune study area.

\subsection{THE TRANSIT SYSTEM: FRONTRUNNER COMMUTER RAIL}

The FrontRunner system, operated by the Utah Transit Authority (UTA), is Utah's first and only commuter rail line. Though FrontRunner was initially constructed, in part, on the famous Union Pacific Railroad corridor, it runs primarily on its own single track. The push-pull diesel locomotive system operates at up to 79 miles per hour (UTA, n.d.). Currently, the FrontRunner corridor spans nearly 90 miles between the cities of Provo and Ogden, with planned extensions to lengthen its route an additional 40 miles.

The FrontRunner system opened in two phases: the northern corridor and the southern corridor. The first phase-the northern corridor-opened in April 2008 with seven stations, which run through Salt Lake, Weber and Davis counties

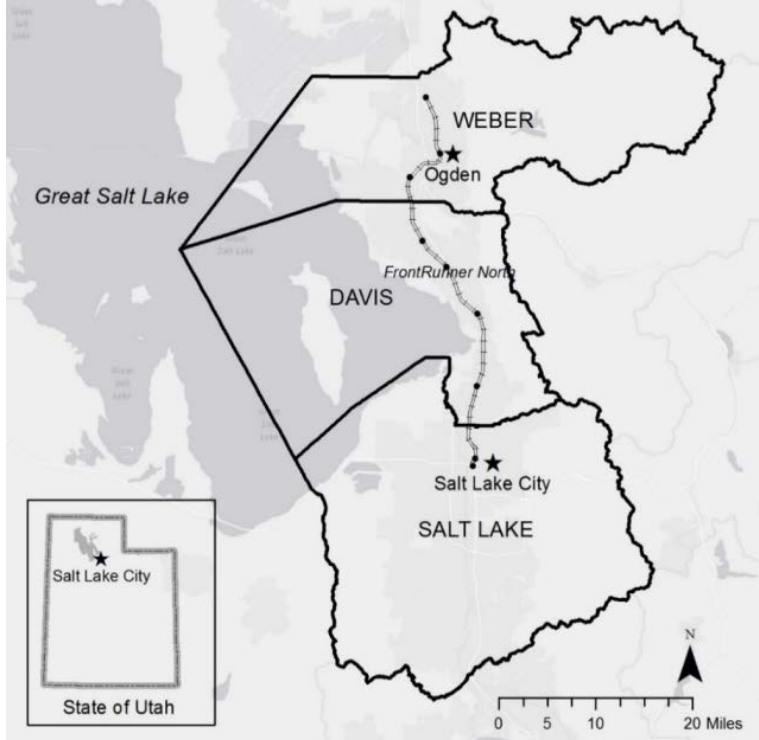

Figure 1.3 Study area (Figure 1.3). The second phase occurred four years later, in December 2012, with eight stations constructed to connect the northern route with Utah County in the south. To work with the most complete data, we excluded the southern corridor from the analyses in this report due to its opening near the end of the five-year period reflected in the most recent ACS data. Consequently, this report focuses solely on the northern route.

According to UTA, each FrontRunner station links to at least one bus route and (with one exception) functions as a park-and-ride facility (example of park-and-ride facility in Figure 1.4). All parking lots are unmetered and generally provide an excess of parking spots. Additionally, 
the stations provide bike storage and are connected with UTA bus routes. Riders can be picked up hourly at each station during the weekdays and every half hour during peak hours. On Saturdays, the trains run on a limited schedule and on Sundays they do not run at all.

FrontRunner trains make complete trips-from Provo to Ogden—about 25 times per day. Fares are based on distance and are generally one-way, though monthly passes, round-trip and group tickets can also be purchased. Tickets start at $\$ 2.50$; each additional stop costs $\$ 0.60$ (UTA, 2015). Additionally, faculty, staff and students of the University of Utah receive free access to most of UTA’s transit system-including FrontRunner.

The FrontRunner's average weekday ridership increased continuously from 4,756 in January 2010 to 5,804 in November 2012, before the southern corridor launch (UTA, internal data). Since the southern line's opening, FrontRunner's ridership has increased to more than 16,000 weekday boardings in 2014. The FrontRunner system's weekday boardings ranked 10th among 28 commuter rail systems in the U.S. (APTA, 2015). Surveyed riders primarily access their origin station by automobile (85\%), then by walking (11\%) and least by biking (3\%). Those same users also egress from their destination station primarily by automobile (51\%), but higher percentages of riders egress via walking (40\%) and biking (9\%) than when accessing stations (UTA, 2011). For most commuters (82\%), their total distance traveled is more than 20 miles, and a majority of their trips start from home and end at a place of employment (51\%), as expected for a commuter rail.

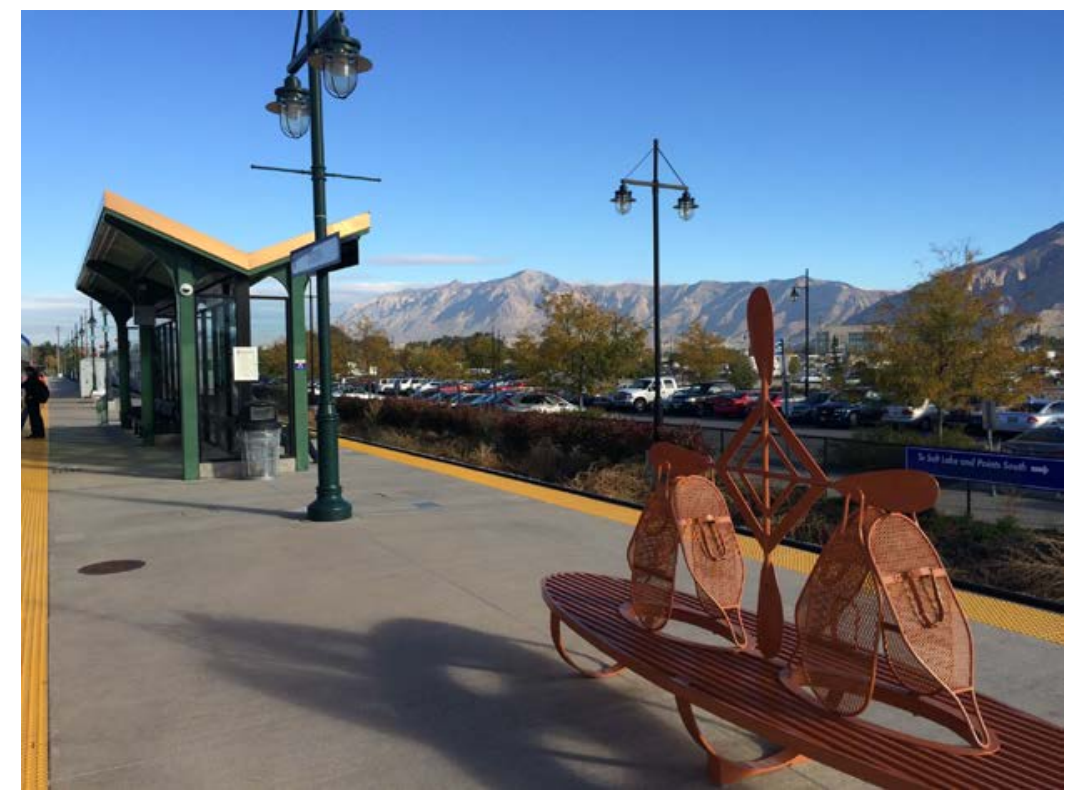

Figure 1.4 Park-and-ride facility next to a FrontRunner station 


\subsection{THE EFFECTS OF COMMUTER RAIL ESTABLISHMENT ON THE RELATIONSHIPS BETWEEN THE BUILT ENVIRONMENT, TRAVEL BEHAVIOR, AND RESIDENTIAL SELF-SELECTION}

Commuter rail systems help metropolitan areas mitigate urban issues by decreasing dependence on automobiles and the related release of greenhouse gas emissions, improving economic development and expanding housing options (APTA, 1997; Ayvalik \& Khisty, 2002; Deka \& Marchwinski, 2014; Kennedy, 2002; Nelson et al., 2015; Seskin et al., 1996). With such benefits - in addition to the fact that sprawl continues across the United States (Hamidi \& Ewing, 2014) — it is unsurprising that commuter rail has expanded ridership even though the transit industry experienced decline (Allen \& Levinson, 2014).

Conversely, the mere existence of or accessibility to commuter rail does not necessitate that residents or workers use it, nor does it automatically reduce vehicle miles traveled (VMT). Instead, it is entirely possible for commuter rail to attract residents to suburban locations where increases in non-work VMT outweigh gains made by commuting by transit. Many dimensions affect a commuter's mode choice, including built environment factors, sociodemographic factors, lifestyles and attitudes, and mode choice costs. The past 20 years have produced studies investigating the association between the built environment and travel behavior (Ewing \& Cervero, 2001; Cervero \& Duncan, 2002; Chatman, 2009; Crane \& Crepeau, 1998; Joh et al., 2008); yet, a majority of these studies do not quantify the relationship between these two elements and residential self-selection (RSS). Specifically, none have quantified changes in this relationship after the introduction of a commuter rail system.

The consequences of this are not trivial. In travel behavior studies, RSS refers to a person's propensity to live in an area conducive to travel abilities, needs and preferences (Litman, 2005). Since commuter rail primarily connects suburban communities to more urban areas where jobs are concentrated, RSS could mean that people preferring more typically urban, public transportation options could be drawn to suburban locations. Alternately, the combination of public transit and lower suburban real estate pricing could attract otherwise urban residents. Under either scenario, commuter rail foments population deconcentration-an issue carrying consequences that commuter rail seeks to remedy. Contrarily, if the built environment's effects dominate RSS' effects regarding commuter rail travel behavior, then planners are well-advised to enhance the built environment around commuter rail stations to increase ridership.

This chapter uses a series of analyses to understand the roles of RSS and the built environment on travel behavior regarding commuter rail. First, we identify how the development of commuter rail impacts various characteristics of surrounding areas, including travel behavior, demographics and elements of the built environment. These findings are indirect evidence in that they rely on an analysis of changes in the nearby residential areas of commuter rail stations using secondary data aggregated to Census tracts. In a second analysis, using limited but disaggregated 
data on commuter rail riders, we provide more direct evidence of these dynamics. Both the indirect and direct evidence argue that the role of the built environment dominantly influences change in travel behavior after the intervention of a commuter rail system.

This chapter is organized as follows: first we provide a synthesized review of literature on RSS and built environment research; then we introduce our reasoning for more mode-specific studies and we describe our data, variables, methodology and findings. To conclude this chapter, we relate these findings to planning practice and mode-specific research.

\subsection{RSS, TRAVEL BEHAVIOR, AND THE BUILT ENVIRONMENT}

Recent research reveals that while the pace has been slow, American metropolitan regions continued to sprawl from 2000 to 2010 (Hamidi \& Ewing, 2014). The extensive use of automobiles via this suburbanization affects the environmental, social and economic well-being of metropolitan areas. In response to these issues, the U.S. federal government's transportation demand management (TDM) policy initiatives have evolved to synergize air quality and energy conservation concerns into transportation planning processes, thus encouraging the use of public transit. Cities and regional transportation planning organizations have responded variably, with some favoring public transit and active transit more than others.

Social behavior, including transportation choices, is affected by urban or environmental design (Cao et al., 2007a; Cao et al., 2007b; Cervero, 2001; Buehler, 2009; Ewing \& Cervero, 2010; Hunecke et al., 2007; Malayath \& Verma, 2013; McFadden, 2007; Mehta, 2013; Meyer, 1999). However, the relationship between the built environment and travel behavior is arguably more complex. Different socioeconomic, demographic, lifestyle and attitude attributes affect travel preferences, travel behavior and residential location choice. The combined outcomes of these related dynamics are analyzed through the operationalized conceptualizations of RSS, the built environment and travel behavior.

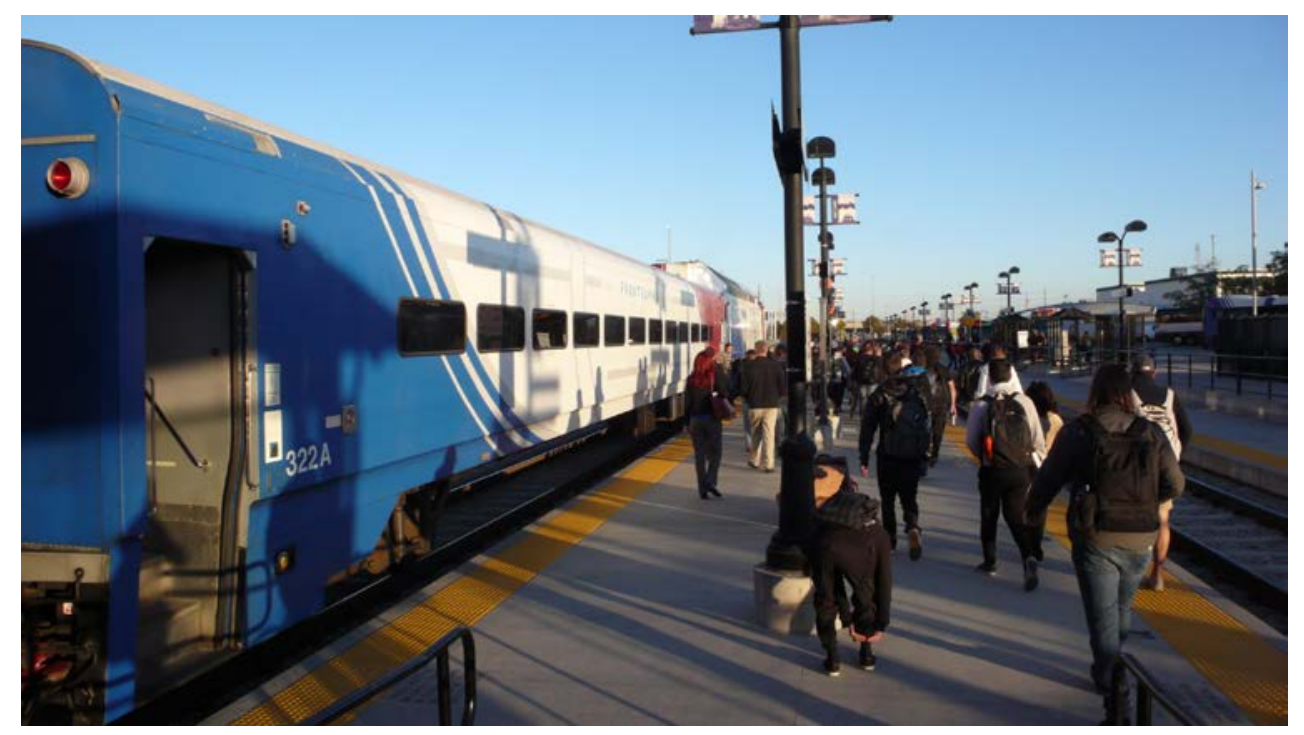

Figure 2.1 FrontRunner's Temple Square station crowded with a mix of demographics and uses 
As stated, the most recurrent description of RSS in travel behavior research originated from Litman (2005, as cited in Mokhtarian \& Cao, 2008; Van Wee, 2009) as a person's propensity to live in an area conducive to respective travel abilities, needs and preferences. The impacts of RSS and the built environment are not mutually exclusive, but rather compounding. As such, if RSS plays a significant role in transportation behavior, then RSS should be considered in addition to the built environment when estimating travel behavior changes within metropolitan regions.

In 2009, Cao et al. recounted 38 papers studying the relationship between RSS, the built environment and travel behavior. Their meta-analysis found that RSS reduces the effect of the built environment on travel behavior, but also confirmed there is a significant relationship between built environments and travel behavior even after controlling for RSS influences (Cao et al., 2009). In contrast, Ewing and Cervero (2010) reviewed 50 related studies and found no effect (or enhanced effects) of the built environment on travel behavior after controlling for RSS. However, the authors of the latter analysis admit their findings could be a result of "lumping all studies that control for self-selection together regardless of methodology” unlike Cao et al. (2009). Based on the conflicting results of these meta-analyses, we lack a clear hypothesis for favoring RSS or the built environment in influencing travel behavior.

Cao et al. (2009) call for more studies that not only quantify such a relationship, but also examine the impact of transportation behavior after a change in the built environment. This manuscript responds to that call, quantifying the change in neighborhoods along multiple dimensions, including transportation behavior after the introduction of commuter rail. Furthermore, by focusing on a single transit system type, this manuscript seeks to illuminate mode-specific mechanisms of travel behavior change.

The majority of RSS travel behavior studies combine multiple transit modes during analysis despite research indicating that different transit modes serve different applications best, that they have different effects on economic development (Bollinger \& Ihlanfeldt, 1997), and that they are perceived differently in terms of social acceptability and safety (Booth et al., 2005; Cho et al., 2009; Lee et al., 2013; Luymes \& Tamminga, 1995; Mehta, 2013; Saelens et al., 2003; Van et al., 2014; Villaveces et al., 2012). Thus, it follows that different transit modes would interface differently with changes to the built environment and travel behavior. While some studies consider rail, they do not specify the type, they combine forms of rail (light rail and heavy rail) into one sample, or they combine rail with other forms of transit (Cervero \& Duncan, 2002, 2008; Chatman, 2009; Cao et al., 2006; Handy et al., 2005; Kitamura et al., 1997; Schwanen \& Mokhtarian, 2005a, 2005b; Boarnet \& Sarmiento, 1998; Khattak \& Rodriguez, 2005; Greenwald, 2003; Bagley \& Mokhtarian, 2002; Cervero, 2001; Pinjari et al., 2007; Scheiner \& Holz-Rau, 2007; Krizek, 2000; Meurs \& Haaijer, 2001). The only exception is the work conducted by Israel and Cohen-Blankshtain (2010), in which they used a ridership survey and a stated preference model specifically on a commuter rail that had just undergone improvements. They find that households who previously lived and worked at the metropolitan core perceived rail transit as an important amenity when making the decision to move from the metropolitan core to its fringe.

While the majority of studies relating the built environment and travel behavior have been conducted in California, specifically in the San Francisco Bay Area or Northern California (Bagley \& Mokhtarian, 2002; Bhat \& Guo, 2007; Cao, 2008; Cao et al., 2006, 2007a, 2007b; 
Cervero, 2001; Chatman, 2009; Circella et al., 2008; Handy et al., 2005, 2006; Kitamura et al., 1997; Pinjari et al., 2007; Schwanen \& Mokhtarian, 2003), our case study analyzes data from the FrontRunner commuter rail system operating in the Salt Lake-Provo-Orem Combined Statistical Area (CSA) in Utah. By studying a different geographic region, we test the generalizability of previous studies and add new context to the relationships at play.

\subsection{METHODS}

We employ a multipronged methodology to identify the impacts of the built environment and RSS on travel behavior following the opening of a commuter rail corridor. The first step investigates these interactions indirectly by evaluating the impacts of the system's installation on surrounding areas. If the system attracted self-selecting migrants in significant numbers, these migrants' demographic and travel behavior characteristics would register as being changed in secondary data aggregated to the Census-tract level. The second step seeks to corroborate the indirect findings by directly linking FrontRunner's On-Board Survey (detailed description below) data with the secondary data that describes residents in nearby Census tracts. In both the indirect and direct analyses, we study the tracts in which commuter rail stations are situated ("host tracts") and tracts that intersect a one-mile buffer around each station ("neighbor tracts”).

\subsubsection{Data Preparation}

In the indirect analysis we construct a series of regression models for four "characteristic areas" that reflect aspects of RSS (we call these characteristic areas "Demographics" and "Economics"1); one aspect of the built environment ("Housing”); and travel behavior (“Transportation”). Compared to other methods of evaluating changes in the Census tracts around commuter rail stations, this approach bears the advantage of being deterministic and disaggregated to allow an understanding of "character” across distinguishable facets (demographics, economics, transportation and housing) inclusive of both the built and social environments while allowing reasonably straightforward interpretation. Notably, an effort to use data reduction techniques to identify naturally emerging sub-indices were ineffective, producing nonsensical variable groupings that would make interpretation challenging.

For each characteristic area, we collate relevant variables for the years 2000 and 2010 then calculate the change in each variable. Those variables, data sources and variable-specific approaches to calculating change are given in Table 2.1

\footnotetext{
${ }^{1}$ While we acknowledge that demographics and economics are not traditional measures of RSS, we nonetheless submit that they are reasonable. "In travel research, influences of the built environment on travel have often been named with words beginning with D. The original 'three Ds', coined by Cervero and Kockelman (1997), are density, diversity and design, followed later by destination accessibility and distance to transit (Ewing and Cervero, 2001). While not part of the environment, demographics are the sixth D, controlled as confounding influences in travel studies” (p. 2331). If demographics are not part of the built environment but impact travel behavior, and if RSS is defined as a person's propensity to live in areas that meet their needs, abilities or preferences for travel, then RSS should be apparent through changes in neighborhood demographics.
} 
Table 2.1 List of variables, data sources, approach to calculation, and characteristic areas

\begin{tabular}{|c|c|c|c|}
\hline Variables & $\begin{array}{c}\text { Data } \\
\text { Source }\end{array}$ & Approach to Calculation Change & $\begin{array}{l}\text { Characteristic } \\
\text { Areas }\end{array}$ \\
\hline $\begin{array}{l}\text { Total Population (14); Female Population (21); One Race- } \\
\text { White (15); One Race-Black or African American (7); One } \\
\text { Race- American Indian, Alaska Native, Native Hawaiian, and } \\
\text { Other Pacific Islander (8); One Race-Asian (9); One } \\
\text { Ethnicity-Hispanic or Latino (of any race) (10) }\end{array}$ & SF1, ACS & $\begin{array}{l}\text { A; To reduce zero (0) values, we combined "American Indian and } \\
\text { Alaska Native" and "Native Hawaiian and Other Pacific Islander" } \\
\text { into one variable category. }\end{array}$ & 1 \\
\hline Median Age (years) (19) & SF1, ACS & $\mathrm{B}$ & 1 \\
\hline Dependency Ratio (18) & SF1, ACS & $\begin{array}{l}\text { C; Calculated the number of dependents (ages under } 15 \text { or over 64) } \\
\text { to the population between ages } 15-64 \text {. }\end{array}$ & 1 \\
\hline Diversity Measure (11) & SF1, ACS & $\begin{array}{c}\text { C; Calculated the number of One Race White-Only Non-Hispanic } \\
\text { or Latino to the Total Population. }\end{array}$ & 1 \\
\hline $\begin{array}{l}\text { Total Households (16); Family Households (Families)-With } \\
\text { own children under } 18 \text { years (17); Total Civilian } \\
\text { Noninstitutionalized Population - With a disability (13) }\end{array}$ & SF1, ACS & A & 1 \\
\hline $\begin{array}{c}\text { Average Household Size (20) } \\
\end{array}$ & SF1, ACS & $\mathrm{B}$ & 1 \\
\hline Occupied Housing Units (50); Vacant Housing Units (51) & SF1, ACS & A & 3 \\
\hline $\begin{array}{c}\text { Homeowner Vacancy Rate (Percent) (47); Rental Vacancy } \\
\text { Rate (Percent) (48) }\end{array}$ & SF1, ACS & $\mathrm{C}$ & 3 \\
\hline $\begin{array}{c}\text { Percent Bachelor's Degree or Higher (Among Population } 25 \\
\text { Years and Over) }(12,22)\end{array}$ & SF1, ACS & $\mathrm{C}$ & 1,2 \\
\hline $\begin{array}{c}\text { Labor Force-Employment Status-Population } 16 \text { Years and } \\
\text { Over in Labor Force (34) }\end{array}$ & SF1, ACS & $\mathrm{C}$ & 2 \\
\hline $\begin{array}{c}\text { Employment Status-Total Population } 16 \text { Years and Over in } \\
\text { Civilian Labor Force-Employed (35) }\end{array}$ & SF1, ACS & $\mathrm{A}$ & 2 \\
\hline $\begin{array}{c}\text { Commuting to Work-Workers } 16 \text { Years and Over-Car, Truck, } \\
\text { or Van -Drove Alone (1); Carpooled (2); Public } \\
\text { Transportation (including Taxi) (4); Walked (5); Worked at } \\
\text { Home (3); Other Means (6); Cars-Household Vehicles } \\
\text { Available (compared to On Board only, not in Appendix) } \\
\end{array}$ & SF1, ACS & B & 4 \\
\hline $\begin{array}{l}\text { Occupation-Management, Business, Science, and Arts (23); } \\
\text { Service (36); Sales and Office (44); Natural Resources, } \\
\text { Construction, and Maintenance (37); Production, } \\
\text { Transportation, and Material Moving (38); Median Household } \\
\text { Income (Dollars) (33) }\end{array}$ & SF1, ACS & A & 2 \\
\hline
\end{tabular}




\begin{tabular}{|c|c|c|c|}
\hline $\begin{array}{l}\text { Employment Industry-Agriculture, Forestry, Fishing and } \\
\text { Hunting, and Mining (39); Construction (24); Manufacturing } \\
\text { (25); Wholesale Trade (40); Retail Trade (26); Transportation } \\
\text { and Warehousing, and Utilities (27); Information (28); } \\
\text { Finance, Insurance, Real Estate, and Rental and Leasing (29); } \\
\text { Professional, Scientific, Management, Administrative, and } \\
\text { Waste Management Services (30); Educational, Health, and } \\
\text { Social Services (31); Arts, Entertainment, Recreation, } \\
\text { Accommodation, and Food Services (41); Other Services } \\
\text { (42); Public Administration (32) }\end{array}$ & SF1, ACS & $\mathrm{D}$ & 2 \\
\hline Change in Median Year House Built (52) & SF1, ACS & $\begin{array}{c}\text { B, where median years in } 2000 \text { and } 2010 \text { were estimated using } \\
\text { linear interpolation with data giving the number of housing units } \\
\text { built in each decade. }\end{array}$ & 3 \\
\hline $\begin{array}{c}\text { Median Housing Value-(Dollars) (Specified Owner-Occupied } \\
\text { Units) (45); Median Gross Rent-(Dollars) (Specified Renter- } \\
\text { Occupied Units) (49) }\end{array}$ & SF1, ACS & A & 3 \\
\hline House and Rent Combined Value (46) & SF1, ACS & $\begin{array}{l}\text { For each year we standardized the rent and housing value and then } \\
\text { calculated the change between the two. } \\
(\# \mathrm{OO} / \mathrm{TotHU}) * \mathrm{ZmedH}))+(\# \mathrm{RO} / \mathrm{TotHU}) * \mathrm{ZmedR})) \text { ) Where OO = } \\
\text { owner occupied housing, TotHU = total number of housing units, } \\
\text { ZmedH = the median housing value, RO= renter occupied housing, } \\
\text { and ZmedR = median rent. }\end{array}$ & 3 \\
\hline Population Density (53) & $\begin{array}{l}\text { LEHD, } \\
\text { NHGIS }\end{array}$ & A & 3 \\
\hline Mixed-Use Neighborhood-Employment Population (43) & $\begin{array}{c}\text { LEHD, } \\
\text { ACS }\end{array}$ & $\begin{array}{l}\text { A; Using the following equation for the original values ("V"): } \\
1-(\mathrm{ABS}(\mathrm{F} 2-0.2 * \mathrm{E} 2) /(\mathrm{F} 2+0.2 * \mathrm{E} 2))=\mathrm{V} 2 \text {, where ABS is the absolute } \\
\text { value, F2 is the total employment for } 2002, \mathrm{E} 2 \text { is the total } \\
\text { employment for } 2000 \text {. Repeat using the total population for } 09-13 \\
\text { and } 2011\end{array}$ & 2 \\
\hline
\end{tabular}

Characteristic Areas: Demographics= "1", Economics= "2", Housing= “3”, and Transportation= "4”. For approach to calculation: Percentage change between recent year value minus initial year value divided by initial year $[(\mathrm{V} 2-\mathrm{V} 1) / \mathrm{V} 1]=$ "A", if used numeric change between recent year value minus initial year value $[(\mathrm{V} 2-\mathrm{V} 1)]=$ "B", to calculate change in percent subtract the current year percent value to the initial year percent value $[(\mathrm{V} 2 \%-\mathrm{V} 1 \%)]=$ "C", Change in Location Quotient: State of Utah (current year industry/current year state industry)-(initial year industry/current year state industry) = "D". 2000 Decennial Census SF1 = “SF1”, 2010 Demographic Profile SF (DP-1) = “DP-1”, ACS 2009-2013 5 year DP05 =”ACS”, LEHD 2002 for Source 2000 = "LEHD”, and NHGIS Source 2009-2013 ACS (LEHD 2011) = "NHGIS” 
To control for the fact that Census geographies change over time, we transform the 2000 data to 2010 geography. This transformation is done with a spatial apportioning process in ArcGIS using the small-area Utah Central State Plane projected coordinate system, which helps to reduce error when compared to geographic coordinate systems or coordinate systems centered on larger geographic areas. There are two components to this process: (1) the observations within a 2000 Census tract $\left(I_{i}\right)$ are allocated to 2010 geographies according to the proportional area of the 2000 Census tract that falls within the boundaries of the intersecting 2010 tract $\left(A_{i j}\right)$, and then (2) the observations are summed across the constituent parts of each 2010 tract $j$.

\subsubsection{The Utah Transit Authority Survey}

The UTA surveys its transit riders at least once every five years to meet federal capital investment grant regulations, to establish validity of ridership projections, and to calibrate a regional travel demand model. This survey, conducted by a third-party consultant agency, provides snapshots of the entire transit system for a given year. The On Board Survey was conducted during March 2011 to collect demographics, travel mode accessibility and frequency, and location-based information.

The sample size for the entire UTA system survey was approximately 125,000 passengers, likely representing 66,000 unique riders according to the consultant agency. The On Board Survey collected over 7,100 responses, consisting of $20.8 \%$ collected electronically, $51 \%$ via paper surveys, and 2,001 (28.2\%) by postcard. We consider only the data collected from FrontRunner riders, which included 1,086 participants. To ensure validity we excluded incomplete surveys, producing a final sample size of 898. This sample size is smaller than the median sample size reported by Cao et al. (2009; median of 1,368, calculated by authors of this manuscript from their publication). However, given the 2012 ridership of 5,804, a sample size calculator suggests that only 361 completed surveys are necessary for statistical purposes, assuming a 5\% margin of error and 95\% confidence level.

The On Board data allows comparisons in income and vehicle availability between riders and residents. Ideally, the On Board Survey would enable comparison of more variables, but unfortunately it does not. As an example, the survey asked respondents to indicate age within one of five age brackets $(<18,18-24,25-44,45-64,>65)$, but because commuter rail predominantly serves the labor force the majority of respondents are between 25 and 64, with the median age in the 25-44 bracket. The median age of the resident labor force in the host and neighbor tracts was almost universally in this range as well. Without more information on the breakdown of ages within the 25-44 range, we could not reasonably compare the age differences between riders and residents. In the future, collaboration between researchers and survey designers early in the survey development process might enable improvements to research.

\subsubsection{Calculating Change in Character}

With these databases developed, we then follow the methods given in Ganning and Flint (2010) for creating a place-based amenity index, although in our case this is an index of change in characteristics rather than a snapshot. We apply their statistical approach for each of the four characteristic areas (transportation, demographics, economics, and housing; henceforth referred to as “characteristic indices”). First, as per Ganning and Flint (2010), the variables are 
standardized to allow the combination of variables in different units (like dollars and people, for instance).

Next, we subject the variables within a characteristic index to Factor Analysis (FA), completed without a rotation and constrained to a single factor, which is appropriate when using FA for indexing rather than for data reduction. We repeat this process for each of the characteristic indices.

Third, as given in Ganning and Flint (2010), we calculate sub-indices using the factor loadings as weights for each variable, transformed according to Equation 2-1 which prevents the number of variables in a sub-index from altering the sub-index's mean value. This step permits us to compare the four characteristic indices of change to each other. Finally, the loadings' signs were checked; 42 of the 53 variables carried positive signs. Of the remaining 11, the negative sign could be clearly interpreted as logical in five. For example, the median rent variable carries a negative loading where owner vacancy and renter vacancy variables carry positive loadings.

$$
\mathrm{w}_{\mathrm{i}}=\mathrm{p}_{\mathrm{i}} *\left[1-\left(\left(\left(\sum_{i=1}^{n} p_{i}\right)-1\right) / \sum_{i=1}^{n} p_{i}\right)\right]
$$

Equation 2-1

Where $\mathrm{w}$ is the weight, $i$ is the variable, and $p$ is the factor loading.

\subsubsection{Testing the Effect of Commuter Rail on Change in Character}

Each of the four sub-indices serves as the dependent variable of a regression model, allowing us to model the change of character in four distinct dimensions. We model each sub-index as a function of FrontRunner presence and a set of initial year characteristics. We measure proximity to FrontRunner through the use of two dummy variables - one noting tracts containing a FrontRunner station (again, referred to as "host”) and another noting tracts that intersect a onemile buffer around each station (noted as "neighbor").

As many FrontRunner stations sit near the edge of a Census tract, the selection of all neighboring tracts would identify tracts that are considerably distant from stations. For instance, if a station is located at the northern edge of an oblong tract, the southern neighbor would be identified through a queen-based weights matrix (the identification of neighbors based on contiguity). The populations of these tracts are likely not near enough to the stations to facilitate reduced vehicle ownership or active transportation to transit. Therefore, the sample includes 54 observed tracts, nine of which are considered "host" tracts with FrontRunner stations, and 45 are considered "neighbor" tracts.

The independent variables represent two overarching considerations: initial year characteristics and the presence of TRAX, the region's light rail (LRT) system. The initial year (2000) characteristics are constructed from the same variables (though with different methods, as detailed below) and are used to construct the dependent variables, with the distinction that they only use the year 2000 values. TRAX, having a demonstrated effect on travel behavior within the region (Ewing et al., 2014), is included to help avoid omitted variable bias. The three corridors of the TRAX system opened in 1999, 2001 and 2011 with ridership that has more than tripled over that period. Thus, TRAX largely pre-existed FrontRunner and had distinct effects on the RSS 
and the travel behavior of the relatively urban residents of Salt Lake County, the county in which TRAX is situated and one of the three counties observed in this study.

For the independent variables, strong correlation between variables recommends an application of Factor Analysis (FA) for data reduction. Within each characteristic area, FA reduces the constituent variables to a smaller number of variables (henceforth called "independent variables”), while still representing most of the variance present in the original data. In this FA application, a varimax rotation is used. Within each characteristic area, the number of independent variables is determined by the number of optimal components as identified through the "noc" diagnostics available in the "nFactors" package for RStudio (R version 3.0.2).

To construct a variable weights matrix, we use a matrix with columns representing the components, rows representing independent variables, and values representing the component loadings in the case that the absolute value of the loading is a given variable's maximum absolute loading value. The remaining cells in each row are left blank or null. Since the independent variables do not need to be combined nor directly compared, it is unnecessary to convert the loadings into indexed weights, as Equation 1 does. Therefore, the matrix described above is used as the weights matrix. For each independent variable, the weights matrix is multiplied against the standardized data matrix, then the rows are summed to produce a vector of values - one per tract for each independent variable. Table A1 in the Appendix gives the factor loadings for each variable in the dependent variable indices and the independent variables which are crucial for interpreting results. The presence of TRAX and FrontRunner stations remains in dummy variable format.

Finally, we check the dependent and independent variables for linear relationships, an assumption of ordinary least squares (OLS) regression. A power relationship between the dependent and independent variables recommends variable transformation via logging both sides. However, the presence of both zeroes and negative values recommends a spline transformation instead, given in Equation 2-2. Following the data transformation, we test the model using OLS regression. The results are tested for heteroskedastic errors (present) and for multicollinearity (not present). To correct for heteroskedasticity, which causes inefficient estimators, we estimate robust error terms via the "coeftest" function from the "sandwich" package in R. After, we estimate parallel regression models for the four dependent variables (characteristic areas).

$$
\hat{x}=\log \left(x+\left(\left(\left(x^{2}\right)+1\right)^{-5}\right)\right)
$$

Equation 2-2

Cao et al. (2009) write that if the travel behavior of transit users matches that of the residents (Cao et al. refer to them as "consonant" residents) of the area where transit is located, then the built environment has a separate and stronger effect on travel behavior than does the role of RSS. Thus, if travel behavior around commuter rail is influenced by RSS, then migrants attracted to host or neighbor tracts because of commuter rail should differ in travel behavior from previously existing residents. In this case, the FrontRunner dummy variable(s) should be significant in the transportation model. Similarly, changing demographics as a result of commuter rail construction should signal RSS at play. Furthermore, On Board Survey data should also corroborate these distinctions directly between riders and residents of host and neighbor tracts. 


\subsection{RESULTS AND DISCUSSION}

\subsubsection{Results}

The regression results are in four panels as shown in Table 2.2, one for each dependent variable modeled. In these models, the model fit diagnostic, $\mathrm{R}^{2}$, hovers around 0.3 , which is anticipated given the small geographic area studied. The initial year control variables are significant in Models 2-4, AgeSz and Value are exceptions.

The key independent variables, FrontRunner Tract (host tracts) and Neighbor Tract warrant inspection. FrontRunner Tract is insignificant across all four models, which was unexpected. However, Neighbor Tract is significant and negative in Models 2 (Demographics) and 4 (Housing). The negative and significant coefficient of Neighbor Tract in the Demographics model suggests a reduction in population in all measured races and ethnicities, but also a decrease in diversity, an increase in median age, and reductions in both average household size and the dependency ratio (both of which logically accompany the increase in median age).

This smaller, older population also appears more likely to rent, as the Housing model shows a relationship between commuter rail, increased rents and decreased rental vacancy rates. Owneroccupied homes increase in number, but also have increased vacancy rates and dampened values. Given that the data reflects change over a decade, it appears likely that the demographic changes suggested by the model reflect suppressed population growth paired with aging in place. It follows - and station area audits (described below) reinforce - that the reduction in single-family housing is met by an increase in other land uses, predominantly commercial. Perhaps more interestingly, as noted, these effects are seen in neighbor tracts rather than host tracts, suggesting complex spatial relationships.

Table 2.2 Regression results

\begin{tabular}{l|c|c|c|c}
\hline & $\begin{array}{c}\text { Model 1: } \\
\text { Transportation }\end{array}$ & $\begin{array}{c}\text { Model 2: } \\
\text { Demographics }\end{array}$ & $\begin{array}{c}\text { Model 3: } \\
\text { Economics }\end{array}$ & $\begin{array}{c}\text { Model 4: } \\
\text { Housing }\end{array}$ \\
\hline Intercept & -0.0473 & $-0.0472^{* *}$ & $-0.0472^{*}$ & -0.0322 \\
\hline $\begin{array}{l}\text { FrontRunner Station } \\
\text { Tract }\end{array}$ & -0.1073 & 0.0513 & -0.0547 & 0.0445 \\
\hline Neighbor Tract & -0.0263 & $-0.0772^{*}$ & -0.0651 & $-0.1004^{* *}$ \\
\hline TRAX Station Tract & -0.0134 & $-0.0374^{*}$ & -0.0285 & $-0.0446^{*}$ \\
\hline AgeDens & $0.1811^{* * *}$ & $0.1065^{* * *}$ & $0.1105^{* * *}$ & $0.1356^{* * *}$ \\
\hline AgeSz & 0.0332 & 0.0000 & -0.0094 & -0.0034 \\
\hline Minority & $-0.0585^{* *}$ & $-0.0686^{* * *}$ & $-0.0455^{* *}$ & $-0.0418^{* *}$ \\
\hline Econ & -0.0447 & $-0.0749^{* * *}$ & $-0.0611^{* *}$ & $-0.0695^{* * *}$ \\
\hline OccVHU & $-0.0905^{*}$ & $-0.0789^{* * *}$ & $-0.1211^{* * *}$ & $-0.1782^{* * *}$ \\
\hline VacRent & $0.1835^{* * *}$ & $0.0965^{* *}$ & $0.1084^{* *}$ & $0.1422^{* * *}$ \\
\hline TNonCar & 0.0049 & $0.0448^{* * *}$ & $0.0378^{* *}$ & $0.0737^{* * *}$ \\
\hline Value & 0.0281 & 0.0721 & 0.0399 & $0.0857^{*}$ \\
\hline $\mathrm{R}^{2}$ & 0.24 & 0.30 & 0.25 & 0.33 \\
\hline Where:**1*25 & & & \\
\hline
\end{tabular}

Where: ***, $\mathrm{p}<0.01 ; * *, \mathrm{p}<0.05 ; *, \mathrm{p}<0.10$ 
While the demographic characteristics change in the FrontRunner neighbor tracts, the travel behavior characteristics do not, as indicated by the insignificant coefficient on either FrontRunner variable in the Transportation model. This finding is consistent with the hypothesis that most of the demographic change observed is aging in place and land use change.

Interestingly, TRAX Station is significant in the same models, also with a negative coefficient of similar magnitude, suggesting that commuter rail stations impact neighboring tracts comparable to LRT's impact on its host tracts. However, let it be noted that the TRAX LRT system only exists in the most urban of the three study counties (Salt Lake County).

This smaller, older population also appears more likely to rent, as the Housing model shows a relationship between commuter rail, increased rents and decreased rental vacancy rates. Owneroccupied homes increase in number, but also have increased vacancy rates and dampened values. Given that the data reflects change over a decade, it appears likely that the demographic changes suggested by the model reflect suppressed population growth paired with aging in place. It follows - and station area audits (described below) reinforce - that the reduction in single-family housing is met by an increase in other land uses, predominantly commercial. Perhaps more interestingly, as noted, these effects are seen in neighbor tracts rather than host tracts, suggesting complex spatial relationships.

While the demographic characteristics change in the FrontRunner neighbor tracts, the travel behavior characteristics do not, as indicated by the insignificant coefficient on either FrontRunner variable in the Transportation model. This finding is consistent with the hypothesis that most of the demographic change observed is aging in place and land use change. Interestingly, TRAX Station is significant in the same models, also with a negative coefficient of similar magnitude, suggesting that commuter rail stations impact neighboring tracts comparable to LRT's impact on its host tracts.

An audit ${ }^{2}$ of all stations on the northern route further informs the hypothesis that station areas have largely experienced population reduction, aging in place and conversion of use. The audit shows that four of the eight station locations consist largely of commercial development. Two of these locations have adjacent big box stores, malls built after 2000, and large parking lots that merge into the park-and-ride lots. The other two station areas are surrounded by small commercial and retail structures such as local restaurants, stores and offices. Low-density, single-family residential neighborhoods border two other stations. Empty lots and industrial buildings ring the remaining stations, with the stations anchoring areas that otherwise lack amenities and cohesiveness. The scale of development around stations is not generally conducive for pedestrian access. Riders arriving by foot encounter at least one parking lot and a four-lane road, in addition to either an interstate highway, a housing subdivision, vacant land or industrial facilities. Thus, the areas near stations have become attractive for development favoring vehicle traffic (i.e., commercial), leveraging the traffic drawn to the commuter rail station or that have retained previous low-density uses.

\footnotetext{
${ }^{2}$ In October 2015, a seven-person team conducted station area audits of these eight stations. The audit consisted of a significantly shortened version of the walkability audit, and added qualitative field notes on things like the integration of historic preservation features. In most cases, two researchers visited each station, documenting everything that they could access within 15 minutes on foot, including time to get back to the platform.
} 
While demographic change should signal that RSS is at play, the nuance revealed in the data and the station audit suggest otherwise. The statistical insignificance of the FrontRunner variables in the Transportation model further reinforce this; if RSS is more strongly at play, we would likely see a change in transportation behavior among residents, but this is not the case. This indirect evidence supporting the role of the built environment is bolstered by direct evidence from the On Board Survey.

We use On Board Survey responses to compare two variables found in the ACS: number of household vehicles and household income. We use chi-square tests for these analyses because both household income and vehicle data are categorized with open-ended upper brackets (e.g., income of $\$ 75,000$ or more, or three or more vehicles) which biases the estimated mean. Additionally, the variables (vehicles and income) were presented to respondents as discrete choices, rather than collecting them as continuous data. The chi-square test evaluates the expected versus observed distribution of characteristics between groups given discrete choices.

To assess vehicle availability, the On Board Survey data is recoded to match ACS (table ACS_13_5YR_DP03) discrete choice categories. The ACS data collects vehicle data in four categories: no vehicle availability, one vehicle available, two vehicles available, or three or more vehicles available. The On Board Survey data includes a fifth category to indicate having four or more vehicles; however, this we recode the On Board data by combining this category with the three-or-more vehicle category to match the ACS data. The chi-square test for vehicle availability indicates a significantly different distribution in vehicle availability. Surprisingly, FrontRunner riders have more vehicles available to them than do households in host and neighbor tracts. This is true in that both a smaller percentage of FrontRunner riders have no cars available (4.5\% versus $7.6 \%$ ), and that a higher percentage have three-plus cars available (33.3\% versus $21.9 \%$ ). While these differences are significant, they support the regression-based finding that transportation behavior did not change in FrontRunner host tracts after the development of the stations. Indirectly, any change in residents did not bring significant, observable new transportation behaviors. Directly, transit users have at least the same ability to use private vehicles as do consonant residents. Therefore, the direct evidence supports the indirect evidence that the built environment influences outweigh the effects of RSS.

We find no significant difference in the distribution of household income between FrontRunner users and residents of host or neighboring tracts. This aligns with the regression-based finding that the economic characteristics of FrontRunner tracts did not change significantly after the corridor's installation. This consonance between riders and residents also provides direct evidence of the dominant role of the built environment.

Taken together, the results suggest that the built environment, the intervention of commuter rail, plays a strong role in travel behavior. The results also show that these mechanisms occur in neighbor tracts rather than in host tracts, suggesting a spatial lag effect in the relationship between commuter rail in the built and social environments. This may be the result of the potential disamenity produced by rail (e.g., noise pollution), though further research on this hypothesized mechanism is required. Finally, the results show that LRT influences transportation behavior and demographics similarly, but that these effects play out in LRT's host tracts, suggesting a different "transit transect" of development radiating from stations. 
To better understand what attracts in-migrants and what influences potential aging-in-place decisions near commuter rail, this research can be extended through qualitative work. Such work can evaluate a population's values during life-cycle phases regarding concepts of transportation, urban form and sustainability. More robust transit survey techniques could also strengthen this research, although we gratefully acknowledge the availability of UTA's On Board Survey data. Finally, this research is limited by the ACS, with its well-known margins of error and pooled data at the Census-tract level, which obscures interpretation.

\subsection{CONCLUSION}

This research was motivated by the desire to help regional and transportation planners better understand the role that commuter rail plays in directing intra-regional development. We investigate the complex influence of the installation of a commuter rail system on surrounding neighborhoods' RSS, travel behavior and the built environment. With continued sprawl and automobile-induced social and environmental issues, it is more important than ever for planners to understand this relationship.

Unlike most studies which integrate RSS, travel behavior and the built environment, we attempt to quantify their mutually influential relationship and we focus on a single form of transit (commuter rail) for analysis rather than combining multiple transit modes. For this investigation, we employ a multiprong investigation: (1) we observe changes in neighborhood characteristics before and after the intervention of a commuter rail system using ACS data, and then (2) directly compare neighborhood residents to a ridership survey to test for consonance or dissonance.

The results of the analyses surprisingly indicate that the development of commuter rail does not alter the host tracts in any of the characteristics observed. However, the results do suggest commuter rail significantly — yet negatively—influences change in the demographic and housing characteristics of neighbor tracts. These findings imply that the neighboring populations are aging in place, new households are smaller than the ones they replace, or that residential areas are transitioning to other uses, in any event suppressing population growth. Paired with direct evidence from the On Board Survey, we find that decisions regarding the use of commuter rail are more likely influenced by the built environment than by RSS. For planners, who can influence the built environment directly, this suggests that a focus on improving the area near stations is a high priority.

Our results suggest that transit-oriented investments in the built environment might encourage commuter rail use. While there are many ways to select projects to invest in, the spatial lag apparent in our results might encourage planners to consider transect-based transit planning. While the use of transect planning as a tool for improving community sustainability is trending (Bohl \& Plater-Zyberk, 2006; Duany \& Talen, 2002; Talen, 2002), transect-based transit planning is less well-known. Yet, as Payton and Hawkes (2012) describe, using transects—or "station area typologies" - can help municipalities and transportation agencies to identify context-specific urban design issues and create plans which are consistent with the needs, character and density of stations or communities. First-mile/last-mile strategies, currently being studied by transit agencies like UTA, could also improve the built environment around commuter rail. 
This conclusion calls on planners to know their communities, to facilitate the identification of amenities that are both context-specific and audience-appropriate. As such, we hope this study encourages others to combine quantitative and qualitative efforts to improve understanding of residential location choices near commuter rail, suburban aging-in-place considerations, and specific built-environment influences changing suburban travel behavior. 


\subsection{THE EFFECTS OF COMMUTER RAIL ESTABLISHMENT ON MIGRATION AND COMMUTING}

Population migration has been evaluated through various theoretical perspectives which anticipate different redistribution tendencies (Berry, 1976; Bunting \& Filion, 1999; Carlino, 2000; Coffey \& Shearmur, 2002; Dean et al., 1984; Frey, 1987; Israel \& Cohen-Blankshtain, 2010; Kahsai \& Schaeffer, 2010; Pfister et al., 2000; Renkow \& Hoover, 2000; Stanback, 1991). One theory, the deconcentration theory, predicts that outward land consumption in a metropolitan area occurs first through the dispersal of households from central cities to the peripheries of these cities, which are then followed by employers. Much of the literature describing population decentralization tends to analyze the trend at the macro level, controlling for big-picture household budgetary constraints to commuting and migration without focusing on specific interventions such as affordable housing, transportation infrastructure, etc. As an exception to this rule, research has focused on the simultaneous development of American suburbanization and interstate highways, which has shown that highway construction induces demand (APTA, 1997; Brock \& Souleyrette, 2013). Considering rail-development investments have increased in recent decades (BTS, 2007; Israel \& Cohen-Blankshtain, 2010), and that commuter rail systems act, in part, as a complement to highways, it is important to consider how these rail systems have influenced metropolitan patterns and population migration in the 21st century.

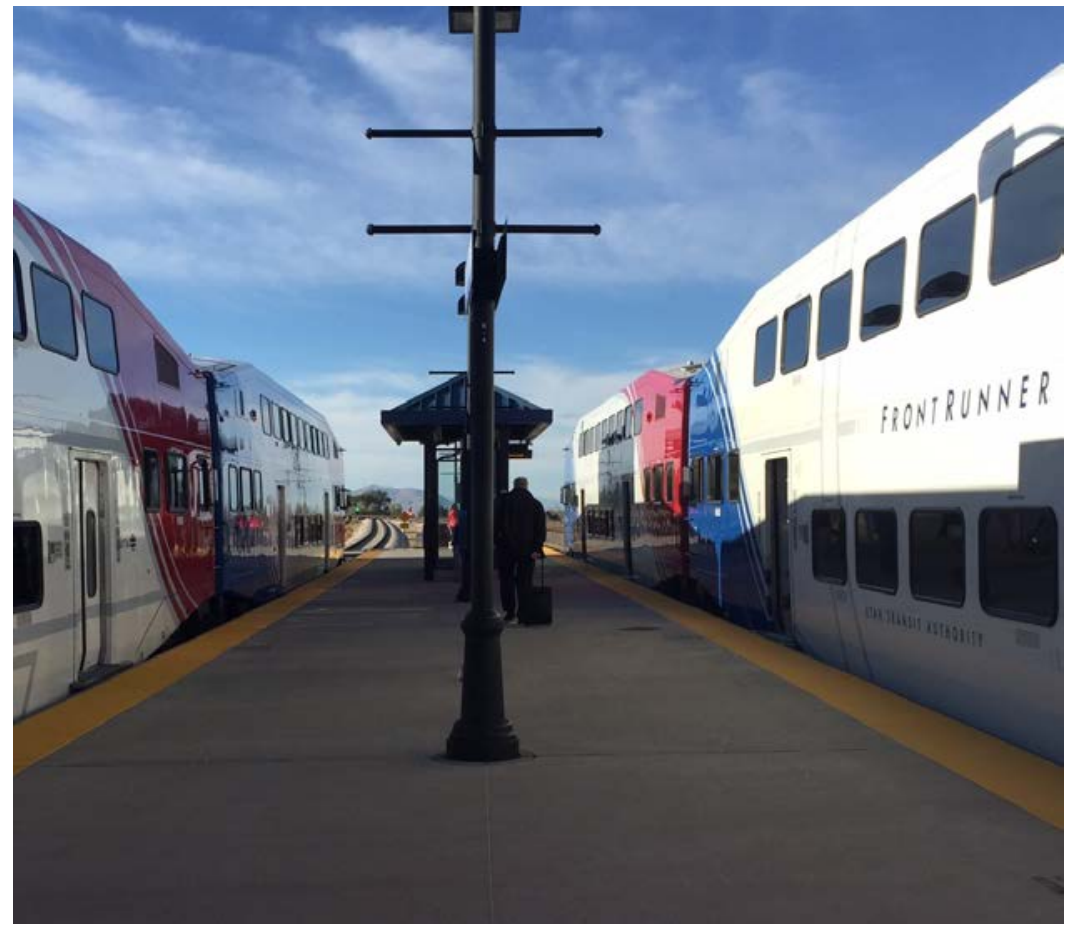

Figure 3.1 FrontRunner's Woods Cross station
Since the APTA first quantified the benefits of commuter rail in 1997, studies of the effects of commuter rail have been conducted nationwide (Allen \& Levinson, 2014; Belzer et al., 2011; Nelson et al., 2015; Seskin, Cervero, \& Zupan, 1996) and on individual commuter rail systems (Deka \& Marchwinski, 2014; Deka et al., 2015; Kennedy, 2002). While research has found associations between the presence of commuter rail and the location choice of industry-specific firms (Belzer et al., 2011; Deka et al., 2015; Nelson et al., 2015), research on the relationship between the provision of commuter rail and regional population dynamics is limited. 
Israel and Cohen-Blankshtain (2010) use a ridership survey and a stated preference model, finding that households who previously lived and worked at the metropolitan core perceived rail transit as an important amenity when making the decision to move from the metropolitan core to its fringe. The central hypothesis of this paper-that commuter rail plays a significant role in household residential and commuting decision making - reflects that finding. We extend this research by approaching it through the lens of regional population dynamics, allowing a quantitative evaluation of the macro-scale effects that commuter rail, when viewed as an amenity, might cause.

Through an analysis rooted in the deconcentration theory, this investigation explores the role that commuter rail availability plays in the propensity to in-migrate and out-commute from suburban neighborhoods. We anticipate finding that regional population deconcentration is occurring in our study area, and hypothesize that the presence of commuter rail will significantly influence the magnitude of deconcentration occurring within the commuter rail stations' host neighborhoods. This hypothesis implies that households considering residential relocation will view commuter rail as a significant component of household travel-budget considerations, and that its presence will thus influence residential location choices of migrants.

We organize this paper by first providing a theoretical overview of deconcentration, followed by a brief history of deconcentration in the U.S. and an overview of residential-location decision making. Then, we introduce the case study area and describe our methods. After, we provide results on the relationships between commuter rail, in-migration and out-commuting. We point toward further research on the larger question of whether commuter rail hastens or slows regional population deconcentration.

\subsection{THEORETICAL OVERVIEW OF DECONCENTRATION}

There have been several terms used to describe the trend in population migration and distribution away from urban cores: "deconcentration," "regional restructuring," "economic restructuring," "spatial restructuring,” "counter-urbanization,” "dispersed city form,” “decentralization,” "nonmetropolitan turnaround," "suburbanization," "depopulation” and even as "edge cities," among countless other terms (Berry, 1976; Bunting \& Filion, 1999; Carlino, 2000; Coffey \& Shearmur, 2002; Dean et al., 1984; Israel \& Cohen-Blankshtain, 2010; Kahsai \& Schaeffer, 2010; Pfister et al., 2000; Renkow \& Hoover, 2000; Stanback, 1991). Some researchers have attempted to distinguish these concepts of population distribution patterns; yet, these concepts have been used synonymously or inconsistently and therefore confusion remains (Kahsai \& Schaeffer, 2010; Mitchell, 2004). This manuscript explicitly focuses on and extends the population deconcentration theory.

Proponents of deconcentration tend to view the trends of rural-urban population dynamics as a consequence of widespread residential preference changes (Frey, 1987; Renkow \& Hoover, 2000). This theory hypothesizes that households are drawn to peripheral locations by technological advancements, easy commutes, and low real estate prices relative to housing size (Audirac \& Fitzgerald, 2003). Models built on this theory conclude that households move first and jobs follow (Renkow \& Hoover, 2000); that the timing and degree of correlation between inmigration and out-commuting vary within regions (Ganning \& McCall, 2012); and that 
population deconcentration effects are attenuated by distance to urban areas (Rupasingha, Liu \& Partridge, 2015). Such models control for budgetary constraints such as distance, localized earning potential and housing costs, and usually have normalized net out-commuting as their dependent variable.

\subsection{A BRIEF HISTORY OF DECONCENTRATION AND ITS RELATIONSHIP TO TRANSPORTATION IN THE U.S.}

Population migration and distribution have long been of interest to policymakers and researchers across disciplines because both significantly influence the social, economic, political and ecological anatomies of regions (DaVanzo, 1981; Kahsai \& Schaeffer, 2010; McDonald, 1989). One of the most notable migrations in recent U.S. history is the demographic migration from urban centers to their surrounding low-density, suburban peripheries (Weisbrod, Ben-Akiva \& Lerman, 1980). While this population deconcentration from city cores has been present since the beginning of the 19th century (Ebner. 1985), most discussions label deconcentration (more widely recognized as the move to the suburbs) as a post-World War II era phenomenon (Carlino, 2000; Mieszkowski \& Mills, 1993).

The U.S.' population location patterns have become increasingly metropolitan and increasingly polycentric with each decade. Whereas in 1910 only $28 \%$ of the population lived in a metropolitan area, $80 \%$ of the population lived in metropolitan areas in 2000 with suburban areas accounting for half of this growth (Hobbs \& Stoops, 2002). Indeed, metropolitan populations have become significantly less urban and more suburban since 1950 (see Figure 3.2).

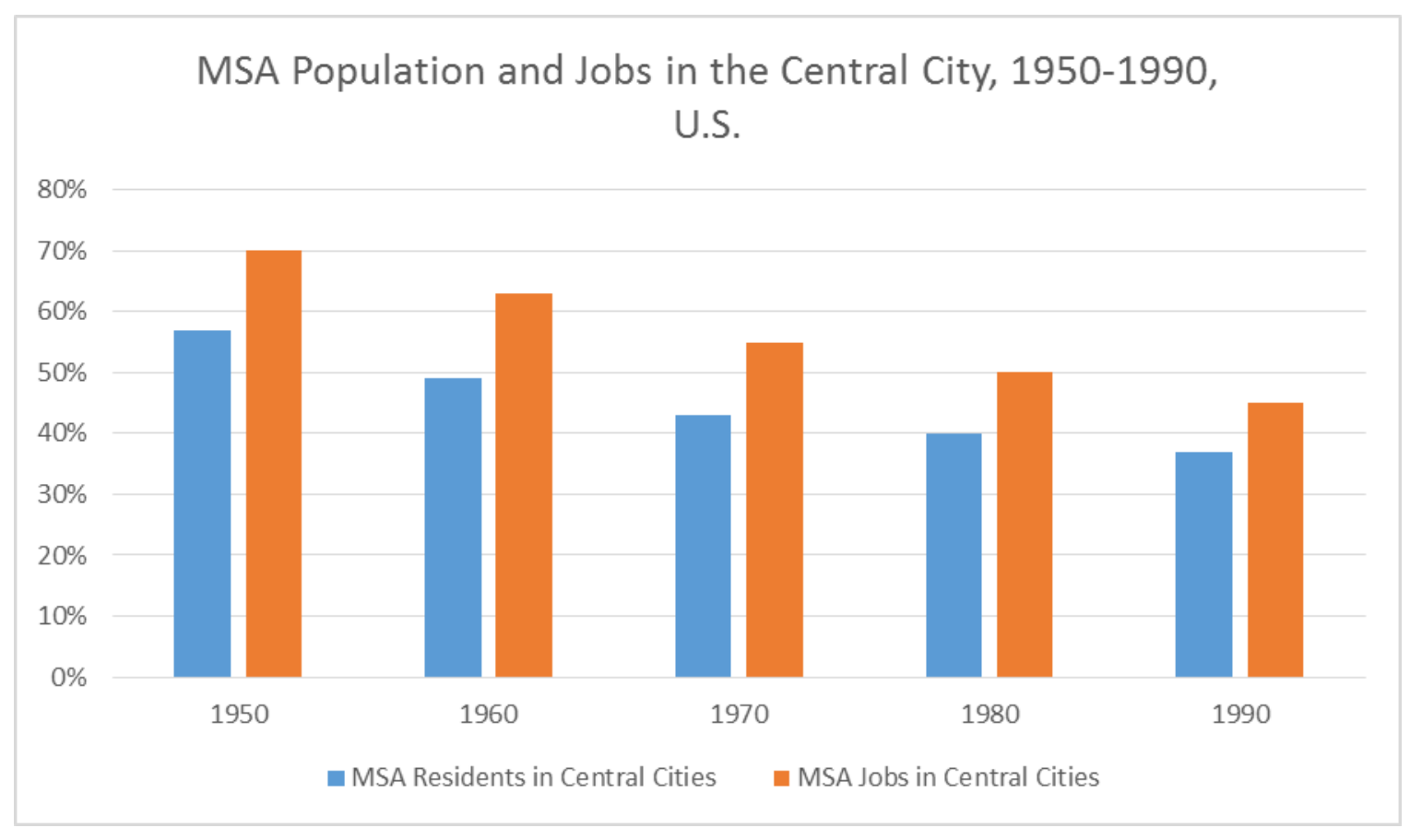

Figure 3.2 MSA population and jobs 1950-1990, U.S. reported by Mieszkowski \& Mills, 1993 
The recent return-to-the-city movement aside, such rapid diffusion of people and jobs from urban cores to more polycentric settlements has resulted in the economic decline of downtowns while the costs of providing public services to peripheral areas have increased (Weisbrod, Ben-Akiva \& Lerman, 1980). Scholars have argued whether it matters if such suburbanization occurs in a monocentric or polycentric manner (Boarnet \& Haughwout, 2000; Ewing, 1997; Gordon \& Richardson, 1997). Either way, this recognized shift has transformed urban growth studies to adopt a more metropolitan perspective to examine what causes this evolution, and how it effects firm and population distribution patterns (Benguigui et al., 2001; Berry \& Kim, 1993; Bontje, 2001; Coffey et al., 1996; Champion, 2001; Craig, 2001; Feng, Wang \& Zhou, 2009; Filion et al., 1999; Ladd \& Wheaton, 1991; Lutz, 2001; Mayer, 2000).

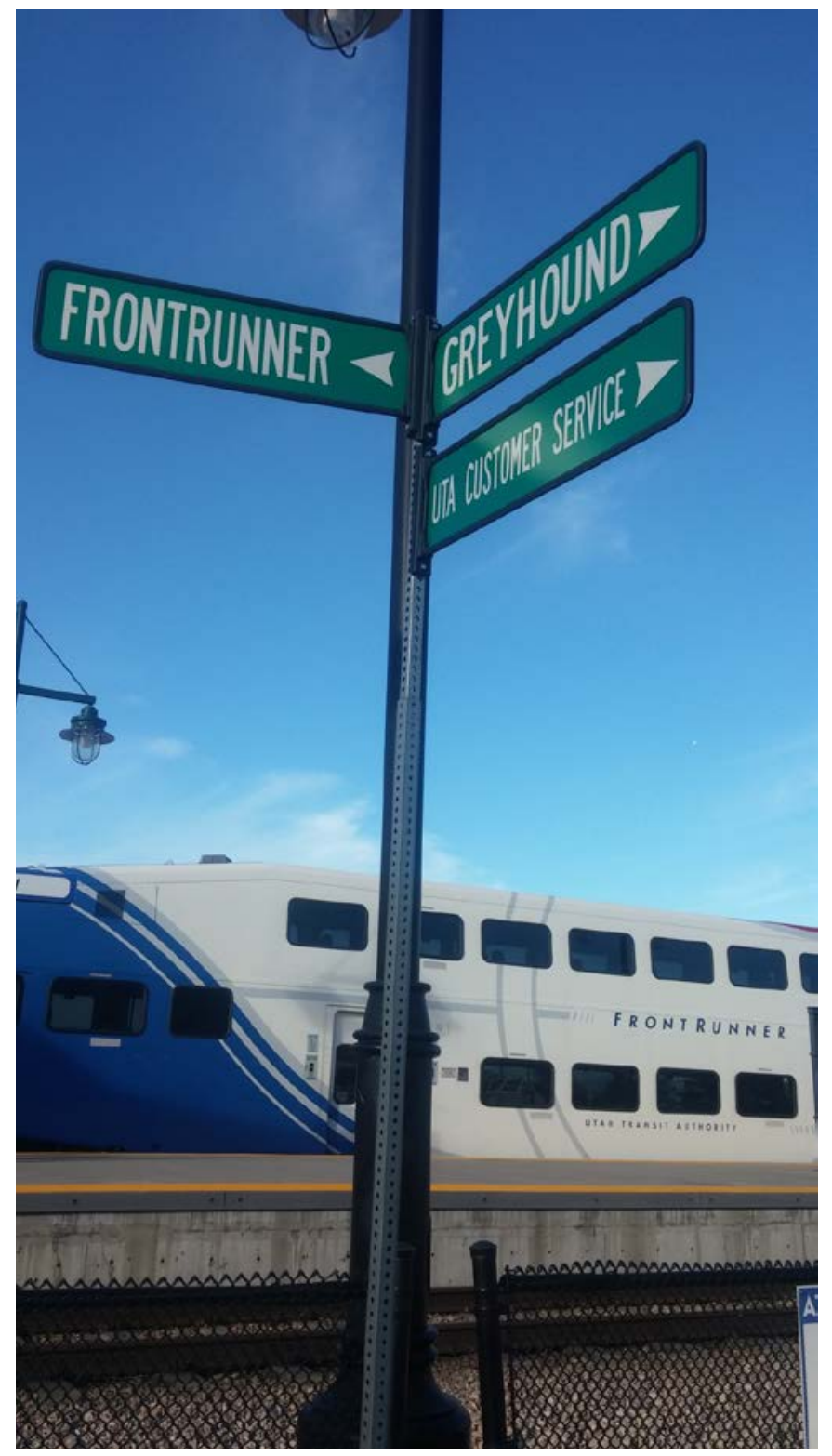

Figure 3.3 FrontRunner station wayfinding signage
Though these studies have identified several factors related to this distributional shift, one of the common factors studied is the innovation of transportation systems which have been recognized as inducing urban spatial reorganization and commuting patterns (Giuliano, 2004; Hawley, 1956; Israel \& CohenBlankshtain, 2010; Knight \& Trygg, 1977; Muller, 2004; Vance, 1986; Yeates \& Garner, 1971). One such transportation innovation linked with major urban transformations was the initial construction of the national interstate highway system, "a transcontinental network of superhighways stretching 42,500 miles and costing sixty billion dollars" to initially construct (Ebner, 1985, p. 379; see also Mohl, 2002). The interstate permanently altered the American landscape and travel abilities by facilitating automobile commuting between central cities and peripheral sprawling suburban neighborhoods (Mohl, 2002). A number of studies have asked the "chicken and egg" question: did this massive highway project act as a conduit for or react to deconcentration (Boarnet \& Haughwout, 2000; Fuguitt \& Beale, 1976; Hansen, 1973; Lee et al., 1971; Lichter \& Fuguitt, 1980)? These studies have only found

vague results. 
A less-recognized transportation innovation that has influenced U.S. metropolitan patterns is commuter rail. Many of the U.S.' human settlements developed in the 19th century around the construction of railways, which contrastingly expanded city sizes but also increased city density (Israel \& Cohen-Blankshtain, 2010; Fishman, 1987; Warner, 1970; Levinson, 2008). While research has found associations between the presence of commuter rail and the location choice of industry-specific firms (Belzer et al., 2011; Deka et al., 2015; Nelson et al., 2015), research to date on the relationship between the provision of commuter rail and population migration dynamics is extremely limited (exceptions, as discussed herein, include Israel and CohenBlankshtain (2010) and Chapter 2 of this report). Therefore, we use the next section of the literature review to discuss the relationship between population migration decision making and commuting as it relates to the theory of deconcentration.

\subsection{AN OVERVIEW OF MIGRATION LOCATION DECISION MAKING AND COMMUTING}

Since the deconcentration hypothesis prescribes that populations migrate to suburban or exurban areas for lifestyle and quality-of-life reasons, we briefly discuss the housing decision-making process and how it relates to commuting. First, it must be noted that the residential mobility and location choice literature is extensive, spans numerous disciplines, and emphasizes different perspectives and approaches (Lee \& Waddell, 2010). We make no effort to summarize the extant literature, but to rather highlight the elements of it that are relevant to hypothesis-building for the present manuscript.

Some argue that the most pressing factor explaining aggregate deconcentration is the increasing value of housing in central areas (Dura-Guimera, 2003). However, there are many motives for residential migration. Most of these can be categorized into three overarching motives: (1) personal characteristics such as age, income, family ties, education level, social networks, personal abilities, daily activities, and physical neighborhood preferences (Clark \& Dieleman, 1996; Dieleman, 2001;Weisbrod, Ben-Akiva \& Lerman, 1980; Buys \& Miller, 2012; Galster \& Hesser, 1981; Lu, 1999; Morris, Crull \& Winter, 1976; Chi \& Voss, 2005; Astone \& McLanahan, 1994; Bartel, 1979; DaVanzo \& Morrison, 1978; Fuguitt \& Brown, 1990; Massey et al., 1987; Mincer, 1978; Smith, Tayman \& Swanson, 2001; Stanbery, 1952); (2) life events such as a marriage, a divorce, childbearing and retirement (Abraham \& Hunt, 1997; Clark, Huang \& Withers, 2003; Chi \& Voss, 2005; Mincer, 1978; Smith et al., 2000; Stanbery, 1952; Clark, Huang \& Withers, 2003; Li \& Wu, 2004; Prillwitz et al., 2007); and of course, (3) qualityof-life features such as climate, quality schools, crime rates and natural beauty (Weisbrod, BenAkiva \& Lerman, 1980; Chi \& Voss, 2005; Clark \& Murphy, 1996; Graves \& Linneman, 1979; Schachter \& Althaus, 1989; Smith et al., 2001; Stanbery, 1952). From these three lists, the deconcentration literature has dealt with only some of the elements listed under personal characteristics and none of the others.

While these personal characteristics, life-cycle phases, and quality-of-life features are important components to consider in the decision-making process, households also make compromises between these components. A popular assumption in residential location-choice research is that this tradeoff process is based on households attempting to maximize their residential utility (Chen, Chen \& Timmermans, 2008; Lee \& Waddell, 2010; Lerman, 1976; McFadden, 1978; Weisbrod, Ben-Akiva \& Lerman, 1980). In this assumption, each family must weigh the value 
(positive or negative) and level of utility of each attribute of a potential house or neighborhood to meet their specific needs (Lee \& Waddell, 2010; Chen, Chen \& Timmermans, 2008).

Transportation - both access to and cost (in dollars and time) of different modes - is one of the most influential amenities considered when compromising within the housing decision-making process (Alonso, 1964; Brown, 1986; Eliasson, Lindgren \& Westerlund, 2003; Eliasson \& Mattsson, 2000; Krizek, 2006; Pinjari et al., 2008) because households are tightly connected with their daily travel activities (Clark \& Dieleman, 1996; Dieleman, 2001).

Empirical studies have examined how families make such compromises between socio-economic factors and public facilities (such as transportation access and other amenities) in their residential location decisions. Some of the earliest studies comparing tradeoffs with transportation found: (1) the effect of transportation access on location-choice decisions is overshadowed by household income and size considerations among other personal characteristics; yet (2) the amount a community spends on education, police, fire and recreation services is less important to most households than transportation accessibility to employment; and (3) a household's automobile-ownership decisions are correlated to residential-location choices (Weisbrod, BenAkiva \& Lerman, 1980; Mayo,1973; Friedman, 1975; Lerman, 1975; Pollakowski, 1975; Molin \& Timmermans, 2003; Rouwendal \& Meijer, 2001; Timmermans, Van Noortwijk, Oppewal \& Van der Waerden, 1996; Weisbrod et al., 1980).

Commuting distance, time and access to employment are considered primary determinants of residential location choice (Abraham \& Hunt, 1997; Alonso, 1964; Anas, 1981; Ben-Akiva \& Bowman, 1998; Eliasson, Lindgren \& Westerlund, 2003; Giuliano, 1989; Inoa, Picard \& De Palma, 2014; Levine, 1998; Levinson, 1998; Partridge, Ali and Olfert, 2010; Rouwendal \& Rietveld, 1994; Van Ommeren, Rietveld \& Nijkamp, 1997, 1999; Weisbrod, Ben-Akiva \& Lerman, 1980). As such, researchers have inferred that as the distance between one's house and their workplace increases, the level of transportation accessibility simultaneously decreases, travel time increases, and travel costs increase to get to work (Alonso, 1964; Partridge, Ali and Olfert, 2010; Weisbrod, Ben-Akiva \& Lerman, 1980; Boarnet \& Haughwout, 2000). One balance of further distance is the cheaper land values and housing (Boarnet \& Haughwout, 2000; Weisbrod, Ben-Akiva \& Lerman, 1980). Still, some households alter their place of residence or place of employment to avoid such commuting penalties-especially to avoid extensive congestion (Gordon \&Wong, 1985; Gordon, Kumar \& Richardson, 1989a, 1989b; Gordan, Richardson \& Jun, 1991), which commuter rail could also help to avoid. Of course, others (Salomon \& Mokhtarian, 1997) suggest that relocation as a strategy to avoid such penalties is a last resort after other inadequate strategies.

Accessibility has been one of the primary elements of traditional micro-economic location theories (Alonso, 1964; Muth, 1969), but has only recently been studied in the context of influencing housing location preference and choice (Tillema, Hamersma, Sussman \& Arts, 2012). Proximity to highway entries or transit stations can provide households with access to markets, resources and employment. Therefore, similar to firms, households that value a particular transportation mode will cluster in neighborhoods near access points of that system because they view it as an amenity (Boarnet \& Haughwout, 2000; Tillema, Hamersma, Sussman \& Arts, 2012). Yet, there are also disadvantages - or negative externalities - to living in close proximity to certain transportation infrastructures. For example, living next to a highway can deliver nuisances such as high noise levels, air pollution, ugly aesthetics, odor and community 
fragmentation, among other social and environmental effects which can affect quality of life (Arsenio et al., 2006; Bateman, Day, Lake \& Lovett, 2001; Hull, 2011; Tillema, Hamersma, Sussman \& Arts, 2012; Wilhelmsson, 2000).

There are many motivations for migrating, just as different modes of transportation have brought about different reactions to development patterns. Yet, in many deconcentration studies, it is not specified as to which mode residents use to commute (Han \& Goetz, 2015; Partridge, Ali \& Olfert, 2010; Renkow \& Hoover, 2000), and those that do (Israel \& Cohen-Blankshtain, 2010) have not quantified impacts to localized population dynamics. We hope to progress modespecific deconcentration research by using a deconcentration model which distinguishes the influence of access to commuter rail stations. This is ideal, as stated by Israel \& CohenBlankshtain (2010), to have a study which compares the development of metropolitan fringe with rail construction in areas that do not have such an amenity.

\subsection{METHODS}

\subsubsection{Variables and Data}

This analysis seeks to determine if commuter rail attracts populations to move to and commute from neighborhoods with commuter rail stations. As specified in the introduction, we use a modified version of a population deconcentration model found in existing literature (Ganning \& McCall, 2012; Renkow \& Hoover, 2000) which has been historically used to determine a general pattern of urban expansion. Specifically, this model adjudicates whether households move first (i.e., population deconcentration) or whether employment centers move first (i.e., spatial restructuring). Research generally supports the deconcentration hypothesis, and we thus anticipate finding regional population deconcentration occurring in our study area. Further, we anticipate that the presence of commuter rail will play a positive, significant role in the relationship between in-migration and out-commuting on the hypothesis that commuter rail influences household budgetary constraints in a manner similar to other control variables in the model: distance, housing costs, wage differentials, etc. This hypothesis is also supported by prior research (Israel \& Cohen-Blankshtain, 2010).

The model's dependent variable is commuting between an origin and a destination ( $i$ and $j$, respectively) which is normalized by the employed population in the origin geography. This is modeled as a function of the distance between the population-weighted centroids of $i$ and $j$; the gross migration rate into $i$ in the previous period and the housing cost; educational attainment (to proxy skill-matching) and wage differentials between $i$ and $j$; and the provision of infrastructure that facilitates commuting. Table 3.1 gives the definition of terms and data sources for each variable. 
Table 3.1 Variables, definitions, and sources

\begin{tabular}{|c|c|c|}
\hline Variable & Definition & Source \\
\hline$C_{i f f}$ & $\begin{array}{l}\text { Net commuting from tract } i \text { to tract } \mathbf{j} \text {, } \\
\text { normalized by the employed population of tract } \\
i \text {, inclusive of primary jobs only }\end{array}$ & $\begin{array}{l}\text { Census LEHD Origin-Destination } \\
\text { Employment Statistics, 2011; } \\
\text { Census LEHD Residence Area } \\
\text { Characteristics (RAC), } 2011\end{array}$ \\
\hline$M_{i}$ & $\begin{array}{l}\text { In-migration into tract } i \text { during the previous } \\
\text { year, normalized by current population }\end{array}$ & $\begin{array}{l}\text { Census ACS 5year, 2009-2013 } \\
\text { (table: B07001) }\end{array}$ \\
\hline$W_{\text {if }}$ & $\begin{array}{l}\text { Difference in wages between tract } i \text { and tract } j \\
(* 1000)\end{array}$ & $\begin{array}{l}\text { Bureau of Economic Analysis, } \\
2011 \text { (table: CA6N, CA25N); } \\
\text { Census LEHD Workplace Area } \\
\text { Characteristics (WAC), } 2011\end{array}$ \\
\hline$D_{\text {if }}$ & $\begin{array}{l}\text { Network distance between tracts } i \text { and } j \text {, with } \\
\text { distance measured from the block group } \\
\text { population-weighted centroid of each tract }\end{array}$ & $\begin{array}{l}\text { Census SF1 2010; Utah AGRC } \\
\text { Street Network data, } 2011\end{array}$ \\
\hline $\boldsymbol{H}_{\text {if }}$ & $\begin{array}{l}\text { Difference in average standard scores of } \\
\text { median gross rent and median housing value } \\
\text { between tract } i \text { and tract } \tilde{j}\end{array}$ & $\begin{array}{l}\text { Census ACS 5year, 2009-2013 } \\
\text { (table: B25064, B25077) }\end{array}$ \\
\hline$E_{\text {if }}$ & $\begin{array}{l}\text { Difference in four-year college degree } \\
\text { attainment rates between tract } i \text { and tract } j\end{array}$ & $\begin{array}{l}\text { Census ACS 5year, 2009-2013 } \\
\text { (table: DP02) }\end{array}$ \\
\hline$E_{X I T_{i}}$ & $\begin{array}{l}\text { The numeric count of exits from surface roads } \\
\text { classified as Interstates in each tract } i \text { that are } \\
\text { not exchanges with other Interstates }\end{array}$ & $\begin{array}{l}\text { Utah AGRC Roads and Highway } \\
\text { System data, } 2014\end{array}$ \\
\hline JUNCTION $_{i}$ & $\begin{array}{l}\text { The numeric count of Interstate exchanges in } \\
\text { tract } i\end{array}$ & $\begin{array}{l}\text { Utah AGRC Roads and Highway } \\
\text { System data, } 2014\end{array}$ \\
\hline FRONTRUNNER & $\begin{array}{l}\text { A dummy variable denoting the presence of a } \\
\text { commuter rail station in tract } i\end{array}$ & $\begin{array}{l}\text { Utah AGRC Commuter Rail } \\
\text { Stations data, } 2013\end{array}$ \\
\hline
\end{tabular}

The wage $\left(\mathrm{W}_{\mathrm{ij}}\right)$, distance $\left(\mathrm{D}_{\mathrm{ij}}\right)$, housing $\left(\mathrm{H}_{\mathrm{ij}}\right)$ and education $\left(\mathrm{E}_{\mathrm{ij}}\right)$ differential variables, as used in existing literature (Ganning \& McCall, 2012; Renkow \& Hoover, 2000), will help signify if budget constraints are significant in the decision to migrate and in the decision to commute. The wage data represent wages at the place of employment rather than residence (making the differential between workers employed in $i$ and $j$, rather than those living in $i$ and $j$.). This figure is relevant in modeling commuting since people commute to earn a wage offered somewhere other than their home tract. However, wage data are not directly available at the tract level. To overcome this challenge, we combine the average wage earned in each two-digit NAICS industry from the Bureau of Economic Analysis at the county level with the number of jobs in each industry according to the Census Longitudinal Employer-Household Dynamics (LEHD) database at the tract level. Wage differentials specific to tract-pair combinations were then calculated as wage in the destination tract $(j)$ minus wage in the origin tract (i), multiplied by 1,000 . Distances between all tract-pairs were calculated by the network distance from the population-weighted tract centroids. We use the 2010 decennial Census block populations to calculate the populationweighted centroid of each tract in ArcGIS.

To reflect both renter- and owner-occupied housing, this study combines median gross rent and median housing value data from ACS 2009-2013 five-year estimates. If the value of median gross rent is greater than $\$ 2,000$, which means that the median falls in an open-ended range, the values (five cases in our data) are estimated at $\$ 2,000$. When there is a missing value or if the margin of error makes the value unreliable with the coefficient of variation over $40 \%$ (a threshold suggested by Esri (2013)), we only include the remaining variable that has reliable 
data. There were seven tracts with unreliable or missing data for owner-occupied housing value, and 16 tracts with unreliable or missing data for median gross rent. Only one tract, which was dropped from analysis, had missing or unreliable data for both owner-occupied housing value and median gross rent. To compute a single variable for housing cost differentials, we convert both variables (median gross rent and median housing value) to z-scores, then average them to create a singular measure of overall housing cost for each tract. Z-scores are obtained by subtracting the mean from an individual raw score, and then dividing the difference by the standard deviation.

Finally, the difference in educational attainment is calculated as the percentage of people age $25^{+}$ having a bachelor's degree or higher in destination tracts $(j)$ minus origin tracts $(i)$. Educational attainment data are from ACS 2009-2013 five-year estimates and the proportion of unreliable data (i.e., coefficient of variation over $40 \%$ ) is less than $1 \%$.

\subsubsection{Model Specification}

The model specification is given in Equation (3-1). Exploratory work revealed a non-linear relationship between the dependent and independent variables, suggesting logging the dependent variable. However, that transformation failed to solve the unequal variance in the residuals of an OLS regression. After testing several generalized linear model (GLM) forms and comparing diagnostics, the Quasi-Poisson emerged as the best fit for our data.

$$
\begin{aligned}
& C_{i j}=\beta_{0}+\beta_{1} M_{i}+\beta_{2} W_{i j}+\beta_{3} D_{i j}+\beta_{4} H_{i j}+\beta_{5} E_{i j}+\beta_{6} \text { EXIT }_{i}+\beta_{7} J_{U N C T I O N_{i}}+ \\
& \beta_{8} \text { FRONTRUNNER }_{i}+\varepsilon_{i}
\end{aligned}
$$

The Quasi-Poisson regression mimics the GLM Poisson regression, and produces identical coefficients, but leaves the dispersion parameter unrestricted. In a Quasi-Poisson regression in R, the independent and dependent variables are by default linked through a log function. In this case, the change in the conditional mean of the dependent variable can be estimated according to Equation (3-2). When the independent variables are set to zero, Equation (3-2) is equal to $\exp \left(\hat{\beta}_{0}\right)$, consistent with an OLS interpretation of the intercept. Unlike OLS interpretation, however, when $\left(x_{1}\right)$ takes a non-zero value (assuming the other predictors remain set at zero, as partial coefficients), $(\hat{y})$ does not increase by adding $\left(\hat{\beta}_{1} x_{1}\right)$ to the coefficient of the intercept, but rather by multiplying the exponent of the coefficient of the intercept by $\exp \left(\hat{\beta}_{1} x_{1}\right)$. A full discussion of the method and its derivation is available in Zeileis, Kleiber \& Jackman (n.d.). The full derivation of the Quasi-Poisson GLM and Equation (3.2) thus guide model interpretation in this manuscript.

$$
\hat{y}=\exp \left(\hat{\beta}_{0}+\hat{\beta}_{1} x_{1}+\cdots\right)
$$


We also tested variations of our dependent variable that include employment data comprised of all jobs, versus primary jobs only. Marginal improvement was seen by using primary jobs only, likely reflecting the higher importance of these positions in residential location decisions. The results presented include primary jobs only.

As established in the literature, we include only the positive half of all the $i$-j commuting pairs (meaning, tracts that have more out-commuters than in-commuters) to avoid selection bias (Renkow \& Hoover, 2000). In our case, this sub-setting also serves to only test the "bedroom community" ends of each commute, which allows us to focus on the effects of commuter rail on residential location choices.

\subsubsection{Methodological Departures from Literature and Limitations}

This manuscript's methods depart from the literature in three key ways: (1) by using Census tracts as the unit of geography rather than counties; (2) by utilizing housing mobility rate as a proxy for the net migration rate due to data limitations; and (3) by including commuting infrastructure (highway exits and interchanges, and commuter rail stations) as distinct independent variables.

The use of Census tracts reflects an appropriate scale for evaluating the role of transportation infrastructure on residential location choice. While research exists to test the economic impact of highway development for counties (Rephann \& Isserman, 1994), it is illogical to assume that a household might choose to move to a county merely because it has an interstate exit. On the other hand, it seems valid that a household would choose a neighborhood (approximated here as Census tracts) for access to transportation infrastructure. We anticipate, however, that using a smaller unit of geography will reduce the overall model fit due to ecological correlation. Our sample includes 314 Census tracts and 37,636 ij tract pairs.

As stated, the second distinction of our model is the use of household mobility rates rather than net in-migration rates tied to the use of Census tracts. There is no data available that provides an annual snapshot of population size at the Census-tract level, and it is statistically indefensible to use data from two overlapping ACS multiyear periods to estimate population change. Together, these data challenges make it impossible to estimate population change, let alone net migration, over any short-term period at the Census-tract level. More direct methods of estimating migration, such as use of the Internal Revenue Service's migration flow files, also do not provide data below the county scale. We thus use the ACS five-year estimates' geographical mobility tables, which report the number of people who lived in a different house one year ago for our relocation variable. By dividing that figure by each tract's current population, we estimate the inmigration rate for each Census tract. We acknowledge that this metric is flawed by being a gross rate rather than the net rate, and by reflecting household mobility instead of in-migration specifically.

The third difference in our analysis from existing models is the inclusion of infrastructure variables to reflect the principal research question: what effect does each distinct type of infrastructure have on the propensity to in-migrate and out-commute? We include interstate exchanges on the hypothesis that having access to more than one interstate would make a location more desirable for dual-income households. Workers may need to split the distance 
between two jobs, or for households with other reasons to maximize accessibility within the region. Interstate exits are included for the obvious benefit of having rapid access to destinations. Both interstate variables are also included as important control variables and to show model validity, considering the more robust existing literature on the effects of highways on migration versus the effects of commuter rail.

We include a dummy variable to reflect the provision of a commuter rail station within each Census tract $i$. If residents use commuter rail (or moved to $i$ intending to use commuter rail) to access employment opportunities that would otherwise require a vehicle, we anticipate a positive coefficient on the commuter rail variable. While we acknowledge that the catchment area of a commuter rail station might better be represented in the form of a buffer, using such a unit of geography necessitates spatially apportioning data since point data does not exist for our variables. This process creates an additional margin of error and could introduce bias into the results. Testing at this spatial scale would, however, present a worthwhile future research endeavor given data availability.

\subsection{ANALYSIS AND RESULTS}

The results of our regional deconcentration model (Table 3.2) show model validity. In published deconcentration models, the equivalent of $M_{i}$ is the key right-hand side variable. If positive (meaning that people in-migrate and out-commute), it signals regional population deconcentration. Table 3.2 shows the expected positive and statistically significant coefficient on this term, lending external validity to the model. Two other points also suggest model validity: the model diagnostics indicate overall model significance, and the control variables (the differential terms for distance, housing, education and wages) are all significant. Table 3.2 presents a model with an $\mathrm{R}^{2}$ of 0.21 , which, as expected, falls below the published model fit cited in literature (Ganning \& McCall, 2012; Renkow \& Hoover, 2000).

The differential control variables for distance, education and wage carry a negative coefficient, consistent with previous literature (Ganning \& McCall, 2012). Importantly for the model's face validity, the distance coefficient is negative, signaling that workers are less likely to commute to places farther away. The last three lines of Table 3.2 show the infrastructure variables. These variables, while adding minimal explanatory power to the model ${ }^{3}$, are statistically significant and positive, meaning that Census tracts with commuting infrastructure have an increased rate of outcommuting.

\footnotetext{
${ }^{3}$ The residual deviance on a model without the infrastructure variables is 283.78, and the McFadden's $\mathrm{R}^{2}$ is 0.2061 .
} 
Table 3.2 Regional population deconcentration model results

\begin{tabular}{|c|c|c|c|}
\hline & Coefficient & Std. Error & Significance $^{\mathrm{b}}$ \\
\hline Intercept & -4.891 & $2.559 \mathrm{E}-02$ & $* * *$ \\
\hline Dij & $-3.165 \mathrm{E}-05$ & 5.900E-07 & $* * *$ \\
\hline Hij & 0.140 & $1.031 \mathrm{E}-02$ & $* * *$ \\
\hline Eij & -7.579E-03 & 5.085E-04 & $* * *$ \\
\hline Wij & $-2.447 \mathrm{E}-05$ & $7.281 \mathrm{E}-07$ & $* * *$ \\
\hline$M i N$ & 1.209 & 0.121 & $* * *$ \\
\hline Junction & 0.138 & 4.763E-02 & $* * *$ \\
\hline EXIT & 4.674E-02 & 1.647E-02 & $* * *$ \\
\hline FrontRunner & 0.306 & 5.893E-02 & $* * *$ \\
\hline
\end{tabular}

a. McFadden pseudo-R²: 0.2088; Adjusted McFadden pseudo-R²: 0.1528; Nagelkerke-McKelvey-Zavoina pseudo$\mathrm{R}^{2}$ : 0.2096. AIC: 300.78 . Null variance: 357.42 on 37,635 DF; Residual variance: 282.79 on 37,627 DF.

b. Significance: $* * * \mathrm{p}<0.01$

When all covariates are set to zero, interpreting the intercept reveals a mean y of 0.0075 . To interpret the effect on this value of the independent variables, we begin at the top of Table 3.2 and move down. Despite being statistically significantly different from zero, the coefficients of three of the four budgetary restriction variables $\left(\mathrm{D}_{\mathrm{ij}}, \mathrm{E}_{\mathrm{ij}}, \mathrm{W}_{\mathrm{ij}}\right)$, as partial coefficients, would only minimally change the effect of the intercept (exponents of the coefficients range from 0.9924 to 0.9999). $\mathrm{H}_{\mathrm{ij}}$ would increase the conditional mean of y by 1.15 times, to 0.0086 . The coefficient of the traditional key independent variable of deconcentration models, migration $\left(\mathrm{M}_{\mathrm{i}}\right)$, here has the highest impact on out-commuting from a tract, increasing $\mathrm{C}_{\mathrm{ij}}$ by 3.35 times, to 0.0252 , when all other covariates are set to zero. It should be noted, however, that these are not standardized coefficients, and are thus difficult to compare given incomparable units.

Fortunately, Junction, EXIT and FrontRunner are all count variables, facilitating comparability in results for these key variables. Assuming each (Junction, EXIT and FrontRunner) were to increase by a count of one, these variables would increase $C_{i j}$ by $1.15,1.05$, and 1.36 times, respectively. In the case of FrontRunner presence, a coefficient of 0.306 means that the addition of one FrontRunner station increases the dependent variable $C_{i j}$ by 0.0102 when all other covariates are set to zero. This increase is slightly less than one standard deviation of $\mathrm{C}_{\mathrm{ij}}$ (0.0108).

These findings suggest, first, that commuter rail presence positively and significantly influences out-commuting from the tract. More specifically, when controlling for migration and household budgetary constraints, the provision of commuter rail more strongly impacts out-commuting than does the presence of an interstate exchange/junction or an exit. One could question whether FrontRunner was placed in these neighborhoods because of a localized trend toward outcommuting. However, as Table 3.3 shows, this is not the case. Instead, even with the Downtown Salt Lake FrontRunner station's tract removed from analysis, tracts with FrontRunner imported substantially more workers (as a percent and as a number) than did other areas in 2002. Nor is there evidence of a trend toward out-commuting in these places; through 2011, FrontRunner tracts' net out-commuting rate, on average, declined. 
Table 3.3 Out-commuting rate and number, 2002 and 2011

\begin{tabular}{l|c|c}
\hline & FrontRunner Tracts & Other Tracts \\
\hline Net out-commuting rate, 2002 (average) & -2.53 & -1.40 \\
\hline Out-commute number, 2002 & $-1,107$ & 149 \\
\hline Net out-commute rate, 2011 (average) & -2.96 & -0.86 \\
\hline Out-commute number, 2011 & $-1,431$ & 148 \\
\hline
\end{tabular}

Our findings could also mean that commuter rail has hastened the deconcentration of populations to suburban locations. In traditional deconcentration analyses, the household budgetaryconstraints measure and control for the value households place on the utility of various things such as distance, housing costs, wages, etc. in making commuting decisions. One could easily extend the logic of the model to interpret the contributions of specific forms of infrastructure the same way; if commuter rail is interpreted as part of a household's travel-budget equation, then its presence in a suburban location is reasonably part of the choice to engage in deconcentration.

However, proving that commuter rail contributes to deconcentration is complex, and requires evidence that: (1) regional deconcentration is occurring, and that it is occurring disproportionately in FrontRunner tracts; (2) regional (not localized) deconcentration is occurring at a higher magnitude or at a larger geographic scope due to the presence of commuter rail; and (3) deconcentration is real rather than apparent, meaning that the in-migrants to suburban commuter rail tracts are coming from more urban areas, rather than shuffling from other similar, suburban tracts. The scope of this manuscript addresses only the first of these criteria. The latter two require extensive, separate analyses, which only partially exist in other publications.

Regarding the first requirement, Table 3.2 clearly supports the instance of regional deconcentration via the positive coefficient on Mi. Is deconcentration occurring disproportionately in FrontRunner tracts? A t-test of $\mathrm{M}_{\mathrm{i}}$ for FrontRunner tracts versus nonFrontRunner tracts confirms that $\mathrm{M}_{\mathrm{i}}$ is higher in FrontRunner tracts than elsewhere (one-tailed pvalue $=0.014$ ), suggesting that the presence of the commuter rail attracts migrants. Returning to regression to complete the logical arc regarding deconcentration, in a re-specification of the model (not shown), we add an interaction term combining FrontRunner and $\mathrm{M}_{\mathrm{i}}$ to understand the combined effect on out-commuting. The interacted term is significant at the 0.05 level, and increases the estimate of the conditional mean of the dependent variable by slightly less than the $\mathrm{M}_{\mathrm{i}}$ term (3.04 times versus 3.16 times the effect of the intercept). This suggests that the combination of stronger migration and a FrontRunner station lead to stronger out-commuting, and FrontRunner also leads to stronger out-commuting when migration is controlled for. Thus, commuter rail appears to be causally linked to out-commuting, both as an independent variable and in concert with $\mathrm{M}_{\mathrm{i}}$. Thus, the first requirement appears to be met; regional deconcentration is occurring and occurs disproportionately in tracts with commuter rail.

The second requirement needed to prove that commuter rail hastens deconcentration is that the presence of commuter rail increases the magnitude of deconcentration regionally. Simply put, we cannot prove this. Future research on this question should involve control cases, perhaps using a difference-in-differences approach matching regions with commuter rail to regions without 
commuter rail and investigating deconcentration over time. This work falls clearly beyond the scope of this manuscript, and is not available to our knowledge in the existing literature.

The third requirement for proving that commuter rail hastens regional deconcentration is that the portion of deconcentration attributable to the presence of commuter rail be real rather than apparent. Real deconcentration means that migrants choosing commuter rail locations are in fact populations which are deconcentrating rather than moving from other, similar suburban locations. At face value, mathematically, deconcentration overall must be real, or the model would not provide a positive coefficient on the migration term. The question at hand, however, pertains specifically to commuter rail's role in regional deconcentration. Here, there is mathematical room for migration to reflect shuffling rather than true deconcentration. Proving this is difficult, especially at the sub-county geographic scale. However, on this front, a nascent literature is emerging. Chapter 2 of this report tests the relationships between the built environment, residential self-selection and travel behavior specific to the introduction of commuter rail. They find that the effects of the built environment outweigh those of residential self-selection for travel behavior of resident workers of tracts with commuter rail. This finding suggests that any deconcentration effects of commuter rail are apparent rather than real; while commuter rail attracts migrants, these individuals appear similar to existing suburban residents along demographic, socioeconomic and travel behavior metrics. As this finding seemingly contradicts Israel and Cohen-Blankshtain (2010), clearly further research is needed.

Collectively, these results provide significant new insights on the relationship between population dynamics and the installation of a commuter rail line in a metropolitan region. Most clearly, we can conclude that commuter rail is a statistically significant element in a household's travel-budget decision making. Quantitatively, the effect of commuter rail is similar to (though slightly stronger than) that of highway exits and interchanges in influencing residential-location decision making. While further testing is needed, we hypothesize that the higher magnitude of influence for commuter rail may stem from its novelty in the U.S., in comparison to highway infrastructure. The presence of commuter rail significantly increases both in-migration and outcommuting from Census tracts. However, it is less clear if commuter rail hastens regional population deconcentration. Preliminary evidence suggests that its effects on regional population dynamics may be apparent rather than real, but further research in this area is clearly necessary.

\subsection{CONCLUSION}

As summarized above, this manuscript finds that commuter rail acts as a significant element in household-location decisions, thus influencing both observable migration and out-commuting within Census tracts. This offers land use practitioners the knowledge that their work on the built environment alters population dynamics, thus offering opportunities to develop other localized amenities to foster these dynamics. Planners might also consider the commuter rail stations' ability to attract migrants as an opportunity to build density and, in the longer term, localized employment. For researchers, this work has contributed methodologically to the deconcentration literature, and has contributed substantively to the nascent literature specific to commuter rail impacts on local and regional development. 
The limitations of this study offer opportunities for future research. First, if data were available to construct a model at the spatial scale of station-area buffers rather than that of host tracts, it would be preferable. Second, improved data measuring net migration at a sub-county level would improve the reliability of our analysis. Finally, though this research extends research on the effects of commuter rail beyond the geographic scope of existing literature, the present analysis should be replicated for other regions to test generalizability.

This manuscript has presented novel evidence of the impact of commuter rail on regional population dynamics and has opened the door to further research on pressing questions. With improvements to existing data and the passage of time following more commuter rail system openings, the development of the scholarly conversation of these questions holds much promise. Research specific to the economic and demographic effects of commuter rail is a relatively recent addition to the research on public transit. Much work remains to be pursued and we hope this manuscript provides a solid step forward in this larger research agenda.

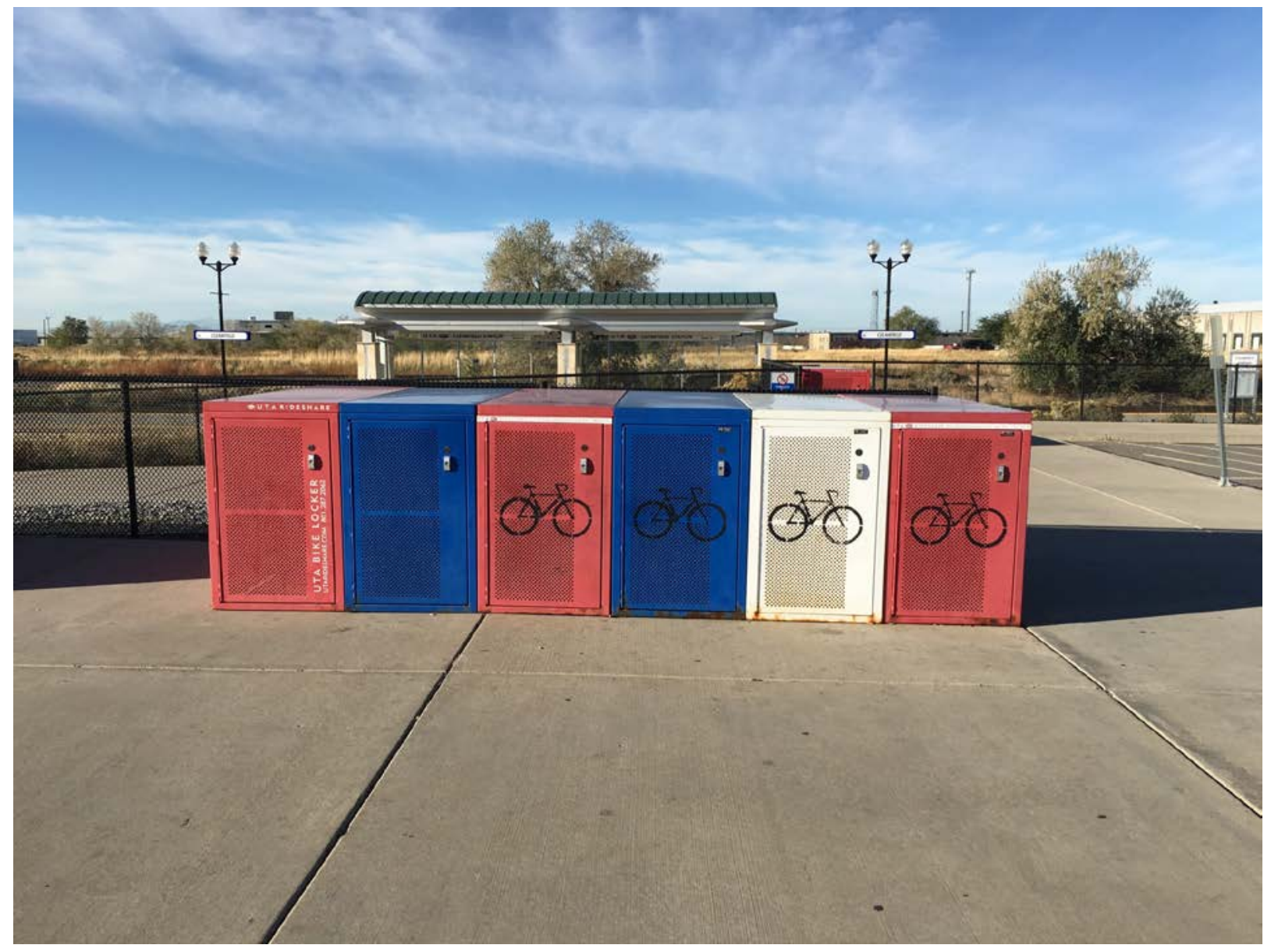

Figure 3.4 Bike lockers are located at each of the FrontRunner stations. Amenities, such as bike lockers, can encourage ridership. 


\subsection{DEVELOPING AN AGENT-BASED MODEL (ABM) FOR ESTIMATION OF LAND USE CHANGES AROUND COMMUTER RAIL STATIONS OVER TIME}

Since the mid-1950s, integrated transportation and land use models have enabled interdisciplinary researchers to understand complex spatial interactions that occur around transportation corridors over time. Spatial interaction models, for example Lowry's gravity model, have demonstrated that the accessibility and connectivity from transportation investments can foster density and mixed-use development near transportation nodes or routes (Acheampong \& Silva, 2015; Batty, 2012; Silva \& Wu, 2012). Specific to public transportation, these models have focused on the density and diversity of land uses as a function of distance to stations or routes. While much of this research has focused on transit generally or rail specifically, studies to date have not focused on the effects of commuter rail on proximate land use changes.

The study presented in this chapter aims to fill the gap of understanding regarding the effects of commuter rail development on future land use changes by employing advanced spatial interaction modeling. Specifically, this study aims to examine the extent to which commuter rail development affects land use near stations, while controlling for distance to highway exits and a central business district (CBD). By comparing model results with and without the influence of stations, planners and decision makers can better anticipate needed zoning changes, real estate economics (and potential related issues of gentrification), and neighborhood development patterns. By understanding these relationships and identifying their potential, we can expand evidence of commuter rail investments as a catalyst for economic development.

In this chapter we develop a modeling approach in which we estimate the probability of land use change at the parcel level as a function of proximity to landscape features, and use this to drive an agent-based model (ABM) to simulate the spatial pattern of land use change. ABMs provide a method to model behavior for individual units (here land parcels), as opposed to classical regression modeling, which relies on a global model. They have recently gained popularity in urban planning, but their applications have been limited to simulate urban expansion or ecological aspects of changes in the built environment. Therefore, to improve understandings of the agent-based modeling process, this chapter first describes ABM. Then, we describe the ABM used for this analysis and report the results. Finally, this chapter concludes with implications for future research.

\subsection{METHODS: OVERVIEW OF AGENT-BASED MODELING (ABM)}

Traditional spatial interaction models describe the state of the whole system using a set of parameters that represents the generalized properties of individuals as a group. Individual models, including ABMs, are distinguished by simulating the behavior of individual agents in response to 
a set of pre-determined assumptions (or “rules”) and environmental inputs. Behavior here generally refers to the change of an agent's characteristics, for example its location, value or group assignment.

In ABM, agents are considered unique and autonomous entities because they possess unique characteristics, and the decision to alter these relies on the information available to each agent. The characteristics may include information such as size, location and type, and are either initialized randomly or using observations (Batty et al., 2012). For example, in the classic ABM "boids" (Reynolds, 1987), a set number of agents (birds) are created with random heading and location. Following the initialization of the model, the ABM is generally run for a set of iterations. During an iteration, each agent is considered in turn, and will change its characteristics based on "the current states of themselves, of other agents, and of their environment" as well as predefined rules (Railsback \& Grimm, 2011). These decisions are generally characterized as stochastic processes, usually by incorporating probability-based behavioral choices. In the "boids" model, one rule causes each agent to adjust its heading by a small, random amount toward the average heading of other agents within a certain window, causing the agents to gradually become aligned. A further rule in this model represents environmental features as obstacles, which cause the agents to readjust their heading to avoid collisions. The overall effect is that the system as a whole (here the full set of agents) starts to exhibit complex flocking behavior, which arises or "emerges" from very simple rules governing the behavior of the individual agents.

The main goal of ABMs is then to simulate many individual-level decisions, allowing the complex system-level behavior to emerge rather than be prescribed. As each decision can be weighted by other agents, or by the environment, ABMs allow researchers to address system dynamics that arise from the interaction between agents and between the system and agents. This also means that ABMs help us implement analyses at two different spatial levels at the same time - agent and system levels. It is important to note, however, that ABMs do not have the same theoretical basis as classical regression models, and so they require testing against observational data (Batty et al., 2012).

There are several primary advantages to using ABMs. First, these models excel at representing the high-level complexity of real systems by simulating a large number of simple, low-level interactions and decisions. Second, they provide a framework for modeling behavior and choices, which may be problematic for linear models. Third, the emphasis on stochastic processes helps to account for uncertainty in the model parameters and rule sets. Finally, ABMs' algorithms and codes are created to ensure they can be duplicated and results can be tested. Indeed, the “Overview, Design concepts, and Details (ODD)” protocol has been developed by Grimm et al. (2006) to facilitate this transparency and overcome criticism of ABM for poor documentation and formulation of the model process (Lorek \& Sonnenschein, 1999).

\subsection{THE ODD PROTOCOL: DESCRIBING AND FORMULATING THE ABM}

The ODD protocol is a standard outline to formulate and document an ABM (Grimm et al., 2010

Grimm \& Railsback, 2005; Polhill et al., 2011). The protocol provides a template for ABM 
"meta-data" so that other researchers can understand and replicate the model. Railsback and Grimm (2011) suggest three purposes for explicitly and thoroughly expressing the ABM formation: (1) to help the model's developer set up the overall model framework; (2) so researchers can more readily collaborate or communicate to improve the model; and (3) to use as an initial resource which outlines the concepts and mechanisms of ABM before programming the model.

The ODD protocol consists of seven categories as follows:

1. Purpose

2. Entities, state variables and scales

3. Process overview and scheduling

4. Design concepts (including basic principles, emergent behavior, objectives, etc.)

5. Initialization

6. Input data

7. Sub-models

The ODD protocol should explain why the model was produced, the necessary inputs and expected outputs and how the model works, replacing the traditional methodology section in publications. Below, we first define some terms frequently used in the model description, then go on to describe these sections in more detail and provide our study's ODD protocol.

\subsubsection{Model glossary}

Transition probability: the probability of transitioning from land use type $i$ to land use type $j$.

Transition probability vector: a vector of length equal to the number of land use types. Each entry represents the transition probability to the land use type corresponding to that vector entry.

Transition probability matrix: a square matrix with one row/column per land use type. Each row represents a transition probability vector for a given land use type. If the row and column are equal, then this represents the probability of remaining the same land use type. As each row represents all possible transitions of a given type, it sums to 1.

Distance buffer: one of a series of concentric circular buffers around a given landscape feature (e.g., station). Used to aggregate locations by proximity to certain features.

Distance transition probability array: a three dimensional array containing a set of transition probability matrices, one per distance buffer. 


\subsubsection{Purpose}

The purpose section includes a brief statement of the problems and questions that the model intends to address. In this study, the ABM will be used to address one simple question from various perspectives: how does proximity to commuter rail stations affect land use changes over time?

\subsubsection{Defining Entities, State Variables, and Scales}

This section explains the components of our ABM and the variables that characterize them. The components include types of agents, the environments where agents are located and interact, and the global environment which possesses state variables that are not affected by agents. Our ABM assumes that space is heterogeneous, and the internal spatial effects within local units of the environment are ignored to reduce calculations of stochastic processes in the modeling process (Railsback \& Grimm, 2011).

Our ABM has one agent type - land parcels - and we assume that internal spatial effects within local units of the environment are ignored to reduce calculation of stochastic processes in the modeling process (Railsback \& Grimm, 2011). Parcels are represented by their centroids (herein referred to as "parcel agents"), and are located by their east and north coordinates, using the Utah State Plane projection. We restrict the current study to Salt Lake County, despite the fact that the northern FrontRunner corridor crosses three counties (Salt Lake, Weber and Davis), as this was the only county for which we had land use information in both 2007 and 2010.

In addition to their coordinates, the agents have 10 variables that are used to determine agents' states (Table 4.1). The most important of these variables is land use type. This is based on an existing land use scheme from Envision Tomorrow Plus, a scenario planning software, and consists of 13 land use categories. Each agent has the distance to the closest of one of three landscape features: (1) the closest FrontRunner station, (2) the nearest freeway exit, and (3) the CBD. The CBD centroid of Salt Lake City is extracted from the 1980 Census CBD block group shapefile. The distance between parcel agents and the CBD is measured as the distance between a parcel's centroid and the centroid of the Salt Lake City CBD. All distance measures are Euclidean and are constants. To facilitate calculations, we created a series of concentric buffer windows around each landscape feature, and assigned each parcel to the window it fell into. Buffer width was 250 meters (approximately 0.16 miles). 
Table 4.1 Parcel agent variables in the $\mathrm{ABM}$ of this study

\begin{tabular}{l|l}
\hline Agent Variables & Brief Description \\
\hline Coordinates (xcor and ycor) & $\begin{array}{l}\text { The X and Y (longitude and latitude) coordinates represents the centroid of } \\
\text { each parcel agent in Salt Lake County, Utah. }\end{array}$ \\
\hline $\begin{array}{l}\text { Distance Measures } \\
\text { (dist-station, dist-exit, dist-cbd) }\end{array}$ & $\begin{array}{l}\text { Euclidean distance between parcel agents (centroids) and three physical } \\
\text { features: (1) the nearest FrontRunner station, (2) the nearest freeway exit, } \\
\text { and (3) the Salt Lake City CBD. The distance is scaled in miles. }\end{array}$ \\
\hline $\begin{array}{l}\text { Distance Window Measures } \\
\text { (win-station, win-exit, win-cbd) }\end{array}$ & $\begin{array}{l}\text { Distance windows ("ring buffers”) of each parcel agent for FrontRunner } \\
\text { stations, freeway exits, and the CBD. }\end{array}$ \\
\hline Land Use Types & $\begin{array}{l}\text { The land use type of each parcel agent (13 different land use categories): } \\
\text { Mixed Use, Multifamily Residential, Single Family Residential, Mobile } \\
\text { Home, Retail, Office, Industrial, Public/Civic, Educational, } \\
\text { Hotel/Hospitality, Utilities/Infrastructure, Agricultural, Open Space, and } \\
\text { Others/Unclassified }\end{array}$ \\
\hline Population & $\begin{array}{l}\text { The estimated number of people who will reside in a parcel agent if land } \\
\text { use changes occur. }\end{array}$ \\
\hline
\end{tabular}

The model also uses a set of probability matrices that are used to estimate whether a parcel will have its current land use transformed ("transitioned") at each time step, and are the main state variable of the model. The first of these, referred to in the report as the base transition probability matrix (Table 4.3), gives a "global" probability of transition between each pair of land use types $(i, j)$. These probabilities are based on an analysis of the 2007 and 2010 land use data for the entire county, and each pairwise transition probability is simply the proportion of land use type $i$ in 2007 that were recorded as type $j$ in 2010. All land use types are based on the Salt Lake County tax assessor databases for 2007 and 2010.

The other three probability matrices (distance transition probability arrays) contain similar transition probabilities, but are calculated for the series of 250-meter buffers around the three landscape features (stations, freeway exits and CBD). For each pair of land use types ( $i, j)$, we calculated the transitional probability as the proportion of land use type $i$ in 2007 that were recorded as type $j$ in 2010 for each buffer. The changes in transitional probability over distance were both non-linear and noisy, so these were smoothed by modeling them as a function of distance using a generalized additive model (GAM; Wood, 2006) with a binomial error distribution and logit link function (Figure 4.1). This yielded a probability matrix for each buffer $(n=16)$, for each of the three distance types. Models could not be built for all combinations of pairs of land use types and buffer windows; when insufficient data points existed, and for these cases, the proportions were marked as missing values ('NA') in the matrices. 


\section{Station: 6 : 8}

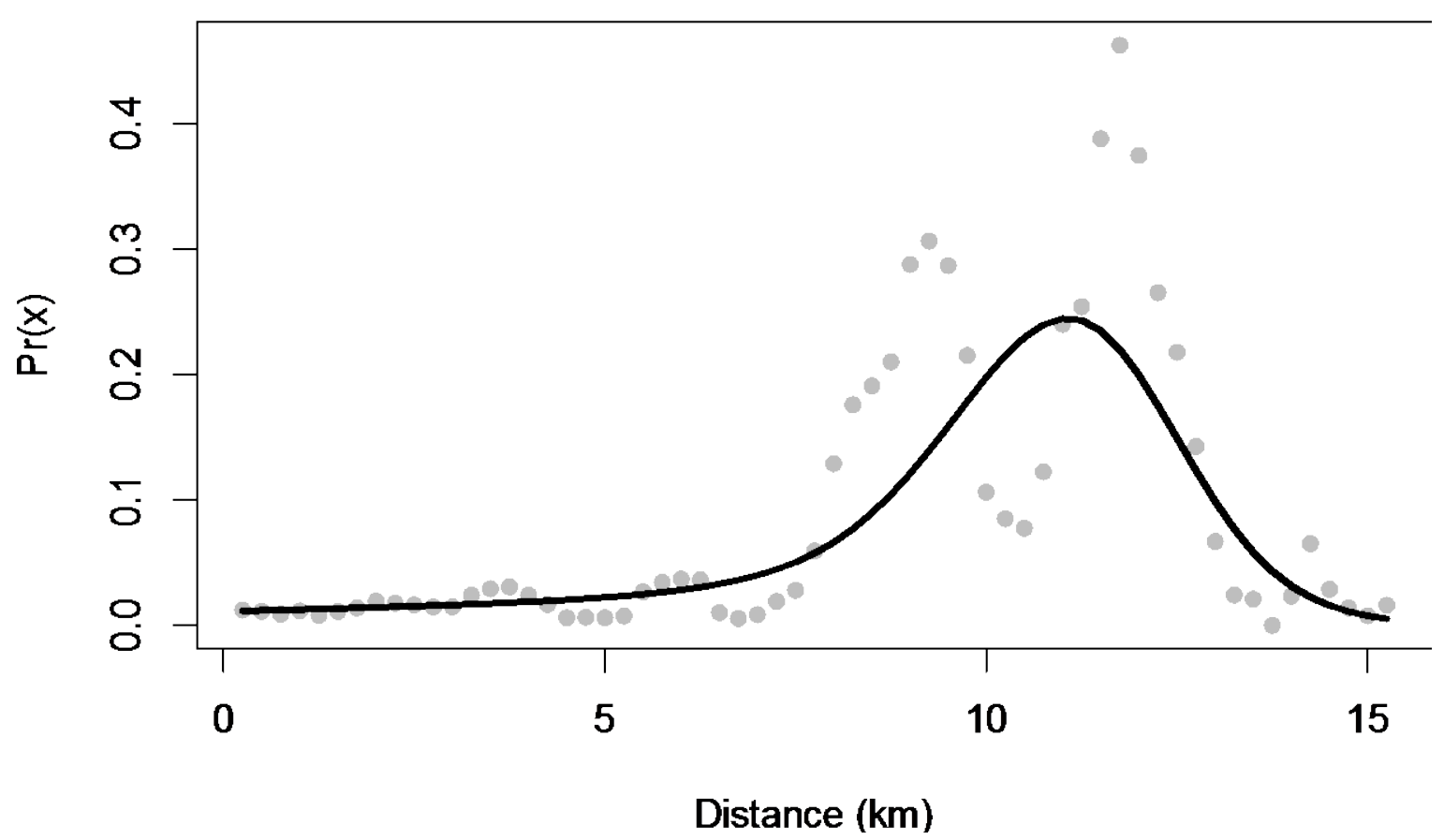

Figure 4.1. Shows changes in the transitional probability from type 6 (retail) to type 8 (industrial) as a function of distance to station. The thick black line is the GAM model fit. Note the large increase in probabilities between $8 \mathrm{~km}$ (approximately 5 miles) to $14 \mathrm{~km}$ (approximately 8.69 miles).

All probability matrices were calculated externally using R 3.2.2 (R Core Development Team, 2015), and stored as text files. As these are not hard coded in the model, they can be easily exchanged for matrices with different transitional probabilities to allow testing of different planning scenarios, or different descriptions of the change of transition probability over distance.

In this ABM, one time period ("tick" in NetLogo software) represents six months. Simulations were performed for the period of 2007 to 2010, to compare with the observed data, and future simulations run out to 2025 to show potential land use changes under a business-as-usual scenario. As the time step of the model (six months) differs from the time step represented by the observed data (four years), the transitional probabilities are standardized to the ratio of these time steps to limit overestimation of land use changes.

\subsubsection{Process Overview and Scheduling}

This section explains the dynamics of the ABM in this study-how parcel agents change their behaviors or status over time. When dynamics of the model are set up, scheduling of the ABM deals with the order of actions that agents take in the process (Railsback \& Grimm, 2011).

The ABM in this study has two processes, which are determined for each parcel in each time step: (1) building a vector of transition probabilities for the parcel's current land use type (i) to all land use types; and (2) determining whether or not a transition occurs. 
The vector of transition probabilities is built in a series of steps:

1. A vector of base transition probabilities is extracted from the base transition probability matrix, according to the current land use type;

2. For each landscape feature, we extract the 13 x 13 matrix of distance-based transition probabilities from the distance transition probability array corresponding to the distance buffer window of the current parcel. We then extract the vector of transition probabilities corresponding to the current land use type;

3. Any missing values in these distance-based vectors are replaced with the base transition probability for that land use type; and

4. This yields three vectors, one per landscape feature, which are then averaged to give a final transition probability vector.

This final vector is of length 13, and represents the probability mass function (see Figure 4.2) describing the possible changes in land use type for that parcel. To select the final type, we extract a land use type randomly from this distribution, and assign that to the parcel for the next time step. If the selected land use type is the same as the current type, then no transition is considered to have occurred. This process is the main source of stochasticity in the model. Figure 4.3 shows the overall process flow of our ABM.

\section{Retail 6}

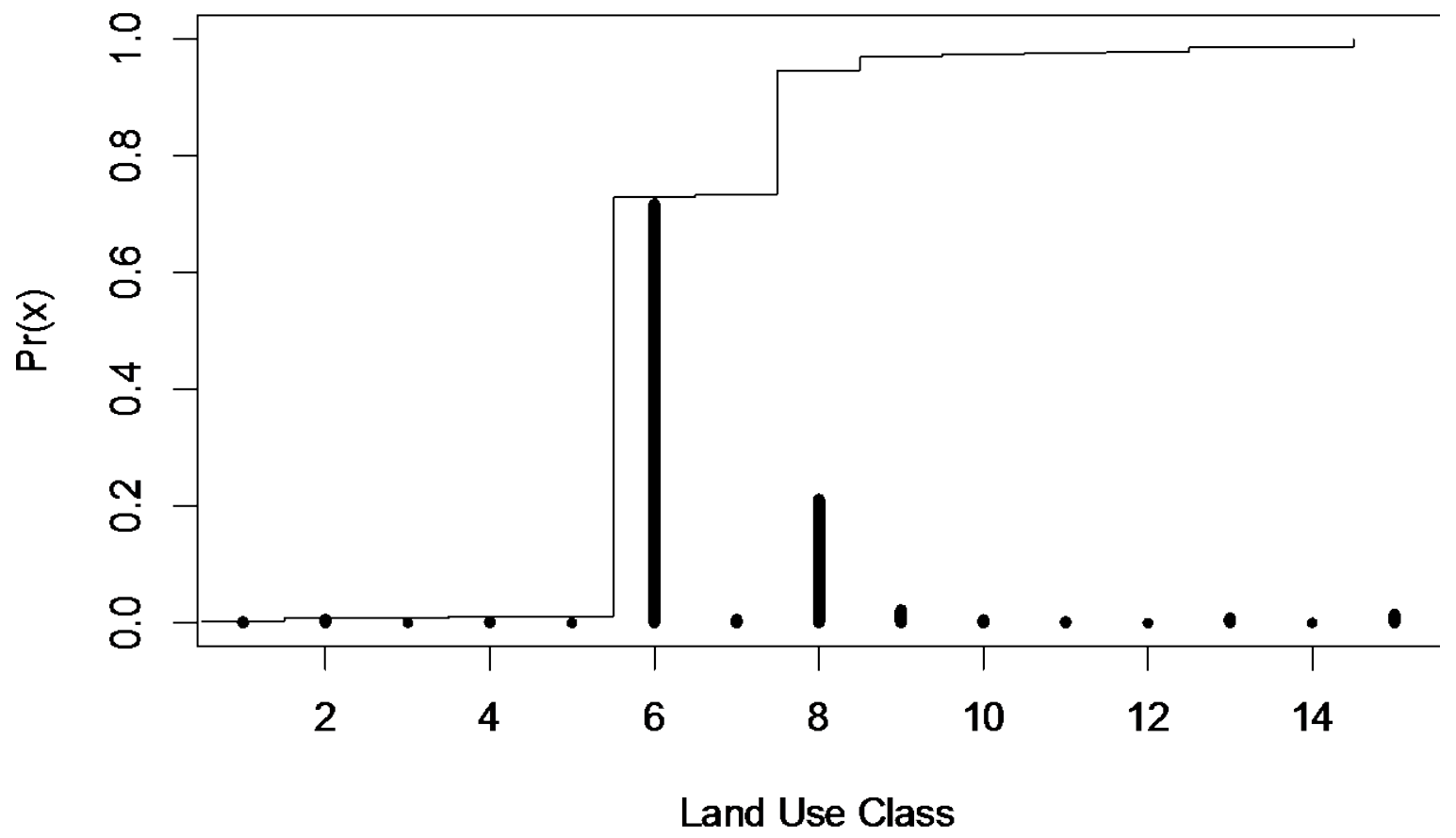

Figure 4.2 showing a transition probability vector for retail land use class. The vertical bars show the probability mass function, with high probabilities for transition to class 6 (= retail, i.e. no transition) and 8 (= industrial). The line represents the cumulative probability function 


\subsubsection{Design Concepts}

The ODD protocol suggests 11 design concepts, though not all are necessarily included in all models or protocols. We identify five design concepts in our ABM. This section discusses each in turn.

1. The basic principle: Our basic principle is the concept of how the proximity to certain infrastructure (commuter rail stations, freeway exits and CBD) may affect land use change over time.

2. Adaptation: The basic principle is addressed by looking at the adaptive behaviors of each parcel agent. The adaptive behaviors assume that when a parcel agent changes land use types, that change affects the transformation probability of future land use changes. These adaptive behaviors are based on prediction and stochasticity processes, which constitute concepts \#3-4.

3. Stochasticity processes: Stochasticity is used to determine how each parcel agent's land use type changes over each time period. Rather than simply selecting the most probable land use type, this is selected randomly using the probability mass function defined in the final vector of transition probabilities. In general, the highest probability occurs for the same land use type as the current type, which reflects the fact that land use changes occur slowly at the time scales considered here.

4. Interactions: The model can include a small adjustment of probabilities dependent on the dominant land use type among the neighboring five parcels. The probability of transitioning to that type is then up-weighted to promote local spatial structure in the land use results. In the models presented here, this was not used as it causes a significant increase in computation time.

5. Finally, the concept of observation is represented in our ABM. To observe the impacts of commuter rail development on land use change over time, this study conducts crossvalidation between the model's results and the actual land use changes. To complete this validation process, we compare observed land use changes between 2007 and 2010 for different land use types by distance from FrontRunner stations, highways and the CBD. To test statistical significance, the simulated results are compared to the observed land use to test validity of the model results. Rather than comparing each simulation results to the observed land use data, we create one aggregated simulation outcome by getting the modal values of land use type for each parcel across the 100 simulations. To crossvalidate the simulated and observed land use patterns, we use tax assessor parcel data from the Wasatch Choice 2040 parcel data layer template. This database can be downloaded in the form of ArcGIS map package files at the Wasatch Choice 2040 website (http://www.wasatchchoice2040.com/wasatch-choice-toolbox/tool-et/item/77downloads). 


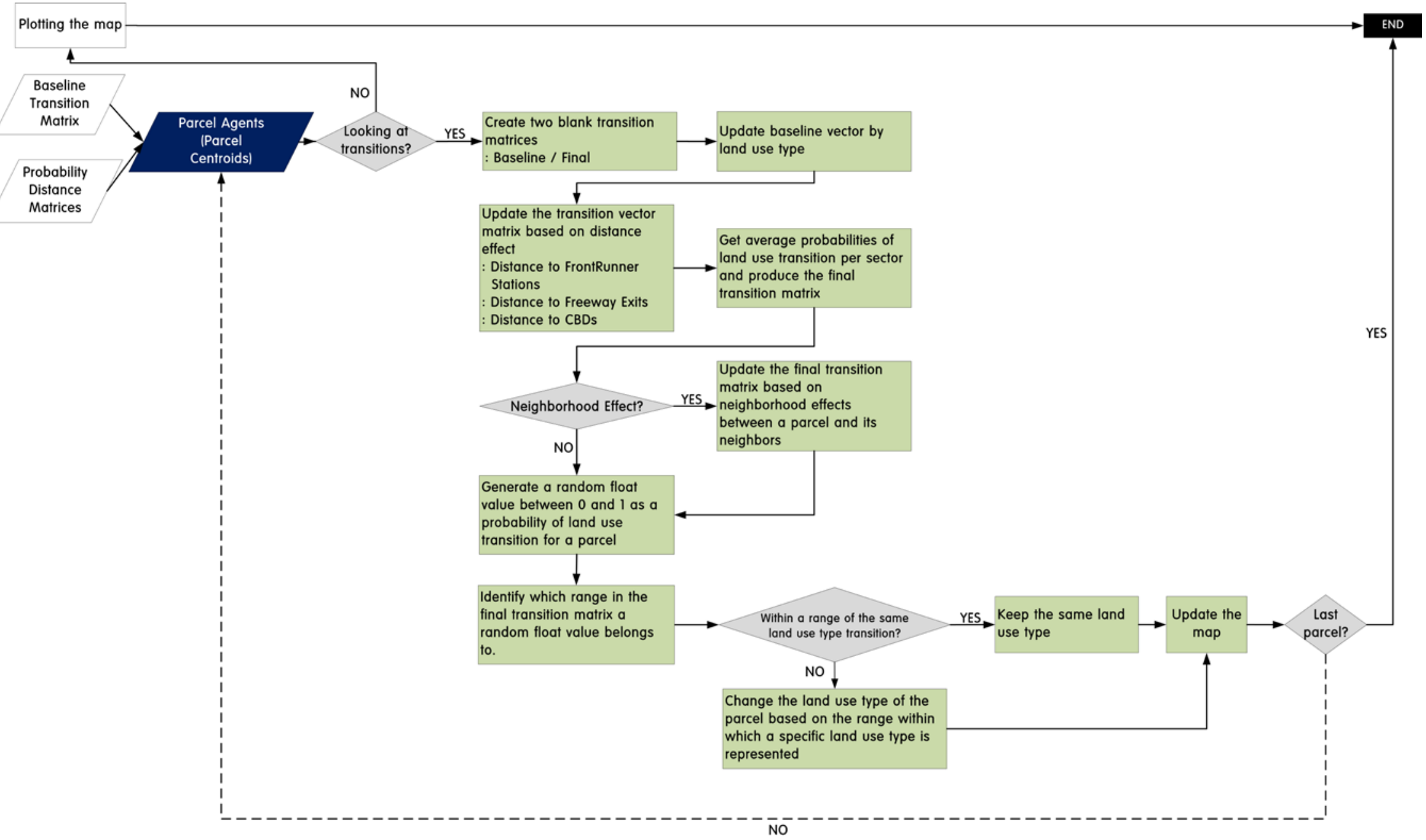

Figure 4.3 Process overview of the agent-based model 


\subsubsection{Initialization}

The initial environment of our model was created by identifying parcel agents, reading transition matrices, and producing a plot of the location and state (land use type) of the parcel agents. We import parcel agents from the GIS shapefile, and initialize the variables of each parcel agent using the attribute table of the parcel centroid GIS shapefile.

When the model starts, four environmental variables are defined as constants: (1) 13 land use types; (2) 16 distance windows (4 kilometers, approximately 2.5 miles) which represent the set of buffer windows around each landscape feature; (3) the time period represented by the transitional probability matrices — set here to four years, the period between tax assessor data; and (4) color coding for each land use type from the text data file. Finally, the distance transition probability arrays and base transition probability matrix are imported into the model.

\subsubsection{Sub-models}

A well-designed ABM divides the entire modeling process into several simple sub-models. We list here the sub-models used, with a brief explanation of the purpose of each one:

- plot-initialize: set up plots in Netlogo window;

- read-initialize: read in file defining land use types;

- set-land use-color: set colors for Netlogo plotting window;

- meters-per-patch: convert between Netlogo scaling and GIS scaling;

- read-transition-matrix: read base transition probability matrix;

- read-pd-mat: read distance transition probability arrays;

- get-pd-win: find distance buffer associated with parcel;

- get-pd-vect: extract vector of transition probabilities from distance transition probability array;

- $\quad$ d-vect-update: replace missing values in vector of transition probabilities from base transition probability matrix;

- average-trans-vector: average all distance-based vectors to obtain final vector of transition probabilities;

- neighbor-update: adjust vector of transition probabilities based on dominant neighboring land use type;

- calc-cumul-sum: convert vector of transition probabilities to cumulative probability distribution;

- type-transition: randomly select new land use type from vector of transition probabilities; and 
- output-parcels: output results.

\subsection{RESULTS}

\subsubsection{Model Experiments}

We designed and ran two separate experiments based on simulations of land use change created in the ABM described above:

1. For Salt Lake County, we ran three scenarios from 2007 to 2010. For each of these scenarios, we analyzed the land use changes within buffers around the stations.

A. A simulation based only on the base transition probability matrix. No distance effects exist in the model. Thus, this did not use any of the distance-based probability information and was designed to test the model behavior based on a global set of transition probabilities (i.e., the proximity of the various landscape features had no impact on land use changes).

B. A simulation including distance-based probabilities for freeway exits and distance to CBD. This was designed to test land use change in the absence of stations and to provide a baseline for calculating the influence of stations.

C. A simulation including the full set of distance-based probabilities. This was designed to provide the fullest test of the model and the results are used in the validation exercise below.

2. A set of simulations for Davis, Salt Lake and Weber Counties using the full set of distance-based probabilities, and run from 2010 to 2025. These were designed to examine a potential scenario of future land use change under the simple assumption that development would follow the same trends as our reference period.

\subsubsection{Model Validation}

Due to the large amount of data involved in the model, we restricted the analysis to a 5-kilometer buffer around the Salt Lake City CBD. Table 4.2 shows the simulated and observed land uses for 2010. Among the 13 land use types, four - single-family residential, retail, office and public/civic land use types - show errors less than $10 \%$ between the land use area simulated and observed. The model performs best in simulated retail development: the observed retail land use area in 2010 is 8,898 acres, while the simulated area is 8,664 acres-a 2.0\% error. Notably, the largest errors occur for land use types with a small spatial footprint, suggesting that the distancebased probabilities are misspecified for these types. Overall, the model appears to effectively project changes in land use types over this period.

Through 100 simulations of the model, the overall match ratio between the observed and simulated land use maps is about $93.47 \%$, which means that out of 182,377 sample parcels within the sample region, 170,459 parcels in the simulated model show the same land use types 
as the observed land use in 2010. Some differences can be seen between the simulated and observed maps (Figure 4.4), but this is not surprising given the stochastic nature of the model.

Table 4.2 A comparative analysis of land use between the observed and the simulated land use maps (2010)

\begin{tabular}{l|c|c|c|c}
\hline LUCAT & $\begin{array}{c}\text { Simulated land } \\
\text { area by land use } \\
\text { type (acres) }\end{array}$ & $\begin{array}{c}\text { Observed land } \\
\text { area by land use } \\
\text { type (acres) }\end{array}$ & $\begin{array}{c}\text { Percentage } \\
\text { Match }\end{array}$ & Error \\
\hline Mixed Use & 110.83 & 267.26 & $41.47 \%$ & $58.53 \%$ \\
\hline Multifamily & 6375.44 & 4817.27 & $132.35 \%$ & $32.35 \%$ \\
\hline Single-Family Residential & 27759.44 & 25971.62 & $106.88 \%$ & $6.88 \%$ \\
\hline Mobile Home & 0 & 1.17 & $0.00 \%$ & $100.00 \%$ \\
\hline Retail & 8898.35 & 8663.56 & $102.71 \%$ & $2.71 \%$ \\
\hline Office & 1747.93 & 1879.70 & $92.99 \%$ & $7.01 \%$ \\
\hline Public/Civic & 1039.67 & 1231.58 & $84.42 \%$ & $15.58 \%$ \\
\hline Educational & 7066.23 & 7552.55 & $93.56 \%$ & $6.44 \%$ \\
\hline Hotel/Hospitality & 1489.10 & 1838.92 & $80.98 \%$ & $19.02 \%$ \\
\hline Utilities/Infrastructure & 1097.90 & 3304.92 & $33.22 \%$ & $66.78 \%$ \\
\hline Agricultural & 38.85 & 59.38 & $65.43 \%$ & $34.57 \%$ \\
\hline Others/Unclassified & 288.63 & 438.62 & $65.80 \%$ & $34.20 \%$ \\
\hline
\end{tabular}
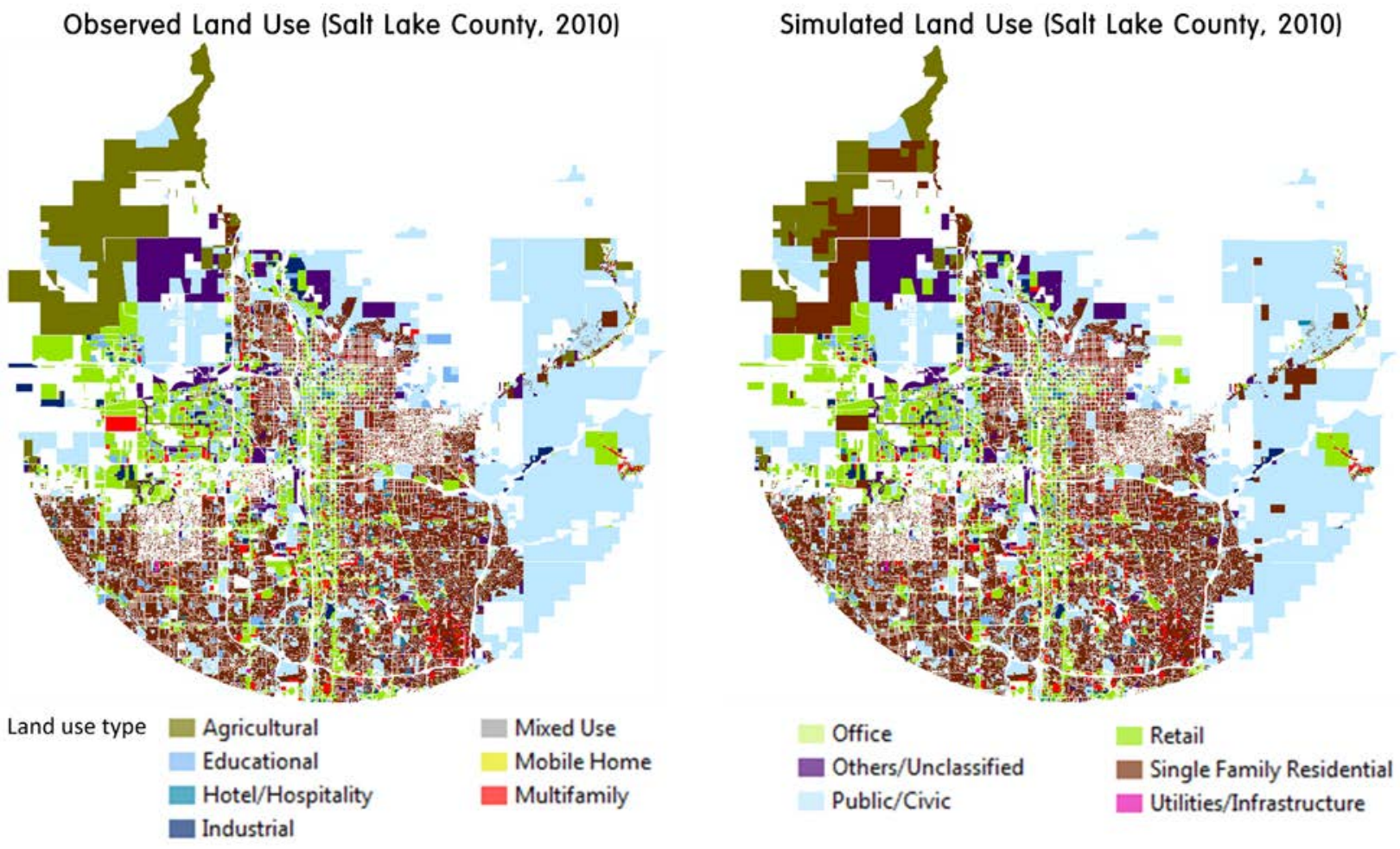

Figure 4.4 Observed land use and simulated maps of land use type in Salt Lake County in 2010 


\subsubsection{Analysis of Transition Matrix for Changes in Land Use Types}

Figure 4.5 compares land use changes between 2007 and 2010 based on the tax assessor parcel databases. During this period, there was only $0.07 \%$ increase in developed land area, meaning that the changes shown in Figure 4.5 represent conversions of already-developed parcels.

Of particular interest for this study, Figure 4.5 shows that across the study area, there were decreases in the share of developed land in either retail or single-family residential uses. At the same time, there were modest increases in the multifamily housing share and a more significant increase in industrial land uses. These findings partially play out in the station areas for the commuter rail system as well, as we show below.

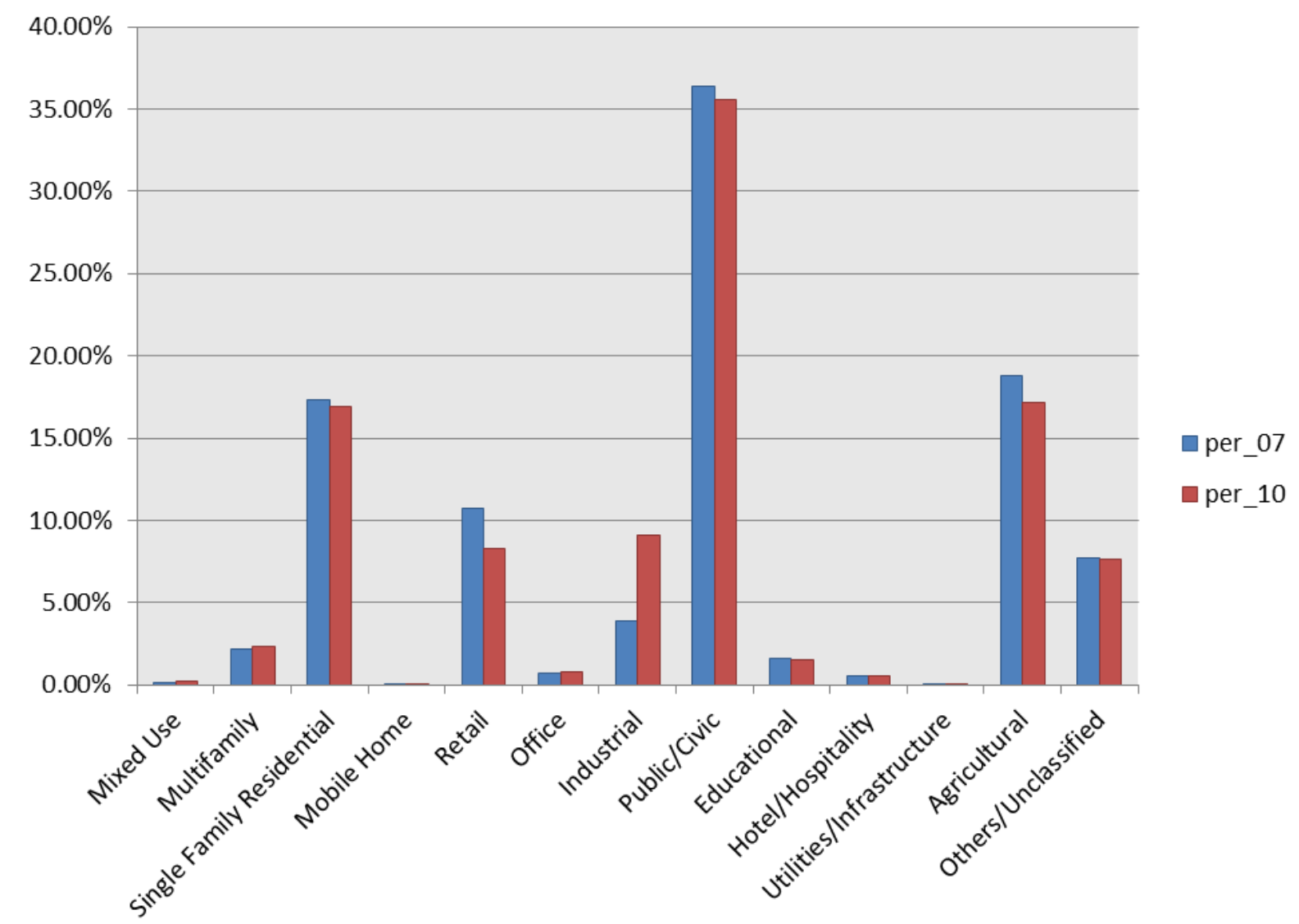

Figure 4.5 Observed changes in land use types between 2007 and 2010

The transition matrix of land use between 2007 and 2010 is shown in Table 4.3. Probabilities in the diagonal of the transition matrix indicate the probabilities that the land use type of a parcel will remain the same, while the probabilities in each row (other than the diagonal) represent the probability of a parcel being converted into one of the other land use type between 2007 and 2010. With only one exception, Table 4.3 also shows that land use types tend to remain the same, as shown by the high values in the diagonal. Mobile homes pose the exception, which, according to Table 4.3, are highly likely to be converted to multifamily housing land use. Finally, the selfreplacement probability of agricultural land is 0.854 based on 2007 and 2010 parcel databases, offering confidence in the possibilities for agricultural land conservation. 
Table 4.3 Transition probability matrix of land use change between 2007 and 2010 in Salt Lake County

\begin{tabular}{|c|c|c|c|c|c|c|c|c|c|c|c|c|c|}
\hline $\begin{array}{l}\text { Land use } \\
\text { Type }\end{array}$ & MU & MF & SF & MH & RET & OFF & IND & PUB & EDU & HOTEL & UTIL & AG & ОТН \\
\hline MU & 0.6450 & 0.0056 & 0.0077 & 0.0000 & 0.0374 & 0.0304 & 0.0116 & 0.2409 & 0.0041 & 0.0005 & 0.0000 & 0.0023 & 0.0146 \\
\hline MF & 0.0010 & 0.8081 & 0.0323 & 0.0000 & 0.0393 & 0.0106 & 0.0209 & 0.0431 & 0.0008 & 0.0035 & 0.0001 & 0.0391 & 0.0013 \\
\hline SF & 0.0014 & 0.0246 & 0.9547 & 0.0000 & 0.0012 & 0.0003 & 0.0011 & 0.0091 & 0.0001 & 0.0001 & 0.0000 & 0.0049 & 0.0023 \\
\hline MH & 0.0000 & 0.7084 & 0.0813 & 0.0650 & 0.0000 & 0.0000 & 0.0000 & 0.0620 & 0.0000 & 0.0000 & 0.0000 & 0.0769 & 0.0064 \\
\hline RET & 0.0021 & 0.0065 & 0.0026 & 0.0000 & 0.7172 & 0.0058 & 0.2121 & 0.0226 & 0.0054 & 0.0020 & 0.0004 & 0.0083 & 0.0150 \\
\hline OFF & 0.0015 & 0.0047 & 0.0008 & 0.0000 & 0.0518 & 0.8954 & 0.0094 & 0.0054 & 0.0143 & 0.0051 & 0.0010 & 0.0000 & 0.0106 \\
\hline IND & 0.0001 & 0.0011 & 0.0001 & 0.0000 & 0.0055 & 0.0010 & 0.9783 & 0.0062 & 0.0032 & 0.0003 & 0.0000 & 0.0005 & 0.0037 \\
\hline PUB & 0.0010 & 0.0011 & 0.0034 & 0.0000 & 0.0050 & 0.0002 & 0.0246 & 0.9339 & 0.0001 & 0.0005 & 0.0000 & 0.0247 & 0.0056 \\
\hline EDU & 0.0000 & 0.0008 & 0.0009 & 0.0000 & 0.0324 & 0.0008 & 0.0752 & 0.0141 & 0.8749 & 0.0000 & 0.0000 & 0.0000 & 0.0009 \\
\hline HOTEL & 0.0008 & 0.0147 & 0.0017 & 0.0000 & 0.0057 & 0.0069 & 0.0020 & 0.0361 & 0.0000 & 0.9284 & 0.0034 & 0.0000 & 0.0003 \\
\hline UTIL & 0.0000 & 0.0000 & 0.0000 & 0.0000 & 0.0000 & 0.0246 & 0.0028 & 0.2534 & 0.0000 & 0.0060 & 0.7132 & 0.0000 & 0.0000 \\
\hline AG & 0.0004 & 0.0009 & 0.0051 & 0.0000 & 0.0076 & 0.0000 & 0.0929 & 0.0373 & 0.0002 & 0.0001 & 0.0000 & 0.8540 & 0.0014 \\
\hline OTH & 0.0003 & 0.0015 & 0.0042 & 0.0000 & 0.0059 & 0.0003 & 0.0167 & 0.0314 & 0.0038 & 0.0000 & 0.0000 & 0.0003 & 0.9356 \\
\hline
\end{tabular}

Source: Land use categories in the table are based on the Envision Tomorrow Plus existing land use scheme (2013).

Note: The land use types in the table are as follows.

MU - Mixed Use / MF - Multifamily Residential / SF - Single-Family Residential / MH - Mobile Homes

RET - Retail / OFF - Office / IND - Industrial / PUB - Public / EDU - Educational / HOTEL - Hotel

UTIL - Utilities / AG - Agriculture / OTH - Others, Unclassified 
Table 4.3 also indicates that the main sources of land use type transition in Salt Lake County are mobile home, mixed use, retail and utilities. On the other hand, land use types such as industrial and single-family residential tend not to convert land uses. Interestingly, the mostly likely conversion of single-family residential, if it were to convert, is to multifamily residential.

\subsubsection{Interpreting Three Scenario Outcomes}

Given the large number of parcels, and the relatively low rates of transition from one land use type to another, interpreting and visualizing the results is problematic. In order to best demonstrate the dynamics of change, we focus on the proportion of parcels for a given type that changed during the simulation. The three-panel plots in Table 4.4 show the derivation of this for single-family and multifamily residential homes for a single simulation under the $1 \mathrm{C}$ scenario. The top plots show the number of parcels by distance for each type in 2007 (black line) and 2010 (red line). The middle plots show the same, but as the proportion of that type in each buffer that underwent transition. Finally, the bottom plot shows the difference in the proportion of that land use type between 2007 and 2010, and most clearly shows any changes around FrontRunner stations. In this plot, a dashed line is drawn at zero. If the black line is below the dashed line, the proportion of parcels in the represented land use declined; the inverse is also true.

This shows that while the numbers of parcels for single-family residential and multifamily residential tend to remain the same in 2007 and 2010, as suggested by the transition matrix, there is a clear and opposing pattern in the change in proportions. There is a general reduction in single-family residential parcels, other than in immediate proximity to FrontRunner stations. The apparent stability in the closest buffer may simply result from the very low proportions of this land use type, so that any reduction is negligible. In contrast, the proportion of multifamily parcels generally increases, again with the exception of parcels located in immediate proximity to the stations.

Table 4.5 shows the probabilities of land use transition for six main land use types based on the three scenarios $1 \mathrm{~A}, 1 \mathrm{~B}$ and $1 \mathrm{C}$ described above. The gray band shows the simulated change in proportions of each land use type between 2007 and 2010 based on 100 simulations, and the thick black line represents the observed change in proportions. The summary results of the three scenarios are described below. All results are calculated as changes in the proportions of different land use types in the buffers around station locations. Although the effects of the FrontRunner stations are not included in the first two scenarios, the results are still based on the same buffers to allow comparison with the full scenario (1C). 
Table 4.4 Simulation results of the number of parcels for single-family and multifamily residential in Salt Lake County in 2007 and 2010

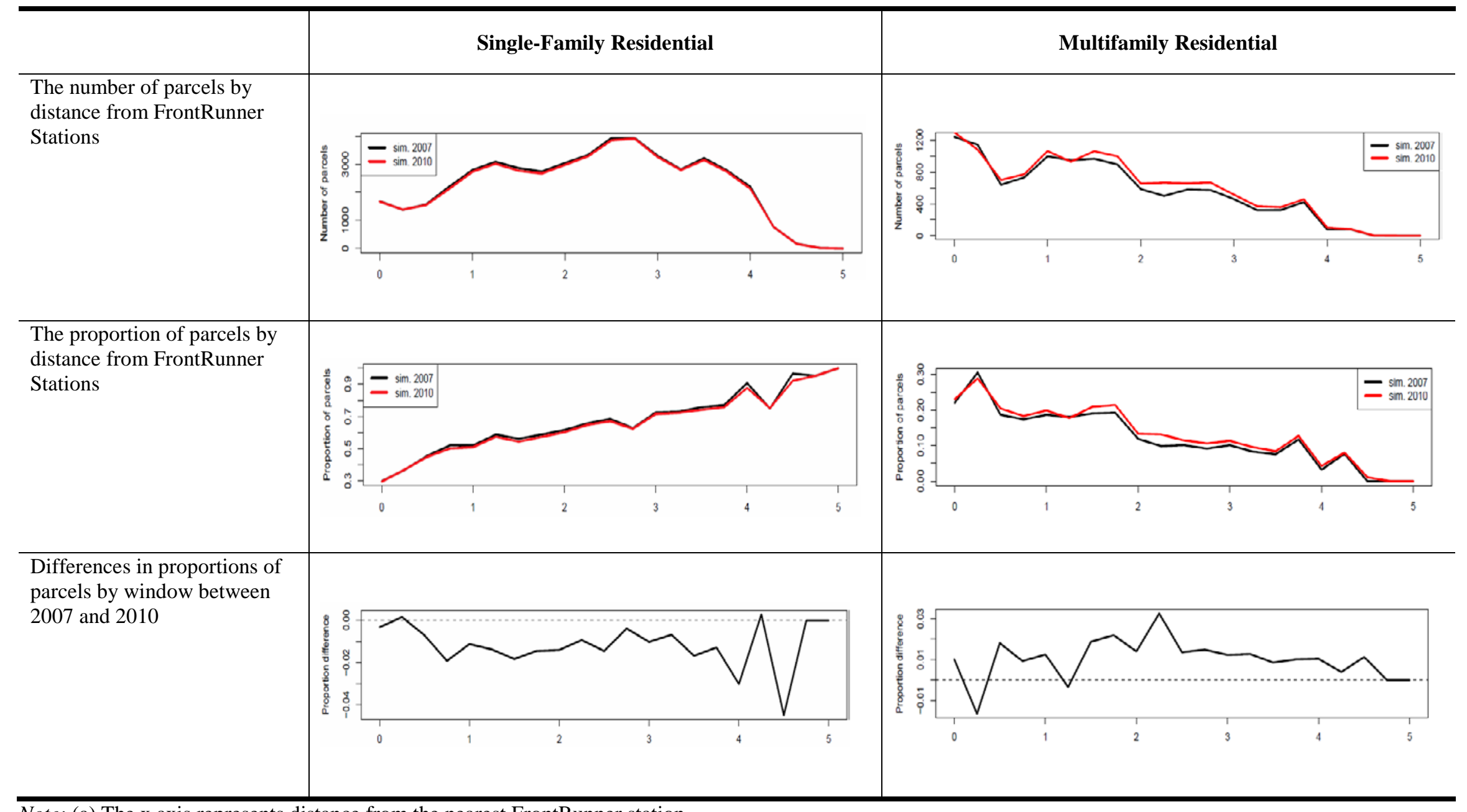

Note: (a) The $\mathrm{x}$ axis represents distance from the nearest FrontRunner station 


\section{Scenario 1A}

If the model assumes that there are no proximity or distance effects for land use changes, the proportion of single-family residential will increase near the FrontRunner stations. On the other hand, parcels of multifamily residential located near the FrontRunner stations tend to be stable, but increase at larger distances. Retail tends to decline close to the stations, but only within a 3kilometer distance. The proportion of industrial parcels increases closest to the stations, and gradually decreases to stable proportions with distance. Most notably, the change in singlefamily residential parcels as simulated in the model is the opposite of the observed pattern.

\section{Scenario 1B}

With the inclusion of distance effects of freeway exits and a CBD, scenario 1B shows several changes to the previous scenario. Other than a slight increase at very short distances, the proportional change in single-family residential is now close to zero over much of the study area. Other land use types show similar patterns as in scenario $1 \mathrm{~A}$, with some slight changes: more multifamily and industrial parcels close to the stations, and a reduction in retail over a wider area. There is better agreement between the simulated and observed results for single-family, but the observed decline is still not reproduced.

\section{Scenario 1C}

When distance effects of the FrontRunner stations are included in the model, the biggest changes are again seen in the changes in single-family parcels. Now there is a decrease in the proportion of these over a distance of about 4 kilometers from the stations. This improves agreement with the observations over much of the area considered, except in immediate proximity to the stations. This decline is compensated for by slight increases in multifamily homes and industrial, and reduced decline in retail parcels. 
Table 4.5 Three scenario results of land use changes by distance from the FrontRunner stations in Salt Lake County in 2010

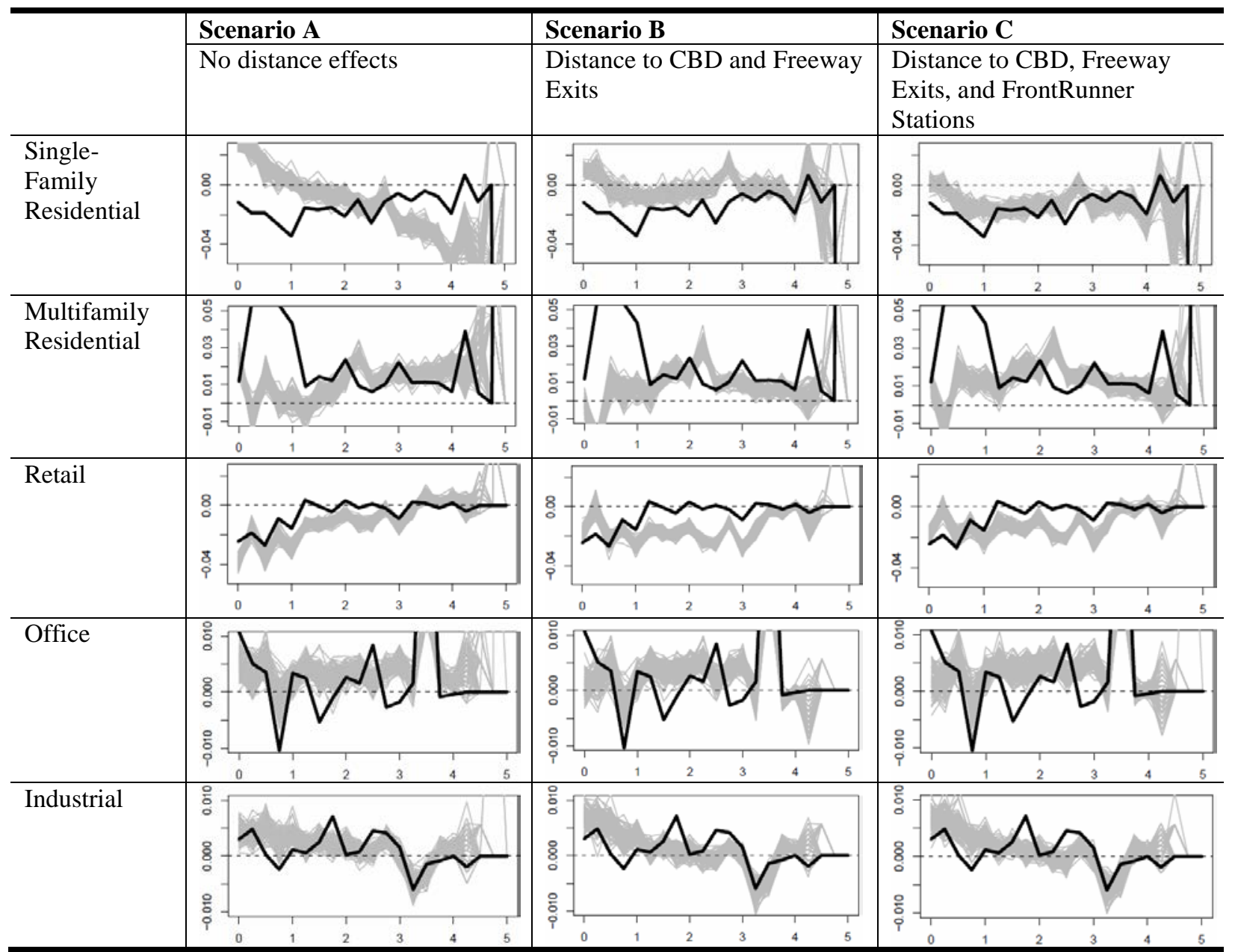

Note: (a) The gray lines represents the simulated results of land use change by the distances in 2010 from the model, and the black thick line stands for the observed results of probabilities of land use transition by the distance from the FrontRunner stations in Salt Lake County in 2010. (b) The y axis represents the probability of land use transition, and the $\mathrm{x}$ axis represents distances from the nearest FrontRunner stations (km).

In order to better show the effects of the stations, the results are further summarized in Table 4.6. This table shows, for a set of land use types, the simulated changes from scenarios $1 \mathrm{~B}$ (no stations, dashed line) and 1C (with stations, dotted line) in the left hand column for the set of 100 simulations, with the median change shown as a black line. The difference between these scenarios is then shown in the right-hand column, as the proportional change in $1 \mathrm{C}$ less the proportional change in $1 \mathrm{~B}$. If the results are negative (e.g., single-family parcels), this indicates that the presence of stations results in a greater turnover of that land use type. Positive results (e.g., multifamily or retail) indicate the opposite, that the stations either reduce loss or increase the development of that type. 
Table 4.6 Simulation results of the number of parcels for single-family and multifamily residential in Salt Lake County in 2007 and 2010

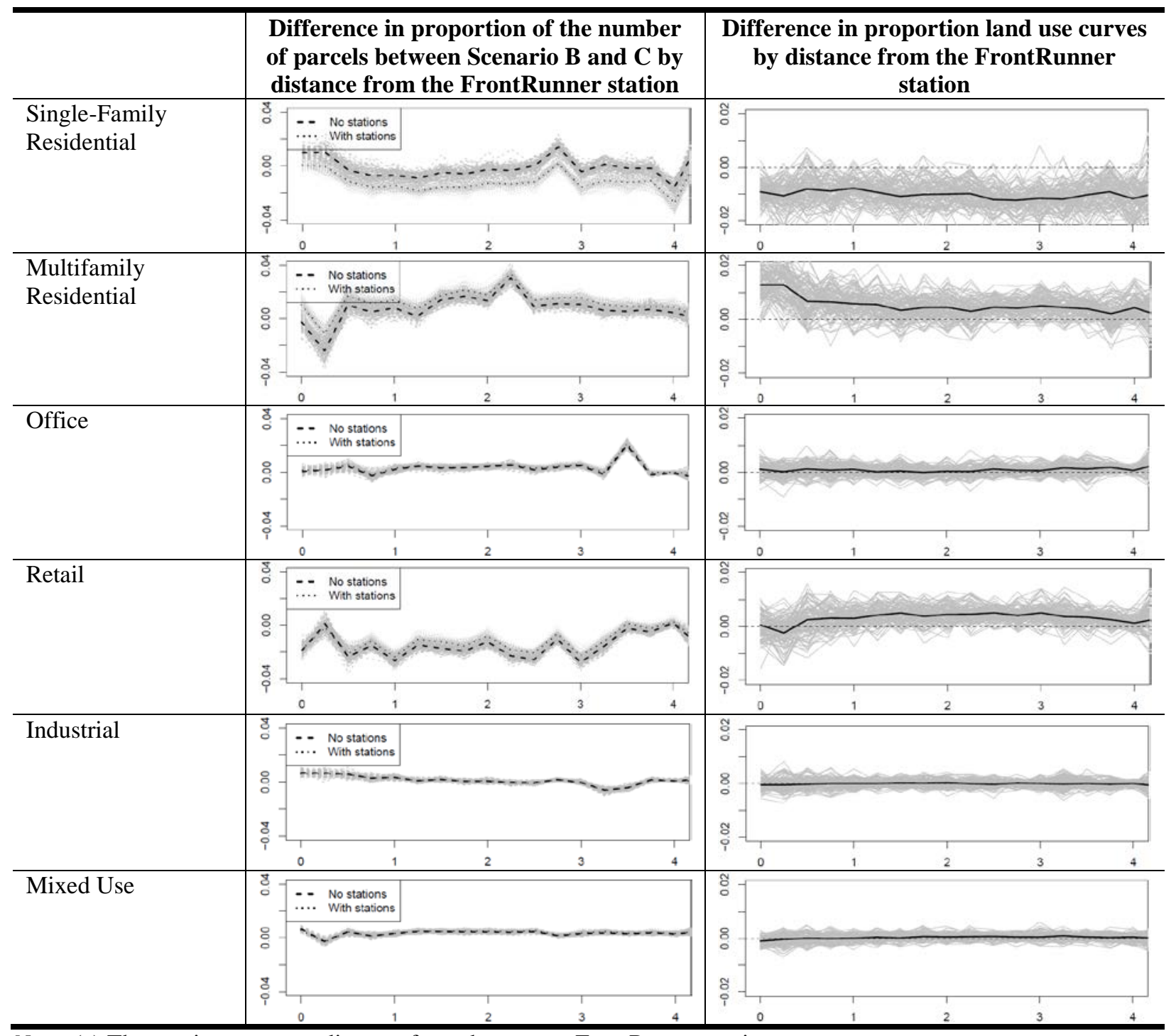

Note: (a) The $\mathrm{x}$ axis represents distance from the nearest FrontRunner station

\subsubsection{Future Simulations of Land Use Change}

Considering distance effects of the FrontRunner stations on land use changes, we can simulate the future land use maps using 2010 as a launch year. Using the land use transition matrix of the 2007-2010 period, the model forecasts the 2025 land use map in Salt Lake, Davis and Weber counties. Figure 4.6 shows the actual land use map in 2010 and the predicted land use map of 2025 in the three counties. Through conversions of public/civic and vacant land areas, the simulated results show an increase in mixed-use land area - from 110.25 acres in 2010 to $15,651.44$ acres in 2025. Due to the very low self-replacement probability of mobile home land use, the simulated land use result over-calculated the future land use changes in mobile homes, showing that there may be no mobile homes in 2025. The model anticipates increased industrial and hotel/hospitality land area near FrontRunner stations in 2025. Agricultural land area would decrease from $10.25 \%$ in 2010 to $0.05 \%$ in 2025 . Both single-family and multifamily residential 
land uses would increase by 2025, but the increasing percentage of multifamily residential would be much higher than that of single-family residential.

Table 4.7 Land use changes between 2010 and 2025 in Salt Lake, Davis, and Weber County

\begin{tabular}{l|c|c|c|c|c}
\hline & $\begin{array}{c}\text { Actual } \\
\text { Land Area } \\
\text { by Land } \\
\text { Use Type } \\
\mathbf{( 2 0 1 0 )}\end{array}$ & $\begin{array}{c}\text { Proportion } \\
\text { of land area } \\
\mathbf{( 2 0 1 0 )}\end{array}$ & $\begin{array}{c}\text { Land Area } \\
\text { by Land Use } \\
\text { Type } \\
\mathbf{( 2 0 2 5 )}\end{array}$ & $\begin{array}{c}\text { Proportion of } \\
\text { land area } \\
\mathbf{( 2 0 2 5 )}\end{array}$ & $\begin{array}{c}\text { Increase in Land } \\
\text { Area (\%) }\end{array}$ \\
\hline Mixed Use & $\mathbf{1 1 0 . 2 5}$ & $0.01 \%$ & $\mathbf{1 5 6 5 1 . 4 4}$ & $1.70 \%$ & $14096.03 \%$ \\
\hline Multifamily & $\mathbf{1 1 0 3 2 . 8 0}$ & $1.20 \%$ & $\mathbf{4 8 2 5 9 . 6 4}$ & $5.24 \%$ & $337.42 \%$ \\
Residential & $\mathbf{1 7 3 6 1 4 . 6 3}$ & $18.86 \%$ & $\mathbf{2 9 4 4 3 6 . 9 4}$ & $31.98 \%$ & $69.59 \%$ \\
\hline Single-Family & $\mathbf{1 7 3 8 . 2 3}$ & $0.19 \%$ & $\mathbf{0 . 0 0}$ & $0.00 \%$ & $-100.00 \%$ \\
\hline Residential & $\mathbf{1 3 2 4 6 . 5 9}$ & $1.44 \%$ & $\mathbf{9 4 7 1 . 9 8}$ & $1.03 \%$ & $-28.49 \%$ \\
\hline Mobile Homes & $\mathbf{6 6 0 3 . 7 1}$ & $0.72 \%$ & $\mathbf{3 3 9 9 . 6 8}$ & $0.37 \%$ & $-48.52 \%$ \\
\hline Retail & $\mathbf{6 6 2 8 7 . 1 7}$ & $7.20 \%$ & $\mathbf{2 4 4 8 0 1 . 3 5}$ & $26.59 \%$ & $269.30 \%$ \\
\hline Office & $\mathbf{3 5 8 9 3 8 . 2 0}$ & $38.99 \%$ & $\mathbf{2 5 7 1 6 7 . 1 0}$ & $27.94 \%$ & $-28.35 \%$ \\
\hline Industrial & $\mathbf{5 7 8 0 . 5 4}$ & $0.63 \%$ & $\mathbf{9 5 1 . 1 6}$ & $0.10 \%$ & $-83.55 \%$ \\
\hline Public/Civic & $\mathbf{8 9 8 . 7 5}$ & $0.10 \%$ & $\mathbf{4 1 3 4 . 9 8}$ & $0.45 \%$ & $360.08 \%$ \\
\hline Educational & $\mathbf{4 0 9 1 . 3 9}$ & $0.44 \%$ & $\mathbf{3 2 3 2 . 8 7}$ & $0.35 \%$ & $-20.98 \%$ \\
\hline Hotel/Hospitality & $\mathbf{9 4 4 0 2 . 2 1}$ & $10.25 \%$ & $\mathbf{4 2 3 . 6 3}$ & $0.05 \%$ & $-99.55 \%$ \\
\hline Utilities/Infrastructure & $\mathbf{1 8 3 8 0 7 . 7 9}$ & $19.97 \%$ & $\mathbf{3 8 6 2 1 . 4 8}$ & $4.20 \%$ & $-78.99 \%$ \\
\hline Agricultural & & & $\mathbf{9 2 0 5 5 2 . 2 5 5}$ & & \\
\hline Others & & & & & \\
\hline
\end{tabular}

Visual analysis of the predicted land use map shows that some public/civic and vacant land in west Weber County may be replaced with industrial land use in 2025, and agricultural land areas in west and south Salt Lake County would be expected to be converted to industrial. As we see in Table 4.7, residential land use types would increase in 2025, but the simulated land use map shows that residential development would be concentrated in Weber County and north Salt Lake County by replacing public/civic and agricultural land with residential land area. Finally, in the case of Davis County, the model shows that intensive industrial development might occur along the FrontRunner corridor. 

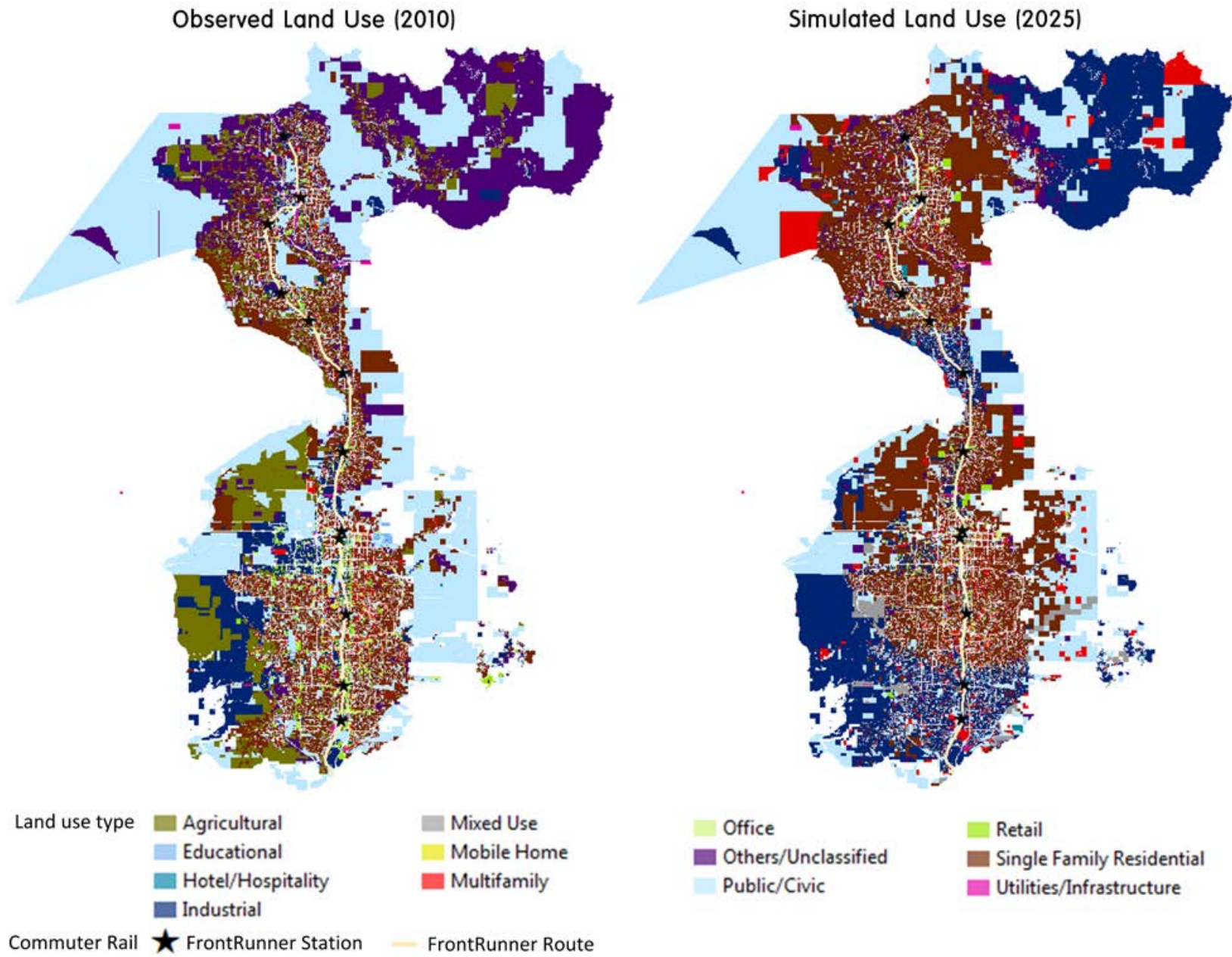

Figure 4.6 The actual and simulated land use map of Salt Lake, Davis, and Weber County

\subsubsection{Estimating the Area of Influence of FrontRunner Stations Based on Land Use Changes over Time}

Areas of influence for different public transit types have been either implicitly defined on the basis of various transit-oriented development projects (APTA, 2009) or measured by using hedonic pricing modeling (Bartholomew \& Ewing, 2011; Nelson, 1992) or transit ridership data (Guerra \& Cevero, 2011). Through simulation of land use transitions by distance from the FrontRunner stations, we can try to estimate the area over which commuter rail development influences land use changes.

Here, we estimate this area by looking for differences between scenario 1B (without stations) and $1 \mathrm{C}$ (with stations). We assume that differences between the scenarios represent the additional impact on land use changes from FrontRunner development. Where no difference is seen, then any additional impact is negligible. If a distinct area of influence exists, we would expect to see clear differences between the scenarios over short distances from stations, and that these differences would drop to zero at the limit of the area of influence. 
Table 4.7 shows results from scenarios $1 \mathrm{~B}$ and $1 \mathrm{C}$ based on 100 simulations. Differences between the scenarios are for 250-meter buffer windows up to 4 kilometers from all stations. As described above, clear differences between scenarios are shown for single-family, multifamily and retail parcels, indicating that there is an impact of the station development. However, these differences remain above or below zero for all distances considered, and so no limit to the area could be identified here. As a result, the current results cannot be used to define the area of influence. Further testing over larger distances would be necessary to fully identify any limits.

\subsection{CONCLUSIONS}

In this study, we have developed an agent-based model (ABM) of land use. We used tax assessor parcel databases of Salt Lake, Davis and Weber Counties to provide information about the probability of different types of land use change and how different landscape features influence this. This information was then used in the ABM to simulate land use changes under a variety of scenarios.

Comparisons of simulated and observed land use changes for Salt Lake County between 2007 and 2010 show that the model is generally capable of simulating the observed trends and directions of land use change. Exceptions to this are land use types with small spatial footprints, which tend to be either over- or underestimated. The influence of stations on the transitions of land use types was demonstrated by comparing the results of simulations with and without stations. Simulations without stations tend to underestimate the reduction in single-family homes and the compensatory increase in multifamily homes and retail parcels. The current set of simulations does not identify the size of the area of influence of the stations.

Future simulations suggest that in 2025, there would be strong demand for industrial development along the FrontRunner routes, and intensive and diverse residential development would occur at the north end of the commuter rail route in the future. The future land use map further shows that strong industrial and mixed-use development would be expected. As a consequence, these future development trends imply that Salt Lake, Davis and Weber County would be at the stage of more compact growth management and development that could facilitate or reflect robust economic growth in the future.

The ABM developed in this study remains very simple, using only distance to various features to simulate changes. There is little interaction between agents, and any spatial structure in development will not be well simulated. The model contains a neighborhood effect, but this should be better parameterized to reflect the nature of this effect, using observed spatial dependencies. Further, the model has little adaptation, other than changes in future transitional probabilities after a change in land use type. Future simulations are then based on a static set of probabilities, and so will follow the trends of the calibration period. A reasonably simple way to improve on this would be to include a supply and demand sub-model, which would promote the development of certain land use types when demand was high, accounting for projected demographic or, ultimately, economic changes. It is worth noting, however, that despite the current model's simplicity, it is capable of simulating the direction and, in some cases, the magnitude of the observed changes. 
The results of the 2025 land use map from the model provide one scenario of how transportation may influence land use change over longer time scales. Further development of the model to include these other processes would provide both planners and decision makers with a chance to test and develop other possible scenarios. Based on the future land use map in 2025, it is clear that growth management programs at the regional scale and policies for encouraging mixed use and industrial development for future economic growth should be necessary for Salt Lake, Davis and Weber County. It is also clear that the FrontRunner development is directly associated with growth management and economic growth in the future. 


\subsection{SUMMARY AND IMPLICATIONS}

\subsection{SUMMARY AND IMPLICATIONS}

In this report, we sought to investigate the relationships between commuter rail, population dynamics and land use change. In Chapter 2, we investigate the economic, demographic, transportation behavior and housing changes associated with the development of commuter rail. We investigate these changes both indirectly (through measuring changes in residents of host tracts) and directly (through comparison of commuter rail riders to residents). In these analyses, we find that the establishment of commuter rail decreases the population in Census tracts neighboring the host tracts, and that ridership seems to be impacted more by the built environment than by self-selection of commuter rail riders. In Chapter 3, we find that the development of a commuter rail station significantly increases both gross migration and outcommuting from station-hosting Census tracts. However, this information is insufficient to conclude if commuter rail increases regional population deconcentration. Chapter 4 corroborates Chapter 2, concluding that single-family residential land uses are likely to decline near station areas and are increasingly replaced by multifamily, commercial and industrial land uses. Substantively, all three of these chapters have added new material to the literature on the effects of transit investments on regions.

All three chapters also make methodological contributions to commuter rail, regional development and urban planning literatures. In Chapter 2, we extend traditional means of relating travel behavior to the built environment and self-selection through the innovation of proxy indices, and through integrating an on-board transit rider survey, all in a region underrepresented and distinct in the literature. In Chapter 3, we extend the methods of traditional population deconcentration models to include information about transportation infrastructure, which has traditionally been assumed to be measured through distance alone. Chapter 4 brings simulation modeling to urban planning research to understand the effects of commuter rail on land use change.

For researchers, the work completed under this grant extends knowledge regarding commuter rail, and the methods by which additional research might be conducted. In addition to initial project goals, during the course of conducting this research, we came to fully appreciate the dearth of commuter rail-specific research. We hope other researchers can use our work as a platform to conduct further investigations on these commuter rail studies.

For practitioners, this report offers useful information in the land use and transportation planning decision-making processes. For example, we suggest that while commuter rail decreases the overall population of adjacent Census tracts (those intersecting a one-mile buffer drawn around stations), the stations significantly increase migration and out-commuting, which suggests high population mobility and that these areas attract residents who need commuting infrastructure. These residents appear, in multiple ways, to resemble the existing residents of the adjacent tracts 
who also enjoy the amenities brought by mixed-use development. For planners, this signals the clear need to consider appropriate site planning and zoning around commuter rail stations. Site planning can facilitate built-environment improvements and zoning can work to anticipate the mixed-use development that favors co-location with stations. Planners can use this knowledge to work toward regional development goals, such as reducing VMT by pairing residential and nonresidential development, and encouraging workers to migrate nearer to commuter rail stations. Planners might also work to boost transit ridership through built-environment improvements.

Taken together, these steps potentially improve regional livability and reduce long-term emissions. Yet, work remains to be done in this research area. Specifically, additional research on regional population deconcentration might take advantage of (yet unrealized) advances in regional data. Given data availability, additional regions could be added to the analysis, testing the generalizability of our findings. Work striving toward delineating the area of influence for commuter rail might be possible given more and better data, and data covering multiple regions, though substantial effort to align the land use databases across regions would be necessary. For planners interested in conducting their own commuter rail research, below we have a brief proposal for a technology transfer that extends and simplifies this report's work.

\subsection{TECHNOLOGY TRANSFER PLAN}

Professional planners use a variety of information and knowledge sources to guide their work; however, these sources often do not fully or clearly integrate cutting-edge planning research into planning practice. Therefore, we propose a project that marries research and practice via the development of a practitioners' manual and computer-based toolbox for planning a new or evaluating an existing commuter rail system. If funded, the contents of the toolbox and manual will be based on the research design and findings disseminated in this report. As this study was the first of its kind to focus on commuter rail research in a metropolitan area with a population below three million, providing a practitioners' toolbox can provide valuable information to other similarly sized regions considering the implementation of a commuter rail system. The proposed handbook transforms this research into a digestible and replicable medium for a larger audience to help guide transportation and land use planning in smaller, rapidly growing metropolitan areas considering commuter rail systems to make their communities more livable.

\subsubsection{Tech-Transfer Target Audience}

There are two primary audience types for the proposed handbook and tools: practitioners and researchers. Considering the rapid urbanization across the U.S., cities of all sizes are considering commuter rail for their transit systems to mitigate air quality, traffic congestion and mobility issues, among others. The proposed deliverables will assist local development agencies and transportation practitioners considering incorporating commuter rail into their community's transportation system to better predict and plan for residential land use patterns and socioeconomic changes that can occur with the application of commuter rail. Furthermore, these tools and manual can help agencies not only quantify such changes for financial and development purposes, but provide the means to develop a meaningful report of their own research process and findings. 
By presenting our research tools and methods in a standard, operational format that allows more detail than can be presented in peer-reviewed, academic publications, researchers will also be able to replicate our original research and expand it to other socio-geographic settings and systems. This handbook can be used by students in urban planning, economic development or transportation-related methodology courses at the university level to develop tangible skills and experience, which can be beneficial for their career development and in the job market.

Other potential audience members will include researchers or consultants in economic development, transit and/or urban planning. To facilitate the distribution of the handbook and tools, a technology transfer website will be created as a part of the Metropolitan Research Center website for ease of access, and regional planning organizations will be selectively contacted directly for dissemination. Of course, this website will include links to and information about the National Institute for Transportation and Communities.

\subsubsection{Goal of Handbook and Toolbox}

The goal of creating a technology transfer is to empower practitioners to quickly and easily conduct their own analysis determining how the intervention of a commuter rail system will or has affected various components of their community. With such empirical findings, planners can recommend policy changes which improve the use, location and/or design of commuter rails that better match their citizen's transportation needs.

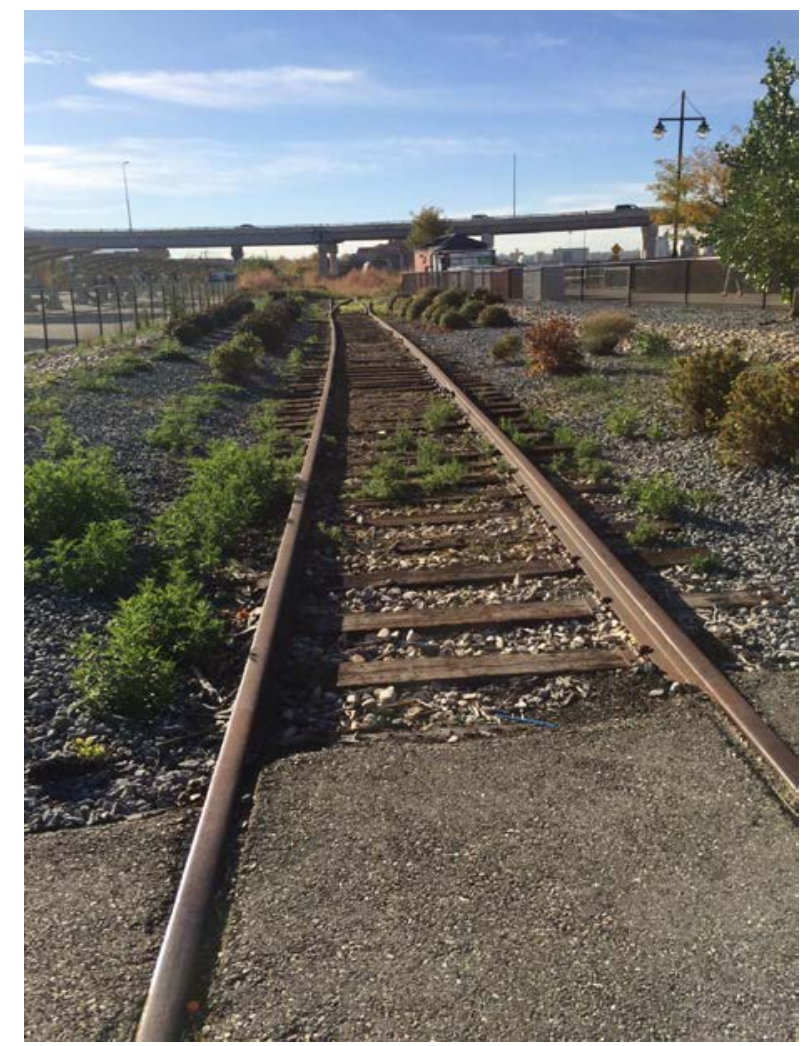

Figure 5.1 FrontRunner corridor under highway infrastructure

In closing, we would like to thank NITC for providing us the opportunity to complete this research. We eagerly hope that our efforts help to move this research agenda forward nationally. 


\subsection{REFERENCES}

Abraham, J. E., \& Hunt, J.D. "Specification and estimation of nested logit model of home, workplaces, and commuter model choices by multiple-worker households.” Transportation Research Record, 1606, (1997): 17-24.

Acheampong, Ransford A., and Elisabete A. Silva. "Land Use-Transport Interaction Modelling: A Review of the Literature and Future Research Directions." Journal of Transport and Land Use, no. 3(2015): 11-38.

Allen, John, and Herbert Levinson. "Accommodation of Long-Term Growth on North America's Commuter Railroads." Transportation Research Record: Journal of the Transportation Research Board 2419 (2014): 40-49.

Alonso, William. "Location and land use. Toward a general theory of land rent." Location and land use. Toward a general theory of land rent. (1964).

Alonso, W. “Location and Land Use.” Cambridge, Massachusetts: Harvard University Press. (1964)

American Public Transit Association. “Defining transit areas of influence” Recommended Practice. (2009).

American Public Transportation Association. “Commuter Rail: Serving America’s Emerging Suburban/Urban Economy.” APTA.com. http://www.apta.com/resources/reportsandpublications/Documents/Commuter_Rail_Subur ban_Urban_Economy_1997.pdf (accessed June 18, 2015). 
American Public Transportation Association. “Ridership Report Archives.” APTA.com. http://www.apta.com/resources/statistics/Pages/RidershipArchives.aspx (2015). (Accessed July 27, 2015).

Anas, Alex. "The Estimation of Multinomial Logit Models of Joint Location and Travel Mode Choice from Aggregated Data." Journal of Regional Science 21, no. 2 (1981): 223-242.

Arsenio, Elisabete, Abigail L. Bristow, and Mark Wardman. "Stated choice valuations of traffic related noise." Transportation Research Part D: Transport and Environment 11, no. 1 (2006): 15-31.

Astone, Nan Marie, and Sara S. McLanahan. "Family structure, residential mobility, and school dropout: A research note." Demography 31, no. 4 (1994): 575-584.

Audirac, Ivonne, and Jennifer Fitzgerald. "Information technology (IT) and urban form: An annotated bibliography of the urban deconcentration and economic restructuring literatures." Journal of Planning Literature 17, no. 4 (2003): 480-511.

Ayvalik, Cemal, and C. Jotin Khisty. "Heuristic analysis of impacts of commuter rail station consolidation on pedestrian access." Transportation Research Record: Journal of the Transportation Research Board 1793 (2002): 47-54.

Bagley, Michael N., and Patricia L. Mokhtarian. "The impact of residential neighborhood type on travel behavior: a structural equations modeling approach." The Annals of regional science 36, no. 2 (2002): 279-297.

Bartel, Ann P. "The migration decision: What role does job mobility play?." The American Economic Review (1979): 775-786.

Bartholomew, Keith, and Reid Ewing. "Hedonic price effects of pedestrian-and transit-oriented development." Journal of Planning Literature 26, no. 1 (2011): 18-34. 
Bateman, Ian, Brett Day, Iain Lake, and Andrew Lovett. "The Effect of Road Traffic on Residential Property Values: A Literature Review and Hedonic Pricing Study." (2001). Batty, Michael, Andrew T. Crooks, Linda M. See, and Alison J. Heppenstall. "Perspectives on agent-based models and geographical systems." In Agent-Based Models of Geographical Systems, pp. 1-15. Springer Netherlands, 2012.

Belzer, Dena, Sujata Srivastava, Mason Austin, Tyler Bump, and Jeff Wood. Transit and regional economic development. No. FTA CA-26-1007-03. 2011.

Ben-Akiva, Moshe, and John L. Bowman. "Integration of an activity-based model system and a residential location model." Urban Studies 35, no. 7 (1998): 1131-1153.

Benguigui, Lucien, Daniel Czamanski, and Maria Marinov. "City growth as a leap-frogging process: an application to the Tel-Aviv Metropolis." Urban studies 38, no. 10 (2001): 1819-1839.

Berry, Brian JL, and Hak - Min Kim. "Challenges to the monocentric model." Geographical analysis 25 , no. 1 (1993): 1-4.

Berry, Brian Joe Lobley. Urbanization and counter-urbanization. Vol. 11. SAGE Publications, Incorporated, 1976.

Betz, Michael R., Mark D. Partridge, David S. Kraybill, and Linda Lobao. "Why do localities provide economic development incentives? Geographic competition, political constituencies, and government capacity." Growth and Change 43, no. 3 (2012): 361391.

Bhat, Chandra R., and Jessica Y. Guo. "A comprehensive analysis of built environment characteristics on household residential choice and auto ownership levels." Transportation Research Part B: Methodological 41, no. 5 (2007): 506-526. 
Boarnet, Marlon G., and Andrew F. Haughwout. "Do highways matter? Evidence and policy implications of highways' influence on metropolitan development." University of California Transportation Center (2000).

Boarnet, Marlon G., and Sharon Sarmiento. "Can land-use policy really affect travel behaviour? A study of the link between non-work travel and land-use characteristics." Urban Studies 35, no. 7 (1998): 1155-1169.

Bohl, Charles C., and Elizabeth Plater-Zyberk. "Building Community across the Rural-to-Urban Transect [The Transect]." Places 18, no. 1 (2006).

Bollinger, Christopher R., and Keith R. Ihlanfeldt. "The impact of rapid rail transit on economic development: The case of Atlanta's MARTA." Journal of Urban Economics 42, no. 2 (1997): 179-204.

Bontje, Marco. "Dealing with deconcentration: Population deconcentration and planning response in polynucleated urban regions in north-west Europe." Urban Studies 38, no. 4 (2001): 769-785.

Booth, Katie M., Megan M. Pinkston, and Walker S. Carlos Poston. "Obesity and the built environment." Journal of the American Dietetic Association 105, no. 5 (2005): 110-117.

Brock, Timothy J., and Reginald R. Souleyrette. "An Overview of US Commuter Rail." (2013).

Brown, Barbara. "Modal choice, location demand, and income." Journal of Urban Economics 20, no. 2 (1986): 128-139.

Buehler, Ralph. "Promoting Public Transportation: Comparison of Passengers and Policies in Germany and the United States." Transportation Research Record: Journal of the Transportation Research Board 2110 (2009): 60-68.

Bunting, Trudi E., and Pierre Filion. "Dispersed city form in Canada: A Kitchener CMA case 
example." The Canadian Geographer/Le Géographe canadien 43, no. 3 (1999): 268-287. http://www.bts.gov/publications/national_transportation_statistics/\#front_matter

Bureau of Transportation Statistics. "National Transportation Statistics.” U.S. Department of Transportation.

http://www.bts.gov/publications/national_transportation_statistics/\#front_matter. (2007)

Buys, Laurie, and Evonne Miller. "Residential satisfaction in inner urban higher-density Brisbane, Australia: role of dwelling design, neighbourhood and neighbours." Journal of Environmental Planning and Management 55, no. 3 (2012): 319-338

Brock, Timothy J. and Reginald R. Souleyrette. “An Overview of US Commuter Rail,” No. KTC-13-18/UTCNURAIL1-12-1F. Lexington: National University Rail Center, Kentucky Transportation Center. (2013).

Cao, X.: Is Alternative Development Undersupplied? Examination of Residential Preferences and Choices of Northern California Movers. Transportation Research Record: Journal of the Transportation Research Board. 2077, 97-105 (2008).

Cao, Xinyu, and Patricia L. Mokhtarian. "How do individuals adapt their personal travel? Objective and subjective influences on the consideration of travel-related strategies for San Francisco Bay Area commuters." Transport Policy 12, no. 4 (2005): 291-302.

Cao, Xinyu, Patricia L. Mokhtarian, and Susan L. Handy. "Cross-sectional and quasi-panel explorations of the connection between the built environment and auto ownership." Institute of Transportation Studies (2007).

Cao, Xinyu, Patricia L. Mokhtarian, and Susan L. Handy. "Do changes in neighborhood characteristics lead to changes in travel behavior? A structural equations modeling approach." Transportation 34, no. 5 (2007): 535-556. 
Cao, Xinyu, Patricia L. Mokhtarian, and Susan L. Handy. "Examining the impacts of residential self- selection on travel behaviour: a focus on empirical findings." Transport Reviews 29, no. 3 (2009): 359-395.

Cao, Xinyu, Patricia L. Mokhtarian, and Susan L. Handy. "Neighborhood design and vehicle type choice: Evidence from Northern California." Transportation Research Part D:

Transport and Environment 11, no. 2 (2006): 133-145.

Cao, Xinyu, Susan L. Handy, and Patricia L. Mokhtarian. "The influences of the built environment and residential self-selection on pedestrian behavior: evidence from Austin, TX." Transportation 33, no. 1 (2006): 1-20.

Cao, Xinyu. "Is alternative development undersupplied? Examination of residential preferences and choices of Northern California movers." Transportation Research Record: Journal of the Transportation Research Board 2077 (2008): 97-105.

Carlino, Gerald A. "From centralization to deconcentration: people and jobs spread out." Business Review Nov (2000): 15-27.

Cervero, R. "Mixed land-uses and commuting: evidence from the American Housing Survey." Transportation Research Part A: Policy and Practice, 30(5), 361-377. (1996).

Cervero, Robert, and Michael Duncan. "Residential self selection and rail commuting: a nested logit analysis." (2008). http://escholarship.org/uc/item/72p9n6qt

Cervero, Robert, and Michael Duncan. "Transit's value-added effects: light and commuter rail services and commercial land values." Transportation Research Record: Journal of the Transportation Research Board 1805 (2002): 8-15.

Cervero, Robert. "Efficient urbanisation: economic performance and the shape of the metropolis." Urban Studies 38, no. 10 (2001): 1651-1671. 
Champion, Anthony G. "A changing demographic regime and evolving poly centric urban regions: Consequences for the size, composition and distribution of city populations." Urban Studies 38, no. 4 (2001): 657-677.

Chatman, Daniel G. "Residential choice, the built environment, and nonwork travel: evidence using new data and methods." Environment and planning. A 41, no. 5 (2009): 1072.

Chen, Jason, Cynthia Chen, and Harry Timmermans. "Accessibility trade-offs in household residential location decisions." Transportation Research Record: Journal of the Transportation Research Board 2077 (2008): 71-79.

Chi, Guangqing, and Paul Voss. "Migration decision-making: a hierarchical regression approach." Journal of Regional Analysis and Policy 35, no. 2 (2005): 11-22.

Cho, Gihyoug, Daniel A. Rodríguez, and Asad J. Khattak. "The role of the built environment in explaining relationships between perceived and actual pedestrian and bicyclist safety." Accident Analysis \& Prevention 41, no. 4 (2009): 692-702.

Circella, Giovanni, Patricia L. Mokhtarian, and Susan L. Handy. "Land use, attitudes, and travel behavior relationships: A cross-sectional structural equations model for Northern California." In Transportation Research Board 87th Annual Meeting, no. 08-0706. 2008.

Clark, David E., and Christopher A. Murphy. "Countywide Employment and Population Growth: An Analysis of the 1980s." Journal of Regional Science 36, no. 2 (1996): 235-256.

Clark, WA William AV, and Frans M. Dieleman. Households and housing: Choice and outcomes in the housing market. Transaction Publishers, 1996.

Clark, William AV, Youqin Huang, and Suzanne Withers. "Does commuting distance matter? Commuting tolerance and residential change." Regional Science and Urban Economics 33, no. 2 (2003): 199-221. 
Coffey, William J., and Richard G. Shearmur. "Agglomeration and dispersion of high-order service employment in the Montreal metropolitan region, 1981-96." Urban Studies 39, no. 3 (2002): 359-378.

Coffey, William J., Réjean Drolet, and Mario Polèse. "The intrametropolitan location of high order services: Patterns, factors and mobility in Montreal." Papers in Regional Science 75, no. 3 (1996): 293-323.

Craig, Neubauer Eric. "Deconcentration, time-space convergence, and metropolitan dominance: The spatial reorganization of the United States urban system, 1940—1990." (2001).

Crane, Randall, and Richard Crepeau. "Does neighborhood design influence travel?: A behavioral analysis of travel diary and GIS data." Transportation Research Part D: Transport and Environment 3, no. 4 (1998): 225-238.

DaVanzo, Julie, and Peter A. Morrison. "Dynamics of return migration: descriptive findings from a longitudinal study." (1978).

DaVanzo, Julie. "Repeat migration, information costs, and location-specific capital." Population and environment 4, no. 1 (1981): 45-73.

Dean, K. G., B. J. H. Brown, R. W. Perry, and D. P. Shaw. "The conceptualisation of counterurbanisation." Area (1984): 9-14.

Deka, Devajyoti, and Thomas Marchwinski. "The revenue and environmental benefits of new off-peak commuter rail service: the case of the Pascack Valley line in New Jersey." Transportation 41, no. 1 (2014): 157-172.

Deka, Devajyoti, Michael Lahr, Thomas Marchwinski, and Maia de la Calle. "Economic Impacts of Rail Transit on Recreational Shore Communities-The Case of the North Jersey Coast Line." In Transportation Research Board 94th Annual Meeting, no. 15-1546. 2015. 
Dieleman, Frans M. "Modelling residential mobility; a review of recent trends in research." Journal of housing and the built environment 16, no. 3 (2001): 249-265.

Duany, Andres, and Emily Talen. "Transect planning." Journal of the American Planning Association 68, no. 3 (2002): 245-266.

Durà Guimerà, Antoni. "Population deconcentration and social restructuring in Barcelona, a European Mediterranean city." Cities 20, no. 6 (2003): 387-394.

Ebner, Michael H. "Re-Reading Suburban America: Urban Population Deconcentration, 18101980." American Quarterly (1985): 368-381.

Eliasson, Jonas, and Lars-Göran Mattsson. "A model for integrated analysis of household location and travel choices." Transportation Research Part A: Policy and Practice 34, no. 5 (2000): 375-394.

Eliasson, Kent, Urban Lindgren, and Olle Westerlund. "Geographical labour mobility: migration or commuting?." Regional Studies 37, no. 8 (2003): 827-837.

Engel-Yan, Joshua, Malvika Rudra, Christopher Livett, and Rebecca Nagorsky. "Strategic Station Access Planning for Commuter Rail: Balancing Park-and-Ride with Other Modes." Transportation Research Record: Journal of the Transportation Research Board 2419 (2014): 82-91.

Esri. The American Community Survey. Redlands: Esri, 2014.

Ewing, Reid, and Robert Cervero. "Travel and the built environment: a synthesis." Transportation Research Record: Journal of the Transportation Research Board 1780 (2001): 87-114.

Ewing, Reid, and Robert Cervero. "Travel and the built environment: a meta-analysis." Journal of the American Planning Association 76, no. 3 (2010): 265-294. 
Ewing, Reid, Guang Tian, Allison Spain, and J. P. Goates. "Effects of Light-Rail Transit on Traffic in a Travel Corridor." Journal of Public Transportation 17, no. 4 (2014): 7.

Ewing, Reid. "Is Los Angeles-style sprawl desirable?." Journal of the American planning association 63, no. 1 (1997): 107-126.

Feng, Jian, Fahui Wang, and Yixing Zhou. "The spatial restructuring of population in metropolitan Beijing: Toward polycentricity in the post-reform era." Urban Geography 30, no. 7 (2009): 779-802.

Filion, Pierre, Trudi Bunting, and Keith Warriner. "The entrenchment of urban dispersion: residential preferences and location patterns in the dispersed city." Urban Studies 36, no. 8 (1999): 1317-1347.

Fishman, Robert. Bourgeois utopias: The rise and fall of suburbia. Basic Books, 1987.

Frey, William H. "Migration and depopulation of the metropolis: regional restructuring or rural renaissance?." American Sociological Review (1987): 240-257.

Friedman, Joseph. "Housing Location and the Supply of Local Public Services." (1975).

Fuguitt, Glenn V., and Calvin L. Beale. Population change in nonmetropolitan cities and towns. US Department of Agriculture, Economic Research Service, 1976.

Fuguitt, Glenn V., and David L. Brown. "Residential preferences and population redistribution: 1972-1988." Demography 27, no. 4 (1990): 589-600.

Galster, George C., and Garry W. Hesser. "Residential satisfaction compositional and contextual correlates." Environment and behavior 13, no. 6 (1981): 735-758.

Ganning, Joanna P., and Benjamin D. McCall. "The Spatial Heterogeneity and Geographic Extent of Population Deconcentration: Measurement and Policy Implications." In International Handbook of Rural Demography, pp. 319-332. Springer Netherlands, 2012. 
Ganning, Joanna P., Kathy Baylis, and Bumsoo Lee. "Spread and backwash effects for nonmetropolitan communities in the US." Journal of Regional Science 53, no. 3 (2013): 464-480.

Ganning, Joanna Paulson, and Courtney G. Flint. "Constructing a community-level amenity index." Society and Natural Resources 23, no. 12 (2010): 1253-1258.

Giuliano, Genevieve. "Incident characteristics, frequency, and duration on a high volume urban freeway." Transportation Research Part A: General 23, no. 5 (1989): 387-396.

Giuliano, Genevieve. "Land use impacts of transportation investments: Highway and transit,” in The geography of urban transportation, edited by Susan Hanson and Genevieve Giuliano, 237-273. New York: Guilford Press, 2004.

Gordon, Peter, Ajay Kumar, and Harry W. Richardson. "Gender differences in metropolitan travel behaviour." Regional Studies 23, no. 6 (1989): 499-510.

Gordon, Peter, Ajay Kumar, and Harry W. Richardson. "The influence of metropolitan spatial structure on commuting time." Journal of urban economics 26, no. 2 (1989): 138-151.

Gordon, Peter, and H. L. Wong. "The costs of urban sprawl: some new evidence." Environment and planning A 17, no. 5 (1985): 661-666.

Gordon, Peter, and Harry W. Richardson. "Are compact cities a desirable planning goal?." Journal of the American planning association 63, no. 1 (1997): 95-106.

Gordon, Peter, Harry W. Richardson, and Myung-Jin Jun. "The commuting paradox evidence from the top twenty." Journal of the American Planning Association 57, no. 4 (1991): 416420.

Graves, Philip E., and Peter D. Linneman. "Household migration: Theoretical and empirical results." Journal of urban economics 6, no. 3 (1979): 383-404. 
Greenwald, Michael J. "The Road Less Traveled New Urbanist Inducements to Travel Mode Substitution for Nonwork Trips." Journal of Planning Education and Research 23, no. 1 (2003): 39-57.

Grimm, Volker, and Steven F. Railsback. Individual-based modeling and ecology. Princeton university press, 2005.

Grimm, Volker, Uta Berger, Donald L. DeAngelis, J. Gary Polhill, Jarl Giske, and Steven F. Railsback. "The ODD protocol: a review and first update." Ecological modelling 221, no. 23 (2010): 2760-2768.

Grimm, Volker, Uta Berger, Finn Bastiansen, Sigrunn Eliassen, Vincent Ginot, Jarl Giske, John Goss-Custard et al. "A standard protocol for describing individual-based and agent-based models." Ecological modelling 198, no. 1 (2006): 115-126.

Guerra, Erick, and Robert Cervero. "Cost of a ride: the effects of densities on fixed-guideway transit ridership and costs." Journal of the american planning association 77, no. 3 (2011): 267-290.

Hamidi, Shima, and Reid Ewing. "A longitudinal study of changes in urban sprawl between 2000 and 2010 in the United States." Landscape and Urban Planning 128 (2014): 72-82.

Han, Yicheol, and Stephan J. Goetz. "The Economic Resilience of US Counties during the Great Recession." The Review of Regional Studies 45, no. 2 (2015): 131-149.

Handy, Susan, Xinyu Cao, and Patricia L. Mokhtarian. "Self-selection in the relationship between the built environment and walking: Empirical evidence from Northern California." Journal of the American Planning Association 72, no. 1 (2006): 55-74.

Handy, Susan, Xinyu Cao, and Patricia Mokhtarian. "Correlation or causality between the built environment and travel behavior? Evidence from Northern California." Transportation 
Research Part D: Transport and Environment 10, no. 6 (2005): 427-444.

Hansen, Niles M. The Future of Nonmetropolitan America; Studies in the Revesal of Rural and Small Town Populationm Decline. Lexington Books, 1973.

Hawley, Amos Henry. "The Changing Shape of Metropolitan American: Deconcentration Since 1920.." (1956).

Hobbs, Frank, and Nicole Stoops. "Demographic Trends in the 20th Century (Census 2000 Special Reports, Series CENSR-4)." Washington, DC: US Government Printing Office (2002).

Hull, A. "Transport matters: Integrated approaches to planning city-regions.” Abingdon: Routledge. (2011).

Hunecke, Marcel, Sonja Haustein, Sylvie Grischkat, and Susanne Böhler. "Psychological, sociodemographic, and infrastructural factors as determinants of ecological impact caused by mobility behavior." Journal of Environmental Psychology 27, no. 4 (2007): 277-292.

Inoa, Ignacio A., Nathalie Picard, and André de PALMA. Intra-household Decision Models of Residential and Job Location. No. 2014-05. THEMA (THéorie Economique, Modélisation et Applications), Université de Cergy-Pontoise, 2014.

Israel, Emil, and Galit Cohen-Blankshtain. "Testing the decentralization effects of rail systems: Empirical findings from Israel." Transportation Research Part A: Policy and Practice 44, no. 7 (2010): 523-536.

Joh, Kenneth, Marlon Boarnet, Mai Nguyen, William Fulton, Wally Siembab, and Susan Weaver. "Accessibility, travel behavior, and new urbanism: case study of mixed-use centers and auto-oriented corridors in the South Bay Region of Los Angeles, California." Transportation Research Record: Journal of the Transportation Research Board 2082 
(2008): 81-89.

Kahsai, M. S., \& Schaeffer, P. V. Deconcentration, Counter-Urbanization, or Trend Reversal? The Population Distribution of Switzerland, Revisited. Open Urban Studies Journal, 3, 89102. (2010).

Kennedy, Christopher A. "A comparison of the sustainability of public and private transportation systems: Study of the Greater Toronto Area." Transportation 29, no. 4 (2002): 459-493.

Khattak, Asad J., and Daniel Rodriguez. "Travel behavior in neo-traditional neighborhood developments: A case study in USA." Transportation Research Part A: Policy and Practice 39, no. 6 (2005): 481-500.

Kitamura, Ryuichi, Patricia L. Mokhtarian, and Laura Laidet. "A micro-analysis of land use and travel in five neighborhoods in the San Francisco Bay Area." Transportation 24, no. 2 (1997): 125-158.

Knight, Robert L., and Lisa L. Trygg. "Evidence of land use impacts of rapid transit systems." Transportation 6, no. 3 (1977): 231-247.

Krizek, Kevin J. "Two approaches to valuing some of bicycle facilities' presumed benefits: Propose a session for the 2007 national planning conference in the city of brotherly love." Journal of the American Planning Association 72, no. 3 (2006): 309-320.

Krizek, Kevin. "Pretest-posttest strategy for researching neighborhood-scale urban form and travel behavior." Transportation Research Record: Journal of the Transportation Research Board 1722 (2000): 48-55.

Ladd, Helen F., and William Wheaton. "Causes and consequences of the changing urban form: introduction." Regional Science and Urban Economics 21, no. 2 (1991): 157-162.

Lane, Clayton, Mary DiCarlantonio, and Len Usvyat. "Sketch models to forecast commuter and 
light rail ridership: Update to TCRP report 16." Transportation Research Record: Journal of the Transportation Research Board 1986 (2006): 198-210.

Lee, Brian HY, and Paul Waddell. "Residential mobility and location choice: a nested logit model with sampling of alternatives." Transportation 37, no. 4 (2010): 587-601.

Lee, Chanam, Xuemei Zhu, Jeongjae Yoon, and James W. Varni. "Beyond distance: children’s school travel mode choice." Annals of behavioral medicine 45, no. 1 (2013): 55-67.

Lee, Everett S., J. C. Bresee, K. P. Nelson, and D. A. Patterson. An introduction to urban decentralization research. No. ORNL-HUD--3. Oak Ridge National Lab., Tenn., 1971.

Lerman, Steven R. "A disaggregate behavioral model of urban mobility decisions." PhD diss., Massachusetts Institute of Technology, 1975.

Lerman, Steven R. "Location, housing, automobile ownership, and mode to work: a joint choice model." Transportation Research Record 610 (1976): 6-11.

Levine, Jonathan. "Rethinking accessibility and jobs-housing balance." Journal of the American Planning Association 64, no. 2 (1998): 133-149.

Levinson, David. "Density and dispersion: the co-development of land use and rail in London." Journal of Economic Geography 8, no. 1 (2008): 55-77.

Levinson, Stanford. Written in stone: Public monuments in changing societies. Duke University Press, 1998.

Li, S. M., \& Wu, F. “Contextualizing residential mobility and housing choice: evidence from urban China." Environment and Planning A, 36(1), 1-6. (2004).

Lichter, Daniel T., and Glenn V. Fuguitt. "Demographic response to transportation innovation: the case of the interstate highway." Social Forces 59, no. 2 (1980): 492-512.

Litman, Todd. "Efficient vehicles versus efficient transportation. Comparing transportation 
energy conservation strategies." Transport Policy 12, no. 2 (2005): 121-129.

Lorek, $\mathrm{H}$ and Sonnenshein, M. "Modelling and simulation software to support individualoriented ecological modelling.” Ecological Modelling 115 (1999): pp. 199-216.

Lu, M. "Determinants of residential satisfaction: Ordered logit vs. regression models.” Growth and Change, 30, 264-287. (1999).

Lutz, J. M., "Determinants of population growth in urban centers in the Republic of Ireland.” Urban Studies, Vol. 38, 1329-1340. (2001)

Luymes, Don T., and Ken Tamminga. "Integrating public safety and use into planning urban greenways." Landscape and urban planning 33, no. 1 (1995): 391-400.

Malayath, Manoj, and Ashish Verma. "Activity based travel demand models as a tool for evaluating sustainable transportation policies." Research in transportation economics 38, no. 1 (2013): 45-66.

Massey, D., R. Alarcon, J. Durand \& H. Gonzalez. Return to Aztlan. The Social Process of International Migration from Western Mexico. Berkeley, CA: University of California Press. (1987).

Mayo, Edward J. Regional travel characteristics of the United States: a psychographic profile of inter-regional auto travelers. University of Notre Dame, (1973).

Mayer, C. J. "Residential construction: Using the urban growth model to estimate housing supply.” Journal of Urban Economics, Vol. 48, 85-109. (2000)

Mayo, Stephen. "Local public goods and residential location: an empirical test of the Tiebout hypothesis." Washington DC: Metropolitan Governance Committee, Resources for the Future (1973).

McDonald, John F. "Econometric studies of urban population density: A survey." Journal of 
urban economics 26, no. 3 (1989): 361-385.

McFadden, D. "Modeling the Choice of Residential Location," in Spatial Interaction Theory and Planning Models, ed. by A. Larlqvist, L. Lundqvist, F. Snickars, and J. Weibull, NorthHolland." (1978).

McFadden, Daniel. "The behavioral science of transportation." Transport policy 14, no. 4 (2007): 269-274.

Mehta, Vikas. The street: a quintessential social public space. Routledge, 2013.

Merriman, David. "How many parking spaces does it take to create one additional transit passenger?." Regional Science and Urban Economics 28, no. 5 (1998): 565-584.

Meurs, Henk, and Rinus Haaijer. "Spatial structure and mobility." Transportation Research Part D: Transport and Environment 6, no. 6 (2001): 429-446.

Meyer, Michael D. "Demand management as an element of transportation policy: using carrots and sticks to influence travel behavior." Transportation Research Part A: Policy and Practice 33, no. 7 (1999): 575-599.

Mieszkowski, Peter, and Edwin S. Mills. "The causes of metropolitan suburbanization." The Journal of Economic Perspectives (1993): 135-147.

Mincer, J. “Family migration decisions.” Journal of Political Economy 8, (1978): 749-773.

Mitchell, C. J. “Making sense of counterurbanization.” Journal of rural studies, 20(1), 15-34. (2004).

Mohl, Raymond. "The interstates and the cities: Highways, housing and the freeway revolt." Poverty and Race Action Council, Washington DC (2002).

Mokhtarian, Patricia L., and Xinyu Cao. "Examining the impacts of residential self-selection on travel behavior: A focus on methodologies." Transportation Research Part B: 
Methodological 42, no. 3 (2008): 204-228.

Molin, Eric, and H. J. P. Timmermans. "Accessibility considerations in residential choice decisions: accumulated evidence from the Benelux." In Präsentiert auf dem „82nd Annual Meeting of the Transportation Research Board "(TRB), Washington, DC. 2003.

Morris, Earl W., Sue R. Crull, and Mary Winter. "Housing norms, housing satisfaction and the propensity to move." Journal of Marriage and the Family (1976): 309-320.

Muller, Peter O. "Transportation and Urban Form-Stages in the Spatial Evolution of the American Metropolis." (2004).

Muth, Richard. "Cities and housing: The spatial patterns of urban residential land use." University of Chicago, Chicago (1969).

Nelson, A. C. "Effects of elevated heavy-rail transit stations on house prices with respect to neighborhood income” Transportation Research Record 1359 (1992): pp. 127-132.

Nelson, A., Dejan Eskic, Joanna P. Ganning, Shima Hamidi, Susan J. Petheram, Jenny H. Liu, and Reid Ewing. "Office rent premiums with respect to distance from light rail transit stations in Dallas and Denver." In 94th Annual Meeting of the Transportation Research Board, Washington, DC. 2015.

Nelson, Arthur C., Matt Miller, Keuntae Kim, Joanna P. Ganning, Jenny H. Liu, and Reid Ewing. "Commuter Rail Transit and Economic Development." In Transportation Research Board 94th Annual Meeting, no. 15-5308. 2015.

Partridge, Mark D., Kamar Ali, and M. Olfert. "Rural- to - Urban Commuting: Three Degrees of Integration." Growth and Change 41, no. 2 (2010): 303-335.

Payton, Neal I., and Amber Hawkes. "Designing new transit systems using a transect-based model." Proceedings of the ICE-Urban Design and Planning 166, no. 4 (2012): 217-228. 
Pfister, Neil, Robert Freestone, and Peter Murphy. "Polycentricity or dispersion?: Changes in center employment in metropolitan Sydney, 1981 to 1996." Urban Geography 21, no. 5 (2000): 428-442.

Pinjari, Abdul Rawoof, Ram M. Pendyala, Chandra R. Bhat, and Paul A. Waddell. "Modeling residential sorting effects to understand the impact of the built environment on commute mode choice." Transportation 34, no. 5 (2007): 557-573.

Pinjari, Abdul, Naveen Eluru, Chandra Bhat, Ram Pendyala, and Erika Spissu. "Joint model of choice of residential neighborhood and bicycle ownership: accounting for self-selection and unobserved heterogeneity." Transportation Research Record: Journal of the Transportation Research Board 2082 (2008): 17-26.

Pollakowski, M. "A conditional logit model of residential choice." In winter meetings of the Econometric Society (December). 1975.

Polhill, G. J., Alessandro Gimona, and Richard J. Aspinall. "Agent-based modelling of land use effects on ecosystem processes and services." Journal of Land Use Science 6, no. 2-3 (2011): 75-81.

Prillwitz, Jan, Sylvia Harms, and Martin Lanzendorf. "Interactions between residential relocations, life course events, and daily commute distances." Transportation Research Record: Journal of the Transportation Research Board 2021 (2007): 64-69.

Pushkarev, B. S., J. M. Zupan, and R. Cumella. "Urban Rail in America: A Regional Plan Association Book." (1982).

Railsback, Steven F., and Volker Grimm. Agent-based and individual-based modeling: a practical introduction. Princeton University Press, 2011.

Renkow, Mitch, and Dale Hoover. "Commuting, Migration, and Rural- Urban Population 
Dynamics." Journal of Regional Science 40, no. 2 (2000): 261-287.

Rephann, Terance, and Andrew Isserman. "New highways as economic development tools: An evaluation using quasi-experimental matching methods." Regional Science and Urban Economics 24, no. 6 (1994): 723-751.

Reynolds, C. W. "Flocks, herds and schools: A distributed behavioral model.” Computer Graphics 21, no. 4 (1987): 25-34.

Rickman, Dan S., and Hongbo Wang. "US regional population growth 2000-2010: Natural amenities or urban agglomeration?." (2015).

Rouwendal, Jan, and Erik Meijer. "Preferences for housing, jobs, and commuting: a mixed logit analysis." Journal of regional science 41, no. 3 (2001): 475-505.

Rouwendal, Jan, and Piet Rietveld. "Changes in commuting distances of Dutch households." Urban Studies 31, no. 9 (1994): 1545-1557.

Rupasingha, Anil, Yongzheng Liu, and Mark Partridge. "Rural Bound: Determinants of Metro to Non-Metro Migration in the United States." American Journal of Agricultural Economics (2015): aau113.

Saelens, Brian E., James F. Sallis, and Lawrence D. Frank. "Environmental correlates of walking and cycling: findings from the transportation, urban design, and planning literatures." Annals of behavioral medicine 25, no. 2 (2003): 80-91.

Salomon, Ilan, and Patricia L. Mokhtarian. "Coping with congestion: Understanding the gap between policy assumptions and behavior." Transportation Research Part D: Transport and Environment 2, no. 2 (1997): 107-123.

Schachter, J. \& P. Althaus. "An Equilibrium Model of Gross Migration." Journal of Regional Science 29:134-159. (1989). 
Scheiner, Joachim, and Christian Holz-Rau. "Travel mode choice: affected by objective or subjective determinants?." Transportation 34, no. 4 (2007): 487-511.

Schwanen, Tim, and Patricia L. Mokhtarian. "Does Dissonance Between Desired and Current Residential Neighbourhood Type Affect Individual Travel Behaviour? An Empirical Assessment from the San Francisco Bay Area." In Proceedings of the European Transport Conference. 2003. http://www.its.ucdavis.edu/cse/?q=RP-03-18.pdf_. (September 2015)

Schwanen, Tim, and Patricia L. Mokhtarian. "What affects commute mode choice: neighborhood physical structure or preferences toward neighborhoods?." Journal of Transport Geography 13, no. 1 (2005): 83-99.

Schwanen, Tim, and Patricia L. Mokhtarian. "What if you live in the wrong neighborhood? The impact of residential neighborhood type dissonance on distance traveled." Transportation Research Part D: Transport and Environment 10, no. 2 (2005): 127-151.

Seskin, S. N., R. Cervero, and J. Zupan. Transit and urban form. Volume 1. Part i: Transit, urban form, and the built environment: a summary of knowledge. Part ii: Commuter and light rail transit corridors: The land use connection. No. Project H-1 FY'92. 1996.

Seskin, Sam, Robert Cervero, Jeffrey Zupan, and Jane Howard. "Transit and urban form." Federal Transit Administration, Washington, DC (1996).

Silva, Elisabete, and Ning Wu. "Surveying models in urban land studies." Journal of Planning Literature 27, no. 2 (2012): 139-152.

Smith, Stanley, Jeff Tayman, and D. A. Swanson. "Population projections for states and local areas: methodology and analysis." (2001). Stanback, Thomas M. The new suburbanization: Challenge to the central city. Westview Press, 1991.

Stanback, T. M., The New Suburbanization: Challenge to the Center City.( 1991) 
Stanbery, V. B. "What Type Regional Planning for the Bay Area." Journal of the American Institute of Planners 18, no. 2 (1952): 63-67.

Talen, Emily. "Help for urban planning: the transect strategy." Journal of Urban Design 7, no. 3 (2002): 293-312.

Tillema, Taede, Marije Hamersma, Joseph M. Sussman, and Jos Arts. "Extending the scope of highway planning: accessibility, negative externalities and the residential context." Transport Reviews 32, no. 6 (2012): 745-759.

Timmermans, H., L. Van Noortwijk, Harmen Oppewal, and P. J. H. J. van der Waerden. "Modeling constrained choice behaviour in regulated housing markets by means of discrete choice experiments and universal logit models: an application to the residential choice behaviour of divorcees." Environment and Planning A 28, no. 6 (1996): 1095-1112.

Transit Cooperative Research Program. “TCRP Report 16.” (Vol 2.). Washington, D.C.: National Academy Press. (1996).

U.S. Census Bureau; American Community Survey, 2009-2013 American Community Survey 5Year Estimates. Using American FactFinder; <http://factfinder2.census.gov>; (7 September 2015).

U.S. Census Bureau; “American Community Survey, 2014 1-Year Estimates.” Using American FactFinder. http://factfinder2.census.gov (accessed 7 September 2015).

U.S. Environmental Protection Agency. “Utah Nonattainment/Maintenance Status for Each County by Year for All Criteria Pollutants.” EPA.gov. http://www.epa.gov/oaqps001/greenbk/anayo_ut.html 
Utah Transit Authority. “About FrontRunner.” RideUTA.com.

http://www.rideuta.com/mc/?page=FrontRuner-AboutFrontRunner (accessed December 18, 2015).

Utah Transit Authority. “FrontRunner Commuter Rail Fact Sheet.” Retrieved from http://www.rideuta.com/files/frontrunner\%20northfacts908.pdf (No Date).

Utah Transit Authority. “On-Board Survey 2011 Report.” Salt Lake City, 2011.

Utah Transit Authority. “On-Board Survey 2013-2014 Report.” Salt Lake City, 2014.

Van Ommeren, Jos, Piet Rietveld, and Peter Nijkamp. "Commuting: in search of jobs and residences." Journal of Urban Economics 42, no. 3 (1997): 402-421.

Van Ommeren, Jos, Piet Rietveld, and Peter Nijkamp. "Job moving, residential moving, and commuting: a search perspective." Journal of Urban Economics 46, no. 2 (1999): 230-253.

Van Wee, Bert. "Self- Selection: A Key to a Better Understanding of Location Choices, Travel Behaviour and Transport Externalities?." Transport reviews 29, no. 3 (2009): 279-292.

Van, Hong Tan, Kasem Choocharukul, and Satoshi Fujii. "The effect of attitudes toward cars and public transportation on behavioral intention in commuting mode choice-A comparison across six Asian countries." Transportation research part A: policy and practice 69 (2014): 36-44.

Vance, James E. Capturing the horizon: The historical geography of transportation since the transportation revolution of the sixteenth century. HarperCollins Publishers, 1986.

Villaveces, Andrés, Luis Alfonso Nieto, Delia Ortega, José Fernando Ríos, John Jairo Medina, María Isabel Gutiérrez, and Daniel Rodríguez. "Pedestrians' perceptions of walkability and safety in relation to the built environment in Cali, Colombia, 2009-10." Injury prevention 18, no. 5 (2012): 291-297. 
Warner, Sam Bass. Streetcar suburbs. Vol. 133. Harvard University Press, 1978.

Weisbrod, Glen, Steven R. Lerman, and Moshe Ben-Akiva. "Tradeoffs in residential location decisions: Transportation versus other factors." Transport Policy and Decision Making 1, no. 1 (1980): 13-26.

Wilhelmsson, Mats. "The impact of traffic noise on the values of single-family houses." Journal of environmental planning and management 43, no. 6 (2000): 799-815.

Wood, S. “Generalized additive models: an introduction with R.” CRC press. (2006).

Yeates, Maurice, and Barry J. Garner. The North American City. HarperCollins Publishers, 1976. 


\section{APPENDIX}

Appendix Table A1: Sub-Variables Comprising Dependent and Independent Variables

\begin{tabular}{|c|c|c|c|c|c|}
\hline Var. ID & $\begin{array}{l}\text { Variables, } \\
\text { Grouped by } \\
\text { Characteristic } \\
\text { Area }\end{array}$ & $\begin{array}{l}\text { Factor Loading in } \\
\text { Characteristic } \\
\text { Areas (Dependent } \\
\text { Variables; Change } \\
\text { in Variables) }\end{array}$ & $\begin{array}{c}\text { Factor } \\
\text { Loadings in } \\
\text { Independent } \\
\text { Variables } \\
\text { (Initial Year } \\
\text { Conditions) }\end{array}$ & $\begin{array}{c}\text { Independent } \\
\text { Variable } \\
\text { Name }\end{array}$ & $\begin{array}{c}\text { Narrative } \\
\text { Description of What } \\
\text { Positive Values } \\
\text { Represent in Tracts }\end{array}$ \\
\hline & Transportation & & & & \\
\hline 1 & CarA & 0.2960 & 0.996 & \multirow{3}{*}{ TCarHome } & Car-based \\
\hline 2 & Carpl & 0.1906 & 0.527 & & commuting or \\
\hline 3 & Work_H & 0.2366 & 0.662 & & working from home \\
\hline 4 & Trans & 0.1300 & 0.734 & \multirow{3}{*}{ TNonCar } & \multirow{3}{*}{$\begin{array}{l}\text { Non-car-based } \\
\text { commuting }\end{array}$} \\
\hline 5 & Walk & 0.0573 & 0.777 & & \\
\hline \multirow[t]{2}{*}{6} & OthM & 0.0896 & 0.664 & & \\
\hline & Demographics & & & & \\
\hline 7 & Blk & 0.0275 & 0.705 & \multirow{7}{*}{ Minority } & \multirow{7}{*}{$\begin{array}{l}\text { Presence of minority } \\
\text { populations, } \\
\text { correlated with } \\
\text { increased disabilities } \\
\text { and low education } \\
\text { attainment }\end{array}$} \\
\hline 8 & AllNat & 0.0228 & 0.83 & & \\
\hline 9 & Asn & 0.1230 & 0.647 & & \\
\hline 10 & HispLat & 0.0429 & 0.94 & & \\
\hline 11 & DiverseMeasure & 0.0058 & -0.909 & & \\
\hline 12 & Bach & 0.0117 & -0.621 & & \\
\hline 13 & Dsblty & 0.1131 & 0.616 & & \\
\hline 14 & TotPop & 0.1311 & 0.977 & \multirow{4}{*}{ PopWht } & \multirow{4}{*}{$\begin{array}{c}\text { The white and overall } \\
\text { population }\end{array}$} \\
\hline 15 & Wht & 0.1310 & 0.98 & & \\
\hline 16 & TotHHs & 0.1310 & 0.887 & & \\
\hline 17 & HHs_wC & 0.1306 & 0.852 & & \\
\hline 18 & $\mathrm{DpR}$ & 0.0077 & 0.412 & \multirow{4}{*}{ AgeSz } & \multirow{4}{*}{$\begin{array}{l}\text { Tracts with young, } \\
\text { large households }\end{array}$} \\
\hline 19 & MedAge & -0.0158 & -0.599 & & \\
\hline 20 & AvgHHsz & 0.0064 & 0.968 & & \\
\hline \multirow[t]{2}{*}{21} & Fmal & 0.1311 & omitted & & \\
\hline & Economics & & & & \\
\hline 22 & Bach & 0.0144 & 0.901 & \multirow{12}{*}{ Econ } & \multirow{12}{*}{$\begin{array}{l}\text { High levels of white- } \\
\text { collar industrial } \\
\text { employment, earning } \\
\text { high incomes and } \\
\text { with high educational } \\
\text { attainment }\end{array}$} \\
\hline 23 & Occ_Mgmt & 0.1521 & 0.869 & & \\
\hline 24 & CONLQ & -0.0029 & -0.63 & & \\
\hline 25 & MANLQ & -0.0024 & -0.699 & & \\
\hline 26 & RETLQ & -0.0062 & -0.116 & & \\
\hline 27 & TRANSLQ & -0.0053 & -0.222 & & \\
\hline 28 & INFOLQ & 0.0017 & 0.26 & & \\
\hline 29 & FINLQ & 0.0231 & 0.406 & & \\
\hline 30 & PROFLQ & 0.0030 & 0.524 & & \\
\hline 31 & EDULQ & -0.0002 & 0.692 & & \\
\hline 32 & PUBLQ & -0.0044 & -0.161 & & \\
\hline 33 & IMed_HHI & 0.0101 & 0.554 & & \\
\hline
\end{tabular}




\begin{tabular}{|c|c|c|c|c|c|}
\hline 34 & Per_LabFo & 0.0128 & 0.218 & \multirow{10}{*}{ Emp } & \multirow{10}{*}{$\begin{array}{l}\text { High employment } \\
\text { levels, in various } \\
\text { occupations and } \\
\text { industries other than } \\
\text { agriculture and the } \\
\text { arts }\end{array}$} \\
\hline 35 & Emp & 0.1557 & 0.93 & & \\
\hline 36 & Occ Serv & 0.1485 & 0.806 & & \\
\hline 37 & Occ_Nat & 0.1477 & 0.847 & & \\
\hline 38 & Occ_Prod & 0.1426 & 0.785 & & \\
\hline 39 & AGRILQ & 0.0069 & -0.241 & & \\
\hline 40 & WHOLQ & -0.0018 & 0.111 & & \\
\hline 41 & ARTSLQ & 0.0074 & -0.13 & & \\
\hline 42 & OTHLQ & -0.0048 & 0.0994 & & \\
\hline 43 & Emp_Pop & 0.0465 & 0.228 & & \\
\hline \multirow[t]{2}{*}{44} & Occ_Sal & 0.1553 & omitted & & \\
\hline & Housing & & & & \\
\hline 45 & Med_Hval & 0.0227 & 0.952 & \multirow{2}{*}{ Value } & High median values \\
\hline 46 & ZHouseRent & -0.0311 & 0.794 & & for all housing \\
\hline 47 & OVRate & -0.0121 & 0.463 & \multirow{3}{*}{ VacRent } & High vacancy rates \\
\hline 48 & RVRate & 0.0009 & 0.476 & & for all units, and low \\
\hline 49 & Med_R & 0.1108 & -0.474 & & median rents \\
\hline 50 & OccHU & 0.3822 & 0.616 & \multirow{2}{*}{ OccVHU } & More occupied and \\
\hline 51 & VHU & 0.2884 & 0.828 & & in number \\
\hline 52 & MedYrHSBuilt & 0.0342 & 0.671 & \multirow{2}{*}{ AgeDens } & \multirow{2}{*}{$\begin{array}{l}\text { Newer homes with } \\
\text { lower densities }\end{array}$} \\
\hline 53 & Pop_Dens & 0.2038 & -0.622 & & \\
\hline
\end{tabular}

Variable ID numbers correspond to variables in Table 2.1 
Transportation Research and Education Center

Portland State University

1900 S.W. Fourth Ave., Suite 175

Portland, OR 97201 